

STUDI E SAGGI

ISSN 2704-6478 (PRINT) | ISSN 2704-5919 (ONLINE)

$-201-$ 


\title{
METHEXIS
}

\author{
Comitato Scientifico \\ Brunella Casalini (Università di Firenze, Direttore) \\ Maria Chiara Pievatolo (Università di Pisa, Direttore) \\ Nico de Federicis (Università di Pisa) \\ Roberto Gatti (Università di Perugia) \\ Roberto Giannetti (Università di Pisa) \\ Michele Nicoletti (Università di Trento) \\ Gianluigi Palombella (Università di Parma) \\ Claudio Palazzolo (Università di Pisa) \\ Salvatore Veca (Università di Pavia)
}

\section{Volumi pubblicati}

Carmelo Calabrò, Liberalismo, democrazia, socialismo. Litinerario di Carlo Rosselli, 2009 Dino Costantini, Multiculturalismo alla francese? Dalla colonizzazione all'immigrazione, 2009

Francesca Di Donato, La scienza e la rete. L'uso pubblico della ragione nell'età del Web, 2009

Marco Goldoni, La dottrina costituzionale di Sieyès, 2009

Immanuel Kant, Sette scritti politici liberi, a cura di Maria Chiara Pievatolo, 2011

Bruella Casalini, Lorenzo Cini (a cura di), Giustizia, uguaglianza e differenza. Una guida alla lettura della filosofia politica contemporanea, 2012

Lorenzo Cini, Società civile e democrazia radicale, 2012

Dino Costantini, La democrazia dei moderni. Storia di una crisi, 2012

Thomas Casadei, I diritti sociali. Un percorso filosofico-giuridico, 2012

Chiara Mastroberti, Assoggettamento e passioni nel pensiero politico di Judith Butler, 2016

Luca Michelini, Il nazional-fascismo economico del giovane Franco Modigliani, 2019 
LuCA Michelini

\section{Il nazional-fascismo economico del giovane Franco Modigliani}


Il nazional-fascismo economico del giovane Franco Modigliani / Luca Michelini. - Firenze : Firenze University Press, 2019.

(Studi e saggi ; 201)

https://www.fupress.com/isbn/9788864539485

ISSN: 2704-6478 (print)

ISSN: 2704-5919 (online)

ISBN: 978-88-6453-947-8 (print)

ISBN: 978-88-6453-948-5 (online)

Progetto grafico di Alberto Pizarro Fernández, Lettera Meccanica SRLs

\section{Certificazione scientifica delle Opere}

Tutti i volumi pubblicati sono soggetti a un processo di referaggio esterno di cui sono responsabili il Consiglio editoriale della FUP e i Consigli scientifici delle singole collane. Le opere pubblicate nel catalogo FUP sono valutate e approvate dal Consiglio editoriale della casa editrice. Per una descrizione più analitica del processo di referaggio si rimanda ai documenti ufficiali pubblicati sul catalogo on-line (www.fupress.com).

Consiglio editoriale Firenze University Press

M. Garzaniti (Presidente), M. Boddi, A. Bucelli, R. Casalbuoni, A. Dolfi, R. Ferrise, M.C. Grisolia, P. Guarnieri, R. Lanfredini, P. Lo Nostro, G. Mari, A. Mariani, P.M. Mariano, S. Marinai, R. Minuti, P. Nanni, G. Nigro, A. Perulli.

๑ L'edizione digitale on-line del volume è pubblicata ad accesso aperto su www.fupress.com.

La presente opera è rilasciata nei termini della licenza Creative Commons Attribution 4.0 International (CC BY 4.0: http://creativecommons.org/licenses/by/4.0/legalcode). La licenza permette di condividere l'opera, nella sua interezza o in parte, con qualsiasi mezzo e formato, e di modificarla per qualsiasi fine, anche commerciale, a condizione che ne sia menzionata la paternità in modo adeguato, sia indicato se sono state effettuate modifiche e sia fornito un link alla licenza.

(C) 2019 Firenze University Press

Pubblicato da Firenze University Press

Firenze University Press

Università degli Studi di Firenze

via Cittadella, 7, 50144 Firenze, Italy

www.fupress.com

This book is printed on acid-free paper

Printed in Italy 
SOMMARIO

INTRODUZIONE

IL NAZIONALISMO ECONOMICO ITALIANO

CAPITOLO PRIMO

QUESTIONI DI METODO

1. Gli scritti giovanili e la storiografia 13

2. Le leggi razziali: passato e presente 16

CAPITOLO SECONDO

IL CONTESTO: LA RIVISTA "LO STATO» 21

1. Per una scienza economica 'nuova' 21

2. Il fascismo sociale $\quad 27$

3. La Grande Crisi 29

4. La pianificazione 32

CAPITOLO TERZO

IL 'RAZZISMO SPIRITUALE' E L'ANTISEMITISMO 37

1. Fascismo e antisemitismo 37

2. Modigliani: Stato, nazione, razza 40

CAPITOLO QUARTO

L'ECONOMIA NUOVA DI MODIGLIANI 45

1. Per la "progressiva regolamentazione di tutta l'economia» 45

2. Protezionismo ed autarchia 50

3. L'utopia dell'economia pura', Costamagna, Keynes e Mussolini 55

4. La tesi di laurea 61

$\begin{array}{lr}\text { CONCLUSIONI } & 67\end{array}$

$\begin{array}{ll}\text { INDICE DEI NOMI } & 73\end{array}$ 



\section{INTRODUZIONE}

\section{IL NAZIONALISMO ECONOMICO ITALIANO}

Il quadro delle ricerche che ho dedicato al nazionalismo economico italiano ritengo che possa costituire un'utile introduzione alla ricostruzione del percorso intellettuale del giovane Franco Modigliani.

Qualche anno fa ho proposto una lettura del pensiero economico del nazionalismo italiano, limitando la mia indagine agli anni in cui il nazionalismo è una organizzazione politica autonoma, indipendente dal fascismo, anche se destinata a confluirvi nel $1923^{1}$. Dalla ricerca emersero due principali correnti di pensiero che caratterizzavano il pensiero economico del nazionalismo italiano: la prima che possiamo definire neo-mercantilista e corporativa, la seconda di matrice liberal-liberista. I personaggi più rappresentativi di questi due filoni sono stati, rispettivamente, il giurista Alfredo Rocco e l'economista Maffeo Pantaleoni. Sul piano politico-governativo Pantaleoni è riuscito ad esercitare una vera e propria egemonia durante la prima fase di potere del fascismo, e cioè fino ai ministeri di Alberto De Stefani, contraddistinti da quella che Pantaleoni definiva una politica economica manchesteriana e che oggi definiremo neo-liberista. Rocco, invece, ha dato un'impronta decisiva all'azione politico-governativa dal momento in cui il fascismo da movimento e da piccolo partito minoritario in Parlamento si trasforma e si struttura in vero e proprio regime, a cominciare dal delitto Matteotti e quindi passando dalla promulgazione delle leggi liberticide del 1925-1926 e dalla svolta protezionista.

Sul piano storiografico la novità che introduceva la mia ricerca consisteva nel mostrare come i più significativi economisti marginalisti dell'epoca, paladini a fine Ottocento delle battaglie liberiste, fossero autori imprescindibili per ricostruire la cultura economica e politica sia del nazionalismo italiano, che del fascismo. Enrico Barone, Pantaleoni, Vilfredo Pareto, insomma gli animatori della più importante rivista italiana di teoria economica, «Il Giornale degli economisti», non erano soltanto

${ }^{1}$ Cfr. L. Michelini, Il pensiero economico del nazionalismo italiano, in Id., Liberalismo, nazionalismo, fascismo, M\&B Publishing, Milano 1999. È in uscita la seconda edizione con il titolo Il nazionalismo economico italiano. Corporativismo, liberismo, fascismo (1900-23), Carocci, Roma 2009. 
all'origine di una grammatica economica destinata a plasmare il pensiero economico mondiale, arrivando, per linee evolutive interne, fino alla manualistica odierna. Lungi da proporre esclusivamente saggi di 'economia pura', la rivista si occupava di politica economica, con particolare riferimento a quella italiana, e aveva anche una rubrica di commento politico che vantava autori di prestigio come, tra gli altri, Pantaleoni, Pareto, Antonio de Viti de Marco, per citare i più famosi. Nella rivista, in altri termini, teoria e politica erano esplicitamente legate e negli anni della nascita del fascismo essa prende apertamente posizione a suo favore. È indispensabile ripercorrere in modo sintetico le principali tappe teoriche e politiche di questo percorso.

Si deve ricordare, in primo luogo, il breve periodo di luna di miele con le ragioni del liberalismo, che spinge alcuni di questi economisti a guardare perfino con simpatia il nascente movimento socialista, a fine Ottocento. Sebbene ne criticano il pensiero economico di riferimento sia esso marxista, revisionista o liberal-socialista -, questi economisti intravvedevano nel movimento socialista l'unica forza sociale organizzata sulla quale avrebbe potuto far perno lo sparuto gruppetto dei liberoscambisti. Sul piano politico, la svolta matura con i primi del novecento, quando le classi dirigenti liberali sembrano voler costruire un dialogo effettivo con il riformismo socialista: manifesto di critica di questa convergenza in pectore è il testo Legislazione di classe e democrazia, pubblicato da Pantaleoni nel 1902 sul «Giornale degli economisti»". È così che, in tempi differenti, $\mathrm{i}$ tre economisti si avvicinano al nascente movimento nazionalista, di cui divengono voce fondamentale. Tra il 1903 e il 1906 Pareto collabora alla rivista "Il Regno», fondata dal patriarca del nazionalismo italiano, Enrico Corradini, scorgendovi il crogiolo di una nuova élite capace di opporsi al socialismo. Barone fonda nel 1909, dirigendola fino al 1916, la rivista «La Preparazione», apertamente nazionalista, dalle cui colonne appoggia l'impresa coloniale dell'Italia in Libia e si batte per l'entrata dell'Italia nella Prima Guerra Mondiale. Pantaleoni, infine, prende in mano la Cronaca politica del «Giornale degli economisti» nel 1912 per patrocinare anch'egli l'impresa coloniale, è in prima fila nello spingere l'Italia nel conflitto mondiale e dà vita ad una campagna di stampa per l'italianizzazione della Banca commerciale, la più importante banca d'investimento del Paese, considerata dall'economista avamposto italiano dell'imperialismo economico e politico della Germania.

A questo percorso politico si affianca una notevole riflessione teorica. Anche con accenti autocritici, i tre economisti abbandonano l'adesione dottrinaria al liberismo in nome di una logica economica che riconosce, non solo sul piano economico ma anche su quello storico, sociologico e politologico, le ragioni del protezionismo: celebre quanto scrive in proposito

2 L'articolo è riproposto dall'autore in M. Pantaleoni, Scritti vari di economia, Sandron, Palermo 1910, vol. 3, pp. 113-132. 
Pareto nel Proemio al Manuale del $1909^{3}$. Sul piano teorico dimostrano come l'interazione tra le differenti sfere dall'azione umana - economica, politica, sociologica, ideologica - dia vita a differenti «sistemi economici» che possono essere comparati sia sul piano economico che su quello storico. I sistemi economici «borghesi» si rivelano caratterizzati da più $o$ meno estese politiche protezioniste e da compromessi sociali differenti, come quello che Pareto definisce «plutocrazia demagogica», destinata ad entrare in conflitto, con il 1914, con gli Imperi centrali, dove a prevalere erano le ragioni del conservatorismo agrario e militarista. Infine dimostrano - con testi come I sistemi socialisti (1902) di Pareto ${ }^{4}$, Il Ministro della produzione nello Stato collettivista (1908) di Barone $e^{5}$, Considerazioni sulle proprietà di un sistema di prezzi politici (1911) di Pantaleoni ${ }^{6}$ - che il sistema economico socialista, se pur in linea teorica risulta un sistema che può raggiungere, a differenza dei sistemi borghesi, la frontiera dell'efficienza, nella concreta realtà storica non può che risultare tra i peggiori possibili: soprattutto per mancanza di capacità imprenditoriale e innovativa e poi perché pervaso da politiche economiche parassitarie, che distruggono sistematicamente ricchezza.

Dopo questa complessa stagione teorica e politica i tre economisti diventano i guardiani dell'ordine borghese. Scorgono, infatti, prima nel nazionalismo e poi nel fascismo le forze politiche e sociali capaci di venire alla resa dei conti definitiva sia con il movimento socialista, fosse esso riformista o rivoluzionario, sia con il debole liberalismo italiano, che, molto timidamente, si andava aprendo alla logica della democrazia politica e sociale. E cercano di indirizzare il fascismo verso un sistema economico che non riproduca i costi economici e gli equilibri sociali tipici dei regimi passati. Senza tralasciare, d'altro canto, la polemica contro i tentativi di sovvertire la scienza economica che i corporativisti propongono in nome delle ragioni del nazionalismo.

3 Pareto critica come «erronea» la propria posizione sostenuta nel Cours d'économie politique a proposito del liberismo. "Scientificamente si può dimostrare che la protezione solitamente reca una distruzione di ricchezza. (...) Ma basta ciò per condannare, nel concreto, la protezione? No davvero; occorre badare alle altre conseguenze sociali di tale ordinamento, e decidersi solo dopo di avere compiuto questo studio (V. Pareto, Manuale di economia politica, Società Editrice Libraria, Milano 1909, p. VIII). «In certi casi la protezione restituisce a una parte delle persone agiate una frazione di ciò che vien loro tolto coll'imposta progressiva, $o$ anche colle altre imposte, di cui il prodotto è speso per provvedimenti di socialismo di Stato» (Ivi, p. 479).

4 V. Pareto, Les Systèmes socialistes, V. Giard et E. Briere, Paris 1902, 2 voll.

${ }^{5}$ E. Barone, Il Ministro della produzione nello Stato collettivista, "Giornale degli economisti», sett.-ott. 1908, rispettivamente pp. 267-293, 391-414.

${ }^{6}$ Pubblicato in origine nei numeri di gennaio e di febbraio del «Giornale degli economisti», l'autore lo ripropone nel volume M. Pantaleoni, La fine provvisoria di un'epopea, Laterza, Bari 1919, pp. 1-53. 
Tra i testi più significativi di questa stagione teorica e politica possiamo ricordare Trasformazioni della democrazia, del 1921 (Milano, Corbaccio), di Pareto e i saggi che egli pubblica per la rivista fascista fondata da Mussolini «Gerarchia»: Paragoni (gennaio 1923), Legalità (aprile 1923), Libertà (luglio 1923) ${ }^{7}$. Si ricordano, inoltre, la raccolta di scritti militanti di Pantaleoni Bolcevismo italiano, del 1922 (Laterza), che è il vero e proprio manifesto del fascismo al potere. Nel saggio Finanza fascista, della primavera del 1923, sia il nazionalismo che il fascismo sono ricondotti all'ortodossia liberista nella speranza di vedere realizzati i propositi della Destra storica, anti democratica, ma dagli indubbi meriti economici. Il fascismo non è «rivoluzione», come vorrebbero alcuni degli stessi fascisti e nazionalisti, ma completa «restaurazione capitalistica» ${ }^{8}$. Le riflessioni politiche di Barone ospitate sulla «Preparazione» vanno a costituire, rivedute, uno dei capitoli dei Principi di economia politica editi nel 1921, che contengono un paragrafo che denuncia il pericolo di una rivoluzione sociale imminente, a cui la borghesia deve resistere con ogni mezzo ${ }^{9}$. sempre Barone a sintetizzare i punti fondamentali del governo MussoliniDe Stefani nella rivista «Per la nostra ricostruzione economica», che egli fonda e propone come baluardo della politica economica fascista ${ }^{10}$. Non può sorprendere che De Stefani, sebbene convertito al credo corporativo, promuoverà a metà anni Trenta la pubblicazione (editore Zanichelli) delle Opere economiche di Barone (1936), nonché di Pantaleoni le raccolte Studi storici di economia (1936) e Studi di finanza e di statistica (1938).

Una seconda novità proposta dalla ricerca sul pensiero economico del nazionalismo italiano consisteva nell'aver individuato una corrente neomercantilista e corporativa destinata ad amplificare le proprie fortune scientifiche ed istituzionali quando il regime fascista, soprattutto negli anni Trenta, darà forte impulso alla creazione di una scienza economica nuova, appunto l'economia corporativa. Si tratta, per gli anni della Prima Guerra Mondiale e del primo dopoguerra, di una serie di scrittori di economia, che trovano ospitalità prevalentemente sulla «Rivista delle società commerciali», espressione del grande capitale nazionale, e su altre iniziative editoriali. Tra questi scrittori possiamo annoverare giuristi come Rocco, dirigenti di grandi aziende, tecnocrati come Filippo Car-

I tre articoli sono ripubblicati, tra l'altro, in V. Pareto, Euvres complètes. Vol. 22. Écrits sociologiques mineurs. Textes en langue italienne, a cura di G. Busino, Droz, Genève 1980, pp. 1155-1160, 1174-1179, 1191-1197.

${ }^{8}$ M. Pantaleoni, Finanza fascista, «Politica», mag.-giu. 1923, pp. 159-187. Il saggio di Pantaleoni è stato considerato come massima espressione dell'assimilazione politica e culturale del fascismo da parte del nazionalismo: F. Gaeta, Il nazionalismo italiano, Laterza, Bari 1980, pp. 243-245.

9 E. Barone, Principi di economia politica, in Id., Opere economiche, Zanichelli, Bologna 1936, vol. II, p. 285.

${ }^{10}$ E. Barone, Ciò che noi ci proponiamo, «Per la nostra ricostruzione economica», 15 ott. 1923, 1, pp. 4-7. 
li, economisti come Gino Arias e Corrado Gini. I loro scritti erano caratterizzati dalla polemica più o meno radicale rivolta proprio contro la grammatica economica dei più significativi collaboratori del «Giornale degli economisti»: sulla scorta degli insegnamenti economici del primo conflitto mondiale, essi perorano un radicale cambiamento del rapporto tra lo Stato e l'economia e tentano di costruire una scienza economica nuova, perché capace di incarnare le aspirazioni della nazione.

Storico del corporativismo medioevale, con i suoi Principii di economia commerciale (Milano, Società Editrice Libraria), del 1917, Arias tenta di andare al di là della scienza economica ortodossa e di costruire un vero e proprio corpus scientifico, che possiamo definire neo-mercantilista. Anche la figura di Gini assume notevole importanza, sancendo il proprio ruolo come uno dei 'soloni' chiamati da Mussolini a ridisegnare l'architettura istituzionale dell'Italia fascistizzata ${ }^{11}$. Le indagini sull'ammontare del reddito nazionale prefigurano intenti di 'programmazione economica' che sfociano in una riflessione che sintetizza le argomentazioni dei teorici nazionalisti e la sviluppano in più punti, dando vita a una analisi sistematica e sintetica dei cambiamenti economici nazionali e internazionali avvenuti prima durante e dopo gli anni del conflitto. Nel 1912, con il volume I fattori demografici dell'evoluzione delle nazioni (Torino, Bocca) Gini si era soffermato sull'evoluzione delle nazioni mettendo in luce l'importanza del meccanismo biologico di formazione delle classi dirigenti, rilevandone le conseguenze economiche, secondo uno schema che si ritrova negli anni successivi in molti nazionalisti, anche di formazione liberal-liberista. Si tratta di un orientamento di ricerca che nel dopoguerra matura in un programma di politica demografica orientata a impedire l'emigrazione onde potenziare economicamente il Paese secondo i consueti dettami della economia nazionale. Quando nel 1923 esordisce la nuova rivista «Economia» all'insegna del nazionalismo economico anti purista, Gini vi esordisce pubblicando nel primo numero, e caratterizzandone l'indirizzo, lo studio La revisione del processo contro il protezionismo al quale seguirà Considerazioni sul valore pratico delle teorie economiche, dove riecheggiano tutte le argomentazioni dei nazionalisti neo-mercantilisti. La "patologia economica», come recita il titolo di un contributo del 1923, che Gini individua come nuova branca della scienza economica, più che studiare situazioni «anormali» e di «malattia economica» come quella della guerra tra le nazioni, studia in realtà situazioni che si rivelano storicamente normali ${ }^{12}$. Siamo, in sintesi, ai prodromi italiani degli studi sui "grandi spazi economici», destinati ad essere

${ }^{11}$ Cfr. C. Gini, Sulle riforme legislative proposte dalla Commissione dei XVIII, Tipografia delle Terme, Roma 1926.

${ }_{12}$ Cfr. in seguito C. Gini, Prime linee di patologia economica, Giuffrè, Milano 1935. 
oggetto di crescente interesse da parte del fascismo a partire dagli anni Trenta per realizzare una politica di potenza imperiale.

Accomunava queste due correnti di pensiero il fervore bellicista che spinse l'Italia nel primo conflitto mondiale; la lotta senza quartiere allo Stato liberale e al movimento socialista; la ripulsa della democrazia politica e del libero sviluppo del dibattito politico; l'avversione radicale a qualsivoglia politica volta a redistribuire ricchezza; l'appoggio organico dato al fascismo, di cui, però, si vuole indirizzare l'evoluzione arginando taluni aspetti del suo programma ritenuti eversivi dell'ordinamento borghese; la creazione di istituzioni parlamentari corporative; infine, l'aspirazione ad una politica imperiale e bellicista dell'Italia.

E importante ricordare che quando Carli propone, come soluzione definitiva alla questione sociale, la partecipazione degli operai alla direzione delle aziende, Pantaleoni, dalle pagine della «Idea nazionale», l'organo di stampa del nazionalismo, lo accusa di essere un bolscevico: l'idea di una qualche forma di partecipazionismo operaio viene così definitivamente espunta dal programma economico del nazionalismo, dettato da Rocco nel primo dopoguerra, e per un breve periodo Carli si allontana dal movimento. Si tratta di una linea di pensiero che Pantaleoni ha occasione di criticare anche quando si deve confrontare, durante l'esperienza di Fiume di cui fu protagonista come ministro di Gabriele D’Annunzio, con la Carta del Carnaro di Alceste De Ambris. Come Mussolini questi aveva appartenuto, prima della guerra, alla corrente di pensiero massimalista del socialismo. Agli occhi di Pantaleoni la Carta risulta incubatrice di un corporativismo che rischia di incrinare il principio della proprietà privata dei mezzi di produzione. Pantaleoni e Rocco, insomma, si oppongono a quelle correnti di pensiero che cercheranno di imprimere al fascismo, di cui sono voce integrante anche se minoritaria, un connotato che potremmo definire labourista e che verrà a costituire la tradizione del cosiddetto fascismo sociale. Una tradizione che, all'indomani della caduta del regime, nel settembre 1943, si radicalizzerà in nome di quello che essa considera il tradimento compiuto dalla monarchia e dalla borghesia italiana nei confronti del fascismo e della nazione, proponendo, durante la Repubblica sociale, l'effimera e poco credibile stagione della socializzazione della produzione.

Le due correnti di pensiero erano invece divise sul piano della visione del rapporto tra Stato e mercato: i corporativisti volevano questo rapporto incentrato sulla attività dello Stato, fino al punto di prospettare un radicale cambiamento della scienza economica. In nome delle esigenze supreme della nazione e sulla base dell'esperienza economica maturata durante il conflitto mondiale, la scienza economica doveva abbandonare alcuni dei propri presupposti, anzitutto l'individualismo, risultando 'l'uomo economico' teorizzato dai manuali di economia 'pura', che avevano avuto proprio in Pantaleoni un precursore di fama internazionale e in Pareto e Barone dei continuatori di eccezionale vigore intellettuale, un'astrazione inconcludente e intrinsecamente perniciosa sul piano della 
elaborazione della politica economica. Essa, infatti, nonostante le aperture dimostrate sul piano teorico alle ragioni del protezionismo, era tendenzialmente votata al liberismo e si opponeva a quelle forme di programmazione economica che avevano cominciato a prendere corpo durante il conflitto mondiale e che invece i corporativi salutavano con favore. Per costoro, insomma, l'economia pura promuoveva una politica economica che rischiava di minare le potenzialità industriali dell'Italia.

La polemica antiprotezionista dei marginalisti, d'altra parte, era sfociata in una visione elitistico-classista dello Stato, così che, anche quando appoggiano il fascismo, essi non rinunciano a criticarne l'operato nelle occasioni in cui sembra di riprodurre la logica delle "plutocrazie demagogiche». Il testo di Luigi Einaudi La condotta economica e gli effetti sociali della guerra italiana (del 1933, edito da Laterza) è la più compiuta espressione di questo tipo di impostazione teorica e storiografica, che ritroviamo in tutti i marginalisti italiani dell'epoca, in primis in Pareto $^{13}$. È anche per questo motivo che gli economisti corporativisti si sforzano di dimostrare che il 'nuovo Stato' nazional-fascista sia invece fondato su una reale collaborazione di classe e sulla costruzione di un effettivo 'interesse generale'.

Le due correnti di pensiero erano divise, infine, sulla soluzione da dare al problema del 'sindacalismo'. Ormai ritenuto un fenomeno intrinseco all'evoluzione capitalistica, Rocco voleva un sindacato controllato dallo Stato e prono alla politica salariale del governo e, in ultima analisi, del fascismo. Pantaleoni, invece, si limitava a salutare con approvazione la dura sconfitta sul piano para-militare che dei sindacati tradizionali aveva dato lo squadrismo, dando voce, al contempo, ad economisti che inneggiavano, in modo del tutto utopistico vista la cornice politica del tempo, al pluralismo sindacale. In ogni caso, quando il fascismo promulgherà la Carta del lavoro, che ambisce a dare una soluzione definitiva al problema sindacale e che dal fascismo sociale verrà utilizzata per tentare di dare un effettivo potere ai sindacati di regime, vi saranno economisti fascisti, ma di matrice liberal-liberista, che la saluteranno come incarnazione storica dei principi enunciati da Pantaleoni volti ad esaltare le virtù economiche e il dominio sociale dell'imprenditore innovatore.

Poiché l'intento metodologico è quello di superare l'individualismo liberale, gli scrittori di economia corporativa o fascista sono cultori o accademici di materie giuridiche, sociologiche, politologiche, storiche in senso lato. I tre economisti marginalisti non si erano affatto limitati a scrivere di economia pura, ma si erano interessati, in modo più o meno sistematico, di scienza delle finanze, di sociologia, di politologia, di diritto, di storia, ed avevano proposto saggi di economia dinamica che anelavano a superare i limiti statici dell'impostazione marginalista a cui

${ }^{13}$ Cfr. L. Michelini, La cronaca, la storia e la teoria della lotta di classe alla prova dei fatti: Luigi Einaudi e il 'controllo operaio', "Il pensiero economici italiano», 2010, 1, pp. 143-165. 
pure avevano dato un impulso decisivo. Sulla base di queste riflessioni nel corso del Ventennio le loro pagine saranno riprese e sviluppate da autori che in quell' intento multidisciplinare e nei loro testi extra-economici cercavano fondamenti e sviluppi per una dottrina fascista e nazionalista, che si coloriva più o meno di corporativismo a seconda degli autori, delle problematiche affrontate e delle circostanze storiche. Per esempio, vi sono economisti che tentano di sviluppare la teoria dei prezzi politici di Pantaleoni in una direzione diametralmente opposta a quella impressa dallo stesso Pantaleoni, tentando cioè di rinnovare, utilizzando la grammatica marginalista, la tradizione mercantilista. Le pagine di Pantaleoni vengono però utilizzate anche in tutt'altra direzione: per razionalizzare e soprattutto per limitare il crescente intervento pubblico in economia avutosi durante la Prima Guerra Mondiale, l'economista aveva proposto la costituzione dello 'Stato azionista', segnando così una proposta destinata ad essere sviluppata da quegli economisti che, di fronte all'inevitabilità dell'intervento pubblico sancito dalla Grande Crisi del 1929, si oppongono alla nascita di qualsivoglia forma di pianificazione economica che segnasse, in qualche modo, un cambiamento di sistema economico.

Sia Pareto che Pantaleoni, in conclusione, rimangono dei punti di riferimento teorico e metodologico di assoluto rilievo durante il Ventennio sia per gli economisti di matrice liberale, fossero o meno fascisti, sia per coloro che aspiravano a costruire una nuova dottrina corporativa. Come vedremo, è significativo che sulla rivista fascista «Lo Stato», alla quale collabora Modigliani, gli economisti abbiano una visione che Keynes definirebbe 'classica' dei rimedi della Grande Crisi del'29, indipendentemente dal grado di coinvolgimento teorico nei riguardi del corporativismo.

Qualche anno più tardi ho approfondito il pensiero economico e politico di Pantaleoni, rimarcando come con i suoi scritti e il suo operato culturale, come condirettore di fatto della rivista «La Vita italiana», fondata e diretta da Giovanni Preziosi, il lettore si confrontava con il primo e il più sistematico teorico dell'antisemitismo politico italiano (non si trattava di razzismo biologico), che dunque aveva origine fin dagli anni 1917-1924. Il nazional-fascismo di Pantaleoni, della «Vita italiana» e di Preziosi, che durante la Repubblica sociale, quando gli ebrei saranno sterminati, diventerà una sorta di ministro per la razza, erano stati la punta di diamante di una polemica antisemita che aveva dato notevole risalto polemico ed editoriale ai famigerati Protocolli degli Anziani Savi di Sion. Gli ebrei costituivano «uno Stato nello Stato» votato alla distruzione della nazione italiana e condensavano in sé il tipico operare degli attori sociali e politici del capitalismo parassitario liberale (giolittiano e nittiano), da un lato, e del parassitismo socialista, soprattutto riformista, dall'altro ${ }^{14}$.

${ }^{14}$ Cfr. L. Michelini, Alle origini dell'anitsemitismo nazional-fascista: Maffeo Pantaleoni e «La Vita italiana» di Giovanni Preziosi, 1915-1924, Marsilio, Venezia 2011. 
Più recentemente mi sono occupato delle origini del nazionalismo economico cattolico. Pur avendo canali di diffusione differenti da quelli degli autori prima citati (riviste, case editrici, occasioni convegnistiche), il nazionalismo cattolico dimostra di avere notevole importanza, assecondando il progressivo avvicinamento tra la Chiesa cattolica e il regime fascista sancito dalla stipula dei Patti Lateranensi nel 1929. Il nazionalismo cattolico, infatti, promuove una vera e propria rinascita neomercantilista, che contiene una implicita polemica con l'economia pura e che trova una significativa sponda intellettuale in Agostino Gemelli, il fondatore dell'Università Cattolica di Milano, in cerca di intellettuali capaci di riconquistare al cattolicesimo la società italiana e di formare una classe dirigente adatta a dirigere lo Stato. Con il neo-mercantilista Jacopo Mazzei, allievo di Giuseppe Toniolo e maestro di Amintore Fanfani, la cultura cattolica si inserisce in modo organico nel tentativo di una parte rilevante della cultura economica fascista di scalzare la tradizione purista. Nel terzo volume della Nuova collana di economisti stranieri e italiani intitolato Storia economica il curatore includerà autori e saggi che interpretano e rivalutano il pensiero mercantilista e che tentano, in epoche diverse e da punti di vista analitici per altro molto diversi, di segnare la fine dell'epoca del laissez-faire. Il volume include Il sistema nazionale dell'economia politica di F. List, un punto di riferimento per i fautori italiani del protezionismo e del nazionalismo, La fine del laissez-faire e Autarchia economica di J. M. Keynes, due testi facilmente utilizzabili ai propri fini dal nazional-fascismo, Il mercantilismo di E. F. Heckscher, infine una dotta disquisizione storica di Mazzei sulle teorie e sulle politiche mercantiliste ${ }^{15}$.

Come il lettore potrà appurare, Modigliani si inserisce esplicitamente e intenzionalmente nella corrente di pensiero nazionalista e corporativa, anche se, come vedremo, presenta alcuni tratti di originalità. Il quadro, tuttavia, con gli anni Trenta, quando il giovane Modigliani si affaccia alla ribalta scientifica e politica, è notevolmente mutato rispetto ai primi anni Venti: il fascismo, infatti, profonde notevoli energie istituzionali per definire i contorni di una economica politica precipuamente fascista, distinta da quella scienza economica che gli intellettuali nazional-fascisti consideravano essere tipicamente liberale e differente, ovviamente, dal comunismo marxista. Se sul piano della politica e della politica economica del fascismo tanto gli economisti, quanto la scienza economica corporativa appaiono rivestire un ruolo del tutto marginale, perché l'azione del governo fascista prescinde dal loro operato, è però anche vero che, soprattutto con la Crisi del 1929, la sollecitazione a impostare il rapporto tra Stato e capitalismo in modo teoricamente differente da quello eredi-

15 Cfr. L. Michelini, L'economia cattolica alla conquista dello Stato: nazionalismo, neo-mercantilismo e questione sociale in Japoco Mazzei, 1913-1925, «Il pensiero economico italiano», 2018, n. 1, pp. 27-66. 
tato dalla tradizione liberale diviene notevole sul piano della riflessione teorica e di politica economica. Dal punto di vista scientifico e culturale, insomma, il tentativo corporativo ebbe notevole respiro, tanto da divenire oggetto di riflessione in ambito internazionale, naturalmente vista anche l'espansione che i movimenti fascisti andavano compiendo in tutto il mondo. Ė in questo contesto culturale nazionale e internazionale che si inserisce la riflessione del giovane Modigliani e la viva curiosità che egli dimostra verso le teorie di Keynes.

Il richiamo che ho fatto agli studi sull'antisemitismo di Pantaleoni consente di affrontare una delle problematiche che pone questa mia nuova ricerca. Di origine ebraica, Modigliani si dichiara fascista e collabora con una importante rivista del regime, «Lo Stato». Diretta da un intellettuale di punta del fascismo, il giurista Carlo Costamagna, la teoria e la propaganda antisemita hanno nelle pagine del periodico uno spazio di rilievo anche prima della promulgazione delle leggi antiebraiche e proprio negli anni in cui vi collabora Modigliani. La mia ricerca suggerisce che il giovane studioso probabilmente viene colto di sorpresa dalla promulgazione delle leggi antiebraiche, avendo forse confidato fino all'ultimo momento che il razzismo politico e 'spirituale' del fascismo non si sarebbe tradotto in discriminazione di Stato.

Come si intuisce, le questioni metodologiche che affiorano dallo studio sono notevoli e meritano una trattazione specifica. Si deve infatti dirimere una questione che, allo stato della documentazione conosciuta, appare fortemente problematica. Il distacco che Modigliani dimostra, pur aderendo alla dottrina nazionalista e fascista, nei confronti delle proposte teoriche e di politica economica degli economisti fascisti, siano essi di matrice neo-liberista o siano essi corporativisti; l'implicita critica della politica economica del fascismo verso il mondo del lavoro, fortemente penalizzato durante tutto il Ventennio; l'interesse per il pensiero di Keynes e per la pianificazione; infine la testimonianza posteriore che l'economista offre nell'autobiografia dei suoi anni giovanili: sono tutti elementi che pongono la questione della natura dell'impegno civile del giovane studioso nei cruciali anni 1937-1938. L'adesione alle teorie nazionaliste e fasciste e l'interesse verso il pensiero di Keynes e la problematica della pianificazione sottende in effetti una posizione politica avversa al regime già prima della promulgazione delle leggi razziali?

Nel rispondere a questa domanda non si affronta solo una tematica di rilievo per l'epoca. Con Modigliani, infatti, si affronta uno degli economisti più importanti a livello mondiale nel secondo dopoguerra. Premio Nobel per l'economia, egli ha rappresentato per generazioni di studiosi, anche italiani, un modello di interpretazione del pensiero di Keynes capace di trovare una sintesi tra la grammatica marginalista a cui ho accennato in precedenza e l'analisi delle cause delle crisi proposta da Keynes. Non meno rilevante, infine, soprattutto per l'Italia, l'impegno civile di Modigliani, così attento a commentare e a indirizzare la politica economica italiana in anni di cruciali cambiamenti, quando il 
Paese sembrava al crocevia del mondo, sospeso tra Occidente e Oriente in ragione della presenza di uno dei più grandi partiti comunisti del mondo liberaldemocratico.

Il saggio è scaturito da un Progetto di Ricerca di Ateneo dell'Università di Pisa dal titolo La scienza economica italiana durante il fascismo: un profilo istituzionale, coordinata da Massimo Augello, che colgo l'occasione per ringraziare per la mole di materiale archivistico e bibliografico messa a disposizione e per aver discusso il testo.

Ringrazio Pier Francesco Asso, Piero Barucci, Fabrizio Bientinesi, Emiliano Brancaccio, Marco Cini, Carlo Cristiano, Luca Fiorito, Alfredo Gigliobianco, Nicola Giocoli, Giovanni Michelagnoli, Roberto Romani, Neri Salvadori, Gabriele Serafini e Giuseppe Vacca per aver commentato il lavoro.

Ringrazio, infine, Jacqueline de Molo Aliprindi Veillon per aver contribuito alla realizzazione della ricerca. 



\section{CAPITOLO PRIMO}

\section{QUESTIONI DI METODO}

\section{Gli scritti giovanili e la storiografia}

Tra il 2004 e il 2007 Daniela Parisi ha ripubblicato cinque articoli giovanili di Franco Modigliani': si tratta di testi pubblicati prima del conseguimento della tesi di laurea, sostenuta all'Università La Sapienza di Roma nel luglio del 1939. I cinque articoli risalgono al 1937 e al 1938 e sono apparsi sulla rivista «Lo Stato. Rivista di Scienze politiche, Giuridiche ed Economiche» e su «Il Ventuno. Rivista dei Littoriali». Su «Lo Stato» i testi sono quattro: Concetti generali sul controllo dei prezzi (aprile 1937); Prezzo politico e prezzo corporativo (luglio-agosto 1937); La crisi dell'economia capitalistica. La divisione internazionale del lavoro (gennaio 1938); Ancora intorno al principio di autarchia (marzo 1938). Su «Il Ventuno»l'articolo di Modigliani ripubblicato è La funzione del partito nel controllo dei prezzi (luglio-agosto 1937). Si tratta dunque di un anno di attività intellettuale, dalla primavera del 1937 a quella del 1938.

Nel riproporre questi testi Parisi ne ha offerto un breve commento, che vale senzaltro la pena riassumere. Da un lato ha ricordando le pagine che l'autore dedica al suo periodo giovanile contenute nell'autobiografia Avventure di un economista, uscita in Italia nel 1998. L'autobiografia non parla di questi testi e del contesto in cui presero forma, quanto, invece, della precoce avversione maturata dal giovane studente universitario nei confronti del regime fascista. Dall'altro lato l'autrice ha richiamato brevemente il contenuto analitico dei saggi, osservando che esso rimanda ai dibattiti allora prevalenti in Italia: la disquisizione sull'autarchia economica, il tema dei prezzi amministrati, infine la riflessione metodologica sul rapporto tra mezzi e fini. La conclusione è un invito all'approfondimento della storia del pensiero economico del periodo².

${ }^{1}$ F. Modigliani, Crisi del sistema economico, prezzi politici e autarchia/ The crisis of the economic system, political prices and autarky. Cinque articoli giovanili/ Five early works (Roma 1937-1938), a cura di Daniela Parisi, Vita e Pensiero, Milano 2007.

${ }^{2}$ D. Parisi, Preface in F. Modigliani, Crisi del sistema economico, prezzi politici e autarchia/ The crisis of the economic system, political prices and autarky, cit., pp. VI-XIII. 
L'importanza di questa ripubblicazione ritengo che sia notevole. Non solo si tratta di articoli che non sono compresi nella raccolta delle opere di Modigliani curata dal MIT di Boston ${ }^{3}$. Si tratta, soprattutto, di testi che invitano all'approfondimento della parabola intellettuale dell'economista italiano, oltre che delle dinamiche della storia del pensiero economico, non solo italiano.

Nonostante questo, la storiografia non ha raccolto, sostanzialmente, l'invito di Parisi. Lo stato dell'arte precedente la ripubblicazione curata dalla studiosa è rimasto quasi immutato. Prevale, infatti, l'interesse per l'interprete del pensiero keynesiano approdato in terra d'America e per l'impegno teorico e civile riservato dall'economista alla politica economica dell'Italia a partire da quel momento. Dei testi giovanili non ne fa alcuna menzione la breve introduzione firmata da Tommaso e Fiorella PadoaSchioppa alla raccolta di testi di Modigliani Reddito, interesse, inflazione né ne accenna quella di Carlo D’Adda alla raccolta Consumo, risparmio, finanza, dove non compaiono nemmeno nella bibliografia di Modigliani proposta in appendice ${ }^{5}$. Sulla notevole attenzione dedicata da Modigliani all'Italia dopo il volontario esilio negli Stati Unititi ha fornito un importante contributo lo scavo storiografico di Pier Francesco Asso, che ha valorizzato l'archivio personale dell'economista ${ }^{6}$. Roberto Maiocchi e Fabrizio Bientinesi si sono poi soffermati brevemente su alcuni aspetti del contributo di Modigliani al dibattito italiano degli anni Trenta sull'autarchia ${ }^{7}$. Più recentemente, un contributo di Michele Alacevich, Pier Francesco Asso e Sebastiano Nerozzi ha opportunamente riannodato la riflessione teorica e di politica economica che Modigliani propone nell'immediato dopoguerra in tema di controllo dei prezzi e di economia pianificata proprio ad uno

3 The Collected Papers of Franco Modigliani, The MIT Press, Cambridge, 19801989, 5 voll.

${ }^{4}$ T. e F. Padoa-Schioppa, «Introduzione» a F. Modigliani, Reddito, interesse, inflazione, Einaudi, Torino 1987, pp. VI-XIII.

${ }^{5}$ C. D’Adda, Introduzione a F. Modigliani, Consumo, risparmio, finanza, a cura di C. D’Adda, Il Mulino, Bologna 1992, pp. 9-23; per la bibliografia cfr. pp. 530 e ss.

${ }^{6}$ Cfr. P.F. Asso, Modigliani e l'Italia, in P.F. Asso (a cura di), Franco Modigliani. L'impegno civile di un economista. Scritti editi e inediti sull'economia e la società italiana, Fondazione Monte dei Paschi di Siena, Protagon Editori, Siena 2007, pp. 9-50; Id., Viaggio attraverso la storia d'Italia. Le carte d'archivio di Franco Modigliani, in P. Barucci, L. Costabile, M. Di Matteo (a cura di), Gli archivi e la storia del pensiero economico, Il Mulino, Bologna 2008, pp. 143-170. Cfr. anche F. Cattabrini, Franco Modigliani and the Italian Left-Wing: the Debate over Labor Cost (19751978), «History of Economic Thougth and Policy», 1, 2012, pp. 75-95; A. Rancan, The wage-employment relationship in Modigliani's 1944 article, «European Journal of History of Economic Thought», April, 2016, pp. 1-32.

7 R. Maiocchi, Scienza e fascismo, Carocci, Roma 2004, pp. 77-106; F. Bientinesi, La parziale eccezione: costi comparati e teoria del commercio internazionale in Italia dalla seconda metà dell'Ottocento alla seconda guerra mondiale, FrancoAngeli, Milano 2011, pp. 317-320. 
dei contributi giovanili ${ }^{8}$. Nel 2017 Harald Hagemann ha ricostruito il profilo teorico di Modigliani sottolineando le influenze che sul suo percorso teorico hanno avuto gli economisti che incontra alla New School, senza però affrontare il periodo italiano 9 . Nel 2018 Renato Camurri ha riproposto un'antologia di testi che Modigliani dedica alla politica economica italiana dal 1970 al 2003, soffermandosi sugli anni giovanili dell'economista sulla base dei testi proposti da Parisi, che tuttavia non vengono analizza$\mathrm{ti}^{10}$. Da un lato Camurri pone in luce un fatto importante e cioè la "assenza di prove documentarie certe» ${ }^{11}$ che consentano di precisare il percorso politico del giovane studente universitario, così che «non è facile stabilire confini precisi» tra coloro i quali che, entro il fascismo, cercavano di indirizzarne in qualche modo gli orientamenti, e quanti, invece, «cercavano di porre le basi per un 'nuovo antifascismo'»' ${ }^{12}$. Dall'altro lato, all'autore non appare però «plausibile» che Modigliani condividesse le posizioni di quei giovani che ancora credevano in «una prospettiva di cambiamento dall'interno del fascismo» ${ }^{13}$.

Insomma, anche quando menzionata, la parabola intellettuale giovanile di Modigliani rimane sfuocata ${ }^{14}$.

Uno dei motivi per il quali i testi giovanili appaiono marginali e poco significativi sul piano della ricerca di storia del pensiero economico è forse da ricercare nel fatto che nell'autobiografia Modigliani non menziona i sei testi raccolti da Parisi. È legittimo ritenere che si tratta di saggi del tutto marginali, visto che sono stati composti quando il futuro premio Nobel per l'economia aveva appena diciannove/venti anni? La risposta ritengo che debba essere negativa. Il periodo, infatti, ha una notevole rilevanza proprio se si leggono le pagine dell'autobiografia. L'autore scrive che dopo un viaggio a Palermo, nel 1938, in occasione dei Littoriali (che si tennero

${ }^{8}$ M. Alacevich, P.F. Asso, S. Nerozzi, The Shaping of Public Economic Discourse in Postwar America: The 1947 Meat Shortage and Franco Modigliani's Meat Plan, «Research in the History of Economic Thought and Methodology», 2015, pp. 21-23.

9 H. Hagemann, Franco Modigliani as 'American' Keynesian: How the University in Exile Economists Influenced Economics, "Social Research: An International Quarterly», Winter, n. 4, 2017, pp. 955-985.

${ }^{10}$ Cfr. R. Camurri, Le lenti del grande esule: l'Italia vista da Franco Modigliani. Introduzione, in F. Modigliani, Rischio Italia. L'economia italiana vista dall'America (1970-2003), Donzelli, Roma 2018, p. XXI nota 12, dove si rimarca come il volume di Parisi «raccoglie tutti gli articoli» pubblicati da Modigliani prima dell'esilio. Pur menzionando gli articoli ripubblicati da D. Parisi, non ne analizza il contenuto né il contesto scientifico e culturale anche il contributo R. Camurri Franco Modigliani: an Exile from Fascsist Italy, «Italian Americana», 1, 2013, pp. 83-92.

${ }_{11}$ R. Camurri, Le lenti del grande esule ecc., cit., p. XXIII.

${ }^{12}$ Ivi, p. XXV.

${ }^{13}$ Ivi, p. XXX.

${ }^{14}$ Nessuna menzione dei testi giovanili anche in P. J. K. Kouri, Franco Modigliani's Contributions to Economics, «The Scandinavian Journal of Economics», 2, Jun., 1986, pp. 311-334. 
in aprile), grazie all'incontro con altri giovani studenti che partecipavano all'evento, una competizione culturale voluta dal fascismo che l'anno prima Modigliani aveva vinto per la sezione economica, egli era diventato "antifascista»; ma già la guerra di Spagna aveva segnato il distacco dal regime. Nell'autobiografia Modigliani dedica un paragrafo agli anni universitari ed il titolo è molto significativo: «I Littoriali e come nacque il mio antifascismo» ${ }^{15}$. Gli anni in questione, insomma, per l'autore sono quelli di una importante presa di coscienza politica.

Tra i testi pubblicati fino al giugno '38 e la tesi di laurea sostenuta a Roma nell'estate del 1939 si inseriscono, come è noto, eventi drammatici per la storia italiana e per Modigliani. È del 14 luglio 1938 la pubblicazione sul "Giornale d'Italia» del Manifesto degli scienziati razzisti e del mese di settembre è la sequenza di provvedimenti razzisti del regime nonché il discorso di Trieste di Mussolini che annuncia la discriminazione degli ebrei. E con le leggi razziali Modigliani è indotto a lasciare l'Italia: prima si reca in Francia, dal settembre 1938 al maggio 1939, e quindi, sostenuta la tesi, nell'agosto 1939 arriva negli Stati Uniti. La metà del 1938 assume, dunque, notevole rilevanza sul piano esistenziale.

Scopo di questo saggio è di approfondire il contenuto del pensiero giovanile di Modigliani nel periodo che inizia con la prima pubblicazione dell'aprile 1937 e che finisce con la tesi di laurea sostenuta nel luglio 1939. A tal fine farò oggetto di analisi non solo i testi ripubblicati da Parisi, ma anche altri due saggi di Modigliani, che non sono stati ripubblicati dalla studiosa italiana, né sono analizzati in altri lavori biografici: si tratta di L'autarchia nazionale, del febbraio 1938, uscito su «Lo Stato», analizzato brevemente nei lavori di Bientinesi e di Maiocchi, nonché valorizzato, in un saggio del 2010, da Marcello De Cecco ${ }^{16}$; e Valore e attualità del nazionalismo, del giugno 1938, pubblicato su «Dottrina fascista», a tutt'oggi sconosciuto dalla storiografia, anche se in qualche caso semplicemente menzionato come rimando bibliografico.

\section{Le leggi razziali: passato e presente}

Sebbene ai testi giovanili non si sia data importanza, come abbiamo visto, non è possibile fare a meno di evidenziare che essi vengono pubblicati su riviste fortemente impegnate a favore del fascismo. "Lo Stato», che ospita cinque articoli di Modigliani, è diretto da uno degli studiosi più in vista del regime: il giurista, nonché deputato al parlamento Carlo Costamagna.

${ }^{15}$ F. Modigliani, Avventure di un economista. La mia vita, le mie idee, la nostra epoca, a cura di P. Peluffo, Laterza, Roma 1999, pp. 12-15.

${ }^{16}$ M. De Cecco, Gli economisti italiani e l'economia internazionale nel Novecento, «Rivista italiana degli economisti», 1, apr., 2010, pp. 6-7. Ringrazio Emiliano Brancaccio per avermi segnalato questo testo. 
Qual è, del resto, il profilo intellettuale del giovane studente universitario che pubblica su «Lo Stato», «Il Ventuno», «Dottrina fascista»? Il profilo intellettuale del giovane studente nei quattordici mesi che corrono dall'aprile 1937 al giugno 1938, è quello di un aspirante 'economista fascista'. Come vedremo, Modigliani critica apertamente la scienza e la realtà economica 'individualiste' e vuole superare la divisione tra politica ed economia tipica del liberalismo. Modigliani, cioè, si inserisce in modo dichiarato in quella corrente di pensiero economico, non solo italiana, che voleva creare una 'nuova scienza economica' capace di dar conto della 'novità' storica rappresentata dal fascismo, ponendo su basi nuove il rapporto tra lo Stato e il mercato. Il giovane studente nei suoi testi cita Gino Arias, Filippo Carli, Carlo Costamagna, tutti celebri corifei della 'nuova economia', più o meno corporativa ma sicuramente incentrata sul ruolo dello Stato fascista. Uno dei testi più impegnativi del giovane universitario rimanda, come vedremo, pur senza citarlo, ad un importante discorso di Mussolini.

Il fatto che gli scritti di Modigliani evidenzino una chiara appartenenza all'universo dottrinario del fascismo, non contraddice necessariamente quanto afferma nell'autobiografia, cioè che egli aveva cominciato a prendere le distanze dal regime fin dagli anni dell'università. Si deve considerare che diversi giovani coinvolti nelle iniziative scientifiche e culturali del fascismo vivono una sorta di doppia esistenza, sia sul piano intellettuale che su quello politico: per rimanere nel campo degli economisti si possono citare alcuni militanti clandestini del partito comunista, come Cesare Dami e Antonio Pesenti. Rimane comunque il fatto che gli intenti dei testi giovanili di Modigliani sono evidenti.

Sul piano metodologico la tematica del rapporto tra Modigliani e il fascismo acquista, dunque, una rilevanza autonoma e importante: non solo sul piano biografico-esistenziale, ma anche su quello della storia del pensiero economico. Tanto più che le fonti documentali fino ad oggi pubblicate non affrontano questo argomento o sono scarse se non inesistenti e tanto più che, al contrario, le fonti a stampa firmate da Modigliani sono esplicite, come esplicita e inequivocabile è la linea editoriale de «Lo Stato» o la prospettiva scientifica e politica di Costamagna, di cui Modigliani cita, in uno dei suoi testi, il noto volume, ancor oggi ripubblicato dall'editoria neo-fascista, Dottrina del fascismo.

Queste osservazioni non sottendono da parte dello scrivente alcun giudizio di valore sul percorso scientifico e civile di Modigliani. Si tratta, invece, di ricostruire gli avvenimenti storici per quelli che essi furono, senza evitare di porsi domande storiografiche e formulare ipotesi di lavoro non solo legittimi, ma del tutto connaturati al periodo storico e al personaggio trattati, nonché alle fonti disponibili.

Il percorso intellettuale di Modigliani pone una seconda tematica storiografica. La lettura della tesi di laurea conferma l'interesse per le trasformazioni del capitalismo avvenute con il novecento, caratterizzate dalla fine della libera concorrenza e dal cambiamento del rappor to tra Stato e mercato. I riferimenti all'esperienza corporativa fascista, ridotti ai minimi termini, 
sono inseriti in un quadro più vasto, che lambisce l'esperienza tedesca, inglese, sovietica e, soprattutto, il New Deal di Roosevelt e la politica economica francese. Gli intenti teorico-metodologici di fondazione di una 'nuova scienza economica fascista' facente perno, come nei saggi precedenti, sullo Stato, sull'autarchia, sulla corporazione e sul partito fascista, come espressione di una nuova e superiore sintesi del rapporto tra nazione e individuo, sono venuti meno. L'impatto delle leggi razziali è stato dunque notevole nel modificare la prospettiva del giovane studioso. Tanto meno vi è traccia di riferimenti al fascismo nei testi scientifici pubblicati dopo l'arrivo in America.

Tuttavia, e veniamo ad una terza tematica, l'individuo come le società sono un impasto, talvolta inestricabile, di passato e di presente: è cioè indispensabile circoscrivere con precisione il cambiamento avvenuto nella prospettiva di ricerca di Modigliani in seguito alla emanazione delle leggi razziali. Come è fondato ricostruire le discontinuità biografico-intellettuali, così è inevitabile ricostruire se vi siano delle continuità. L'importanza dei testi redatti e pubblicati prima della tesi di laurea risalta, allora, anche sul piano analitico, come accennato dalla storiografia esistente, perché Modigliani affronta una serie di tematiche sulle quali continuerà a riflettere anche una volta raggiunta l'America. Due di queste tematiche sono particolarmente rilevanti: si tratta del pensiero di Keynes e della pianificazione.

Da quanto evidenziato, sul piano storiografico si aprono due prospettive interpretative.

Il lettore di Modigliani che ricostruisce la linea editoriale dello «Stato» e di «Dottrina Fascista», può legittimamente considerare il giovane studente una delle voci del fascismo: così hanno proposto sia Bientinesi che Maiocchi. Volendo mettere in luce i silenzi dell'autobiografia e valorizzando quanto sostenuto apertamente nei testi, si può parlare di un giovane che crede sinceramente negli ideali del regime, che assumono anche intonazioni socialiste, come del resto era proprio di una parte dei teorici del fascismo. Saranno allora le leggi razziali a imprimere una svolta politica al giovane studioso, che svilupperà le idee keynesiane e pianificatrici in una cornice politica del tutto differente da quella fascista una volta giunto in America.

Seguendo, invece, le indicazioni dell'autobiografia, si può rintracciare nei testi giovanili una sorta di doppio messaggio, l'uno di facciata, fascista, l'altro invece già antifascista, che poi potrà liberamente svilupparsi una volta raggiunta l'America.

Il fatto è che sul piano documentale non abbiamo elementi per dirimere la questione, né Modigliani ha voluto offrire indicazioni in proposito. Né è intenzione di queste mie pagine cercare di spiegare i motivi del silenzio di Modigliani su quei testi ${ }^{17}$. Per farlo sarebbe necessario non so-

17 Sulla problematicità delle autobiografie come fonti storiografiche cfr. Economists' Lives: Biography and Autobiography in the History of Economics. Annual Supplement to Volume 39 History of Political Economy, edited by E. Roy Weintraub and Evelyn L. Forget. 
lo trovare fonti documentali (come le carte di Costamagna), ma allargare la visuale della ricerca: si dovrebbe cioè ricorrere alla letteratura di coloro che hanno indagato in modo sistematico, sul piano storico, antropologico e psicologico, gli effetti che la persecuzione razziale nell'Italia e nell'Europa di quel periodo ha impresso ai ricordi dei perseguitati, al loro modo di raccontarli o ai silenzi che hanno scelto di mantenere; più in particolare e precisamente, si dovrebbe fare uno studio sistematico, che mi sembra ancora agli albori ${ }^{18}$, sui silenzi di coloro che prima aderirono al fascismo e poi ne furono perseguitati.

Anche se non tenterò di addentrarmi in questa problematica, ciò non mi impedirà di approfondire il mio studio, che, in mancanza di documentazione dirimente, cercherà di mantenere aperte entrambe le ipotesi di lavoro. In ogni caso, premetto che i testi del giovane universitario, in modo particolare quello pubblicato su «Dottrina fascista», fanno propendere, al momento, per la prima ipotesi.

${ }_{18}$ Mi sembra significativo, per esempio, che nell'importante volume Storia della Shoah in Italia (a cura di M. Flores, S. Levis Sullam, M.-A. Matard-Bonucci, E. Traverso, Utet, Torino 2010, 2 voll.), non vi sia un capitolo dedicato agli ebrei fascisti e alle testimonianze che hanno lasciato, se sopravvissuti alla persecuzione, della loro esperienza. 



\title{
CAPITOLO SECONDO
}

\author{
IL CONTESTO: LA RIVISTA «LO STATO»
}

\section{Per una scienza economica 'nuova'}

Il profilo della riflessione economica di Modigliani può essere messo a fuoco richiamando in modo sintetico il contesto editoriale sul quale compare.

La linea editoriale de «Lo Stato», che richiamo per gli anni che corrono dal primo numero del gennaio 1930 a tutto il 1938, presenta il fascismo come una "dittatura»" e un regime totalitario che ambisce ad avere caratteristiche differenti, e superiori, sia dal liberalismo che dal comunismo. Data la presenza di studi circostanziati su uno dei due direttori della rivista, il già menzionato Costamagna ${ }^{2}$, basti qui ricordare alcune sue pagine.

In Politica ed economia, del maggio 1930, l'autore scrive che «la definizione del rapporto tra politica ed economia è il punto centrale di ogni dottrina dello Stato». Costamagna è per la «supremazia del principio politico e quindi dello Stato come unica organizzazione necessaria». Il fascismo, dunque, «condanna come un'utopia la tesi liberale che vorrebbe raggiungere un ordine generale mediante una organizzazione spontanea delle utilità individuali»e, in opposizione, attribuisce allo Stato, «unico centro dell'organizzazione civile, il compito di assicurare il coordinamento fra le iniziative economiche individuali subordinandole al criterio di una utilità generale che nello Stato stesso esclusivamente si concreta». Non esiste, dunque, un "ordine economico universale o cosmopolitico»,

${ }^{1}$ E. Rosboch, L'influenza del fascismo in Europa, «Lo Stato», fasc. 1, 1930, p. 8. Il nome per esteso della rivista è «Lo Stato. Rivista di scienze politiche, giuridiche ed economiche»; da ora in poi la citeremo in forma abbreviata come «Lo Stato».

${ }^{2}$ C. Costamagna (1881-1965) fu magistrato, deputato, senatore, organico al PNF, al quale era scritto fin dal 1921, insegnante universitario a Ferrara, Pisa e Roma, anche se non ottenne la cattedra di diritto corporativo. Cfr. M. Toraldo di Francia, Per un corporativismo senza 'corporazioni': "Lo Stato» di Carlo Costamagna, "Quaderni fiorentini per la storia del pensiero giuridico moderno", 1989, pp. 267327; P. Costa, Lo 'Stato totalitario': un campo semantico nella giuspubblicistica del fascismo, "Quaderni fiorentini per la storia del pensiero giuridico moderno", 1999, t. 1, pp. 61-174; M. Benvenuti, Il pensiero giuridico di Carlo Costamagna nel dibattito su metodo, diritto e Stato durante il regime fascista, «Nomos», 1-2, 2005, pp. 17-102. 
ma solo un ordine «nazionale e politico». «L'economia, nella gerarchia fascista delle scienze, è perciò distinta dalla politica, ma subordinata ad essa, in quanto economia individuale». A loro volta, politica ed economica sono subordinate alla "dottrina generale dello Stato» ${ }^{3}$. In Direttive di azione economica, del gennaio 1933, Costamagna precisa quelli che a suo giudizio dovrebbero essere i contorni del fascismo, prendendo posizione nel dibattito interno allo stesso fascismo: «dopo un troppo lungo e confusionario periodo di retorica corporativa», l'azione politica del fascismo, anche sul piano legislativo, ha mostrato che il corporativismo è uno strumento, non un fine e che «non vi è alcuna seconda rivoluzione corporativa da compiere». Non si tratta di «aprire la via ad una trasformazione a tipo sindacale o corporativo della gestione delle imprese economiche», quanto di «conseguire il massimo utile della comunità nazionale, garantendo il patrimonio che è scaturito dalla iniziativa dei singoli produttori e tutelando l'interesse pubblico». Costamagna continua: «il pensiero fascista (...) si è reso una buona volta conto che i soggetti, i titolari, i destinatari dell'economia nazionale sono e devono essere esclusivamente due: lo Stato e l'individuo». Nel quadro della nuova economia nazionale non è però «l'amministrazione pubblica, centrale o sindacale», ad essere investita di «funzioni economiche dirette». «Il presupposto del nuovo ordine economico nazionale resta con l'individuo, l'iniziativa privata», che è il "caposaldo della costituzione fascista» ${ }^{4}$.

Quello di Costamagna, insomma, è un fascismo che si presenta come baluardo del capitalismo 5 . L'economista paretiano Luigi Amoroso è forse l'autore che meglio riassume questo assunto in Economia e politica: «La Carta del lavoro afferma che la direzione della produzione spetta al capitale. Ciò significa che della filosofia liberale la città corporativa accetta l'organizzazione monarchica dell'industria $»^{6}$. Va ricordato che Costamagna aveva collaborato con Pantaleoni nei primi anni Venti ed era tra coloro che si erano schierati per una soluzione liberista al problema sindacale, salvo poi cambiare totalmente opinione una volta che aveva prevalso la linea di Rocco, volta al controllo statale e fascista dei sindacati. Costamagna aveva anche collaborato alla stesura della Carta del lavoro e tra gli economisti vi è chi, come Gustavo Del Vecchio, collaboratore dello «Sta-

${ }^{3}$ C. Costamagna, Politica ed economia, «Lo Stato», fasc. 5, 1930, pp. 562-564.

${ }^{4}$ C. Costamagna, Direttive di azione economica, «Lo Stato», fasc. 1, 1933, pp. $1-2$.

5 Tra l'altro Costamagna era stato della cerchia di intellettuali vicini a Pantaleoni nei primi anni venti: cfr. L. Michelini, Il pensiero economico del nazionalismo italiano, cit., le note a pp. 72-75.

6 L. Amoroso, Economia e politica, «Lo Stato», fasc. 11-12, 1932, p. 775.

7 Cfr. C. Costamagna, I conflitti collettivi del lavoro, «Rivista di Diritto Pubblico», 1925, pp. 245-247; sul tema rimando a L. Michelini, Il pensiero economico del nazionalismo italiano, cit., nota 199. 
to», ne interpreta in contenuti come realizzazione dei principi economici scanditi da Pantaleoni ${ }^{8}$.

In ogni caso, una volta mutato il quadro politico col prevalere della linea di Rocco, per Costamagna lo Stato, controllato dal duce e, un gradino più in basso, dal partito e dal Gran Consiglio, doveva avere una netta prevalenza sulle corporazioni, anche se rimaneva impregiudicata e da definire con precisione la gerarchia delle fonti costituzionali, per riprendere la terminologia del giurista. Erano soprattutto la Carta del lavoro e i testi di Mussolini a costituire il filo conduttore del nuovo Stato. Un intero numero della rivista è dedicato a chiosare la voce sul fascismo firmata da Mussolini per l'Enciclopedia Treccani di Giovanni Gentile e pubblicata su «Lo Stato» nell'ottobre del 1932 con il titolo La dottrina politica e sociale del fascismo, testo dove a primeggiare è il ruolo dello Stato totalitario 9 .

Tra i collaboratori impegnati a teorizzare lo Stato totalitario emerge Carl Schmitt, che pubblica diversi testi sulla rivista ${ }^{10}$. Commentando una conferenza tenuta a Roma, la direzione della rivista chiosa con approvazione un testo in cui si legge: "Il sorgere di un'era integralmente politica della civiltà, come quella in cui viviamo, si palesa (...) nel fatto che le fallaci astrazioni delle scienze morali, rientrino esse nell'ambito del diritto, della morale o della economia, vengono sottoposte al vaglio di un criterio politico». La politica è diventata totalitaria perché totalitaria è stata la Grande Guerra: «così si dovrà ritenere, che per l'attuale epoca, specificamente politica, il criterio decisivo della politica interna ed esterna si basa

${ }^{8}$ Cfr. G. Del Vecchio, Prefazione a M. Pavesi, Economia corporativa e dottrine realiste, Stabilimento Poligrafico Riuniti, Bologna 1929; rimando a L. Michelini, Il pensiero economico del nazionalismo italiano, cit., nota 203.

9 «Lo Stato», fasc. 10, 1932, pp. 655-667. Chiosano il testo i seguenti autori con i rispettivi saggi: C. Costamagna, Pensiero ed Azione, pp. 668-673; P. De Francisci (ministro della giustizia), Ai giuristi italiani, pp. 674-691; A. Solmi (sottosegretario per l'educazione nazionale), Le origini del fascismo, pp. 692-696; V. Leonardi (deputato), Individuo e Stato nella dottrina fascista, pp. 697-706; C. Curcio, Lo Stato, la guerra, la pace, pp. 707-714; C.E. Ferri, La dottrina economica del fascismo, pp. 715-722; G. Borgatta, Il primo decennio della politica economica del fascismo, pp. 723-741; S. Fabbri, Politica demografica, pp. 742-748; A. Buffa, L'etica sociale del fascismo, pp. 742-758. Nel fascicolo successivo (fasc. 11-12, 1932) sempre a commento del testo di Mussolini si pubblica di O. Spann Istinto e conoscenza nella storia del fascismo, pp. 759-763.

10 C. Schmitt, La categoria del 'Fuehrer' come concetto fondamentale del diritto socialnazionalista, «Lo Stato», fasc. 12, 1933, pp. 834-839; Id., L'era della Politica integrale, «Lo Stato», fasc. 4, 1936, pp. 193-197; Id., La dottrina del diritto nel Fascismo e nel Nazionalsocialismo, "Lo Stato», fasc. 5, 1936, pp. 299-300; Id., La settima trasformazione della Società delle Nazioni, «Lo Stato", fasc. 7, 1936, pp. 385-392; Id., Stato totalitario e neutralità internazionale, «Lo Stato", fasc. 11, 1938, pp. 605-612. Non è questa la sede per richiamare il dibattito scientifico-storiografico sul pensiero di Schmitt, che ha avuto differenti interpretazioni. In questa occasione importa invece ricostruire la figura di Schmitt che emerge dalle pagine de «Lo Stato». 
sulla distinzione fra amico e nemico». «Sinora, due Nazioni Europee, la Germani e l'Italia, hanno trovato le forme adeguate alla realtà attuale della unità politica». "Oggi il movimento fascista ha compreso e sta attuando (...) lo 'Stato Nuovo'» e l'auspicio è che, collaborando le due nazioni, possa nascere una «Europa Nuova’»" .

Le opere del giurista vengono commentate da diversi collaboratori della testata, che lo presentano come teorico del nazionalsocialismo. Ricordato il poco favore incontrato presso il pubblico italiano e le principali opere dell'autore, il politologo Carlo Curcio ne introduce il pensiero come antitesi del liberalismo. Mostrato come solo la Chiesa realizzi l'unità perfetta di ordinamento giuridico e di imperium, Schmitt mostra l'inevitabilità delle rivoluzioni: «non ci sono mai leggi eterne, costituzioni eterne». « $\mathrm{E}$ la rivincita della politica». In questo contesto la «dittatura rivendica una sua elevata funzione, non solo politica, ma giuridica»: «prepara il nuovo diritto; fonda la nuova società», altrimenti è «tirannide»» ${ }^{12}$.

Anche l'economista Celestino Arena sottolinea compiaciuto il totalitarismo dello studioso tedesco in Liberalismo, pluralismo e Stato unitario, che ne caldeggia le tesi notando come «il principio del non intervento in economia, della neutralità di fronte ai conflitti economici è l'espressione del pluralismo liberale in economia» ${ }^{13}$. Nel gennaio 1934 «Lo Stato» dà conto delle critiche mosse dal nazista Alfred Rosemberg a Schmitt: la preoccupazione è che il nazionalsocialismo trovi ostacolo nella continuità storica, e dunque pre-nazista, della statualità ${ }^{14}$. Alla fine del 1934 si ricorda un testo nel quale $\mathrm{Schmitt}$ difende il nazismo dall'accusa di essere «barbaro» ${ }^{15}$. In un altro numero la rivista si chiede se il totalitarismo di Schmitt apra anche al comunismo ${ }^{16}$ ed è poi Julius Evola a commentare l'interpretazione di Hobbes proposta dallo studioso ${ }^{17}$. Nel gennaio 1937 «Lo Stato» si chiede per quale motivo in Germania, come informa la rivista «Deutsche Juristenzeitung», non si possono più pubblicare «nuove opere giuridiche di autori ebrei né possono essere fatte ristampe di libri degli stessi autori». «Lo dice, nello stesso fascicolo della rivista nazionalsocialista, il prof. Schmitt: i giuristi ebrei sono i responsabili, come, del resto, tutta la cultura ebraica, della crisi del diritto e dello Stato moderno ${ }^{18}$.

${ }^{11}$ C. Schmitt, L'era della politica integrale, «Lo Stato», fasc. 4, 1936, pp. 194-196.

${ }^{12}$ C. Curcio, Tendenze nuove della dottrina tedesca: C. Schmitt, «Lo Stato», fasc. 4, 1930, p. 482.

13 «Lo Stato», fasc. 7, 1931, p. 550 .

${ }^{14}$ La rivista ne dà conto con G. Glaesser, in Stato totalitario o Stato strumentale, «Lo Stato», fasc. 1, 1934, pp. 45-47.

${ }_{15}$ Cfr. l'anonimo commento in «Lo Stato», fasc. 11-12, 1934, pp. 772-773.

${ }^{16}$ Cfr. quanto scrive F. Ermarth in Osservatori ed interpreti tedeschi della costituzione fascista, «Lo Stato», fasc. 4, 1931, pp. 275-282.

17 J. Evola, Modernità di Hobbes?, «Lo Stato», fasc. 1, 1939, pp. 24-33.

18 Anonimo, Ebraismo e scienza del diritto, «Lo Stato», fasc. 1, 1937, p. 58. 
È in questa cornice teorica di rivincita della Politica (uso il maiuscolo, come da sintassi fascista) e dello Stato sull'Economia che prende corpo il tentativo di creare una 'scienza economica corporativa'. Nelle Precisazioni programmatiche del periodico si legge: «Questa rivista è indubbiamente sospinta da un sentimento politico ad affrontare la rielaborazione delle diverse discipline, politiche, giuridiche, economiche, alla luce del principio corporativo» ${ }^{19}$.

Come osserva l'economista liberale Pasquale Jannaccone discutendo le tesi del filosofo gentiliano Ugo Spirito, il problema della 'nuova economia corporativa' è però notevole: si tratta, infatti, di passare dalla critica della scienza economica liberale, alla edificazione di una scienza economica nuova. Difficoltà che, osserva un 'economista fascista' che collabora a «Lo Stato», Carlo Emilio Ferri, il comunismo non aveva, avendo come punto di riferimento il pensiero di Marx e il marxismo, anche se l'italiano, come da vulgata non solo fascista, li riteneva fallimentari sul piano scientifico ${ }^{20}$. In effetti, quando si tratta di costruire una nuova grammatica economica non raramente ci si imbatte in autori o in singoli saggi che propongono ragionamenti che sono al limite della farneticazione retorica, almeno da quanto si legge sulla rivista: mi riferisco, in modo particolare, ad alcuni contributi dello stesso Costamagna ${ }^{21}$ e a quelli di Ferri ${ }^{22}$ e di Evola ${ }^{23}$.

Il corporativismo è però solo uno degli strumenti, per altro molto discussi su «Lo Stato» come abbiamo visto, per costruire una delle fondamentali caratteristiche 'totalitarie' della nuova scienza economica, che doveva promuovere una nuova sintesi del rapporto tra Politica ed Economia, dove la prima, incarnazione del Popolo, della Nazione e dello Stato, non poteva che avere la prevalenza sulla seconda. Con la guerra coloniale è l'autarchia economica a diventare uno strumento altrettanto efficace del corporativismo, se non superiore, per creare la nuova scienza. Superiore perché vi era una corposa tradizione di pensiero economico prima mercantilista, quindi protezionista e infine neo-protezionista e neo-mercantilista, che ne giustificava le aspirazioni: e non è un caso che questa linea di pensiero venga ricostruita, sulla rivista, da Roberto Michels sul primo numero dello «Stato ${ }^{24}$. Le pagine che Modigliani

19 «Lo Stato», fasc. 1, 1930, p. 57.

20 C.E. Ferri, Per l'indipendenza dell'idea fascista, «Lo Stato», fasc. 2, 1931, p. 94.

${ }^{21}$ C. Costamagna, Politica ed economia, «Lo Stato», fasc. 5, 1930, pp. 562-565; Id., L'universalismo economico e la crisi, «Lo Stato», fasc. 2, 1933, pp. 82-93; Id., Principi generali di economica corporativa, «Lo Stato», fasc. 2, 1935, pp. 124-128.

${ }_{22}$ C.E. Ferri, L'optimum corporativo, «Lo Stato», fasc. 5, 1931, pp. 343-350.

${ }^{23}$ Cfr. J. Evola, La ricostruzione dell'idea di Stato, «Lo Stato», fasc. 4, 1934, pp. 253-265.

${ }^{24}$ Cfr. R. Michels, L'idea dello Stato nella storiografia delle dottrine politiche ed economiche, «Lo Stato», fasc. 1-2, 1930, pp. 31-39. 
dedica al protezionismo e all'autarchia (senza ricadere nel mercantilismo), brillano nel confronto con i novatori prima citati, per lucidità e razionalità e valorizzano il protezionismo, l'autarchia e il partito come strumenti della edificazione della nuova scienza economica e della nuova nazione scegliendo, al contempo, come terreno d'argomentazione le categorie proprie all'economia politica.

Naturalmente, pubblicare su una rivista non significa necessariamente condividerne in toto la linea, che del resto era in continua evoluzione, anche perché sollecitata dal susseguirsi di avvenimenti epocali sia sul piano interno che su quello internazionale. La direzione, infatti, non passa numero in cui non cerchi di puntualizzare l'orizzonte dottrinario del fascismo, bacchettando autori fascisti e non.

$\mathrm{Su}$ «Lo Stato» scrivono economisti che, per quanto organicamente fascisti, non danno credito eccessivo agli intenti di superamento della scienza economica 'classica' e si limitano a riproporre, per venire incontro alle esigenze del regime, la giustapposizione paretiana tra discipline indipendenti. Mi riferisco, per esempio, a Guido Sensini e a Gustavo Del Vecchio ${ }^{25}$, che valorizzano la distinzione di Vilfredo Pareto tra utile per la collettività e utile della collettività, così da far risaltare come l'interesse dello Stato, che si può studiare con il ricorso alle discipline della sociologia, della politologia e della storia, della scienza delle finanze, non sia necessariamente la risultante, la somma, degli interessi individuali, ma sia, invece, quell'entità superiore e indipendente dagli individui di cui parla senza tregua alcuna qualsivoglia teorico del fascismo ${ }^{26}$. La prospettiva indicata dai due economisti è chiara, perché volta a ribadire la validità della teoria economica paretiana ${ }^{27}$. Semmai l'auspicio, per altro interessante sul piano scientifico, è che nasca un filone di studi sul «sistema economico corporativo» ${ }^{28}$, che dunque, di fatto, ma questa è una osservazione dello scrivente, si sarebbe andato ad affiancare al filone di studi sui sistemi economici analizzati da Pareto: quelli socialisti e quelli plutocratici (il demagogico e il conservatore), che si erano scontrati durante la Prima Guerra Mondiale.

Sintetizzando: ciò che voglio sottolineare con la rapida carrellata ora proposta $^{29}$ è che collaborare a «Lo Stato» implicava fare una scelta di campo.

${ }^{25}$ Per l'impegno filo-fascista dei due economisti rimando ad vocem a L. Michelini, Il pensiero economico del nazionalismo italiano, cit.

${ }^{26}$ Si tratta, del resto, di una riflessione condivisa da Costamagna, che infatti si richiama a Pareto: C. Costamagna, Principi generali di economica corporativa, «Lo Stato, fasc. 2, 1935, p. 126.

${ }_{27}$ Cfr. G. Sensini, Le equazioni dell'equilibrio economico in regime corporativo, «Lo Stato», fasc. 5, 1932, pp. 350-357.

${ }^{28}$ Cfr. G. Del Vecchio, Per la teoria economica dell'ordinamento corporativo, «Lo Stato», fasc. 5, 1930, pp. 509-511.

${ }^{29}$ Carrellata non esaustiva: da segnalare lo sforzo di definire una 'finanza corporativa': cfr. A. Garino-Canina, Il fondamento economico e politico della finanza pubblica nello Stato corporativo, «Lo Stato», fasc. 2, 1930, pp. 159-164. 
Sarebbe naturalmente molto importante ricostruire la cronaca archivistica della collaborazione di Modigliani con la rivista e, più in particolare, la documentazione di una eventuale relazione personale con Costamagna o con altri collaboratori. Ad oggi, purtroppo, non abbiamo documentazione archivistica in proposito. In ogni modo, l'universo problematico dei testi e della collaborazione editoriale di Modigliani risultano del tutto interni al fascismo. Del resto, vi erano riviste di economia che avevano una fisionomia scientifica autonoma dal fascismo, sia perché nate prima del fascismo, sia perché attente a rimanere quanto più possibile sul piano del dibattito scientifico secondo quelle categorie economiche che il fascismo tentava di superare o di utilizzare. Durante il regime, per quanto la censura e le persecuzioni limitassero drasticamente la libertà di pensiero e di ricerca, resistono spazi di riflessione autonoma dal fascismo.

E di questo, non a caso, non smette di lamentarsi il 'totalitario' direttore dello «Stato», Costamagna, al quale il fascismo appariva troppo poco risoluto nel 'fascistizzare' tutte le scienze sociali italiane, economia compresa. Perfino Gentile, il maggior teorico del fascismo, appariva timido agli occhi di Costamagna, poiché aveva fondato e dirigeva un Istituto Fascista di Cultura e non un Istituto di Cultura Fascista. Per Costamagna esisteva inoltre un'aggravante: Gentile aveva dato vita ad una scuola di economia, la Scuola di Pisa, che, come da prassi idealistica (infatti Hegel porta a Marx), aveva generato il corporativismo «antifascista» (questo il termine usato da Costamagna) di Spirito e di Arnaldo Volpicelli, un tipo di 'economia nuova' che osava parlare di «corporazione proprietaria» e di corporazioni pari o superiori allo Stato, al capo del fascismo, al partito fascista, al Gran Consiglio ${ }^{30}$. Si tratta di una critica che Costamagna estende anche ad altri teorici della scienza economico-giuridica fascista, come, tra gli altri (l'elenco sarebbe notevole), Othmar Spann, il suo allievo Walter Heinrich, l'economista e politico romeno Mihail Manoilescu, il giurista Sergio Panunzio ${ }^{31}$.

\section{Il fascismo sociale}

La tesi di laurea non contiene riferimenti a Keynes eppure Modigliani cerca di trovare la Teoria generale fin dagli anni dell'università ${ }^{32}$. Sarà solo in America che egli riuscirà a confrontarsi con quel testo. I risultati

${ }^{30}$ Cfr. C. Costamagna, Dal parlamento sovrano alle grandi magistrature nazionali, «Lo Stato», fasc. 11-12, 1934, pp. 721-727; nello stesso numero cfr. G. Cavallucci, Gli innominabili dell'attualismo corporativo, pp. 761-765. Cfr. anche La Direzione, Nascita dell'Istituto Nazionale di Cultura Fascista, «Lo Stato», fasc. 1, 1937, pp. 51-54.

${ }_{31}$ Cfr. C. Costamagna, Equivoci corporativi, «Lo Stato», fasc. 1, 1935, pp. 1-11.

32 Cfr. F. Modigliani, Le avventure ecc., p. 13. La data è sottolineata da L. Pasinetti, Quanto Keynes c'è in Franco Modigliani?, «Moneta e credito», giu.-sett., 2005, p. 24. 
del confronto, come è noto, sono condensati nel saggio del 1944 Liquidity Preference and the Theory of Interest and Money, che canonizzerà l'interpretazione di Keynes che si diffonderà in tutto il mondo dopo la Seconda Guerra Mondiale. Tuttavia, i testi giovanili evidenziano un anelito al conseguimento della giustizia sociale utilizzando anche argomentazioni che richiamano il pensiero di Keynes. Talvolta le pagine di Modigliani lambiscono intonazioni socialiste laddove criticano l'egualitarismo puramente formale del liberalismo. Gli scritti italiani del giovane studioso contengono una critica alla legge degli sbocchi di Say e della teoria quantitativa della moneta e sono circostanziati nel criticare il liberismo.

Anche in questo caso, è importante ricordare una delle caratteristiche del fascismo: e cioè che esiste un fascismo sociale. Partendo dal comune intento proprio di tutto il fascismo e il nazionalismo di assorbire nel regime la spinta sociale del movimento operaio, una volta repressane la libertà di movimento, attraverso l'istituzionalizzazione del sindacato, questo fascismo sociale cerca di imprimere al corporativismo fondato sulla Carta del lavoro una coloritura che potremmo definire lavoristica, secondo teorie e proposte che cambieranno al volgere degli scenari nazionali e internazionali, fino ad arrivare, radicalizzati, alla Repubblica di Salò, dove quello che viene identificato come il 'tradimento della borghesia' compiuto ai danni del fascismo e della nazione si tradurrà in propositi di socializzazione della produzione. Si tratta di una linea di pensiero che, come ho evidenziato nell'introduzione, Pantaleoni aveva già criticato allorquando si era dovuto confrontare con la Carta del Carnaro di Alceste De Ambris, al tempo dell'avventura politica di Fiume di cui fu protagonista. Anche Costamagna, come abbiamo visto, insiste nel polemizzare con il corporativismo che possiamo definire di sinistra.

Non può sorprendere, insomma, la presenza nei testi giovanili di Modigliani di una mescolanza di aspirazioni provenienti da tradizioni differenti: tra gli scopi precipui della 'nuova' scienza economica fascista vi era non solo la critica della scienza economica liberale classica, quella fondata, cioè, sul trinomio liberismo-liberalismo-individualismo e sulla separazione tra politica ed economia. C'era anche l'aspirazione a perseguire obiettivi di giustizia sociale. Perfino Costamagna si cimenta con la materia pubblicando Giustizia sociale, testo in effetti di maniera e soprattutto attento a sottolineare come non potessero essere le corporazioni a farsene promotrici ${ }^{33}$. In Integralismo fascista l'economista austriaco Ludwig Lachman definisce il fascismo uno Stato sociale autoritario ${ }^{34}$. Ma sono solo degli esempi. Un altro vale la pena di ricordare: nientemeno che sulle pagine della rivista più autorevole del fascismo, "Gerarchia», ideata e diretta per lungo tempo da Mussolini, si possono leggere articoli che presentano il fascismo non solo come baluardo contro il socialismo, ma an-

33 C. Costamagna, Giustizia sociale, «Lo Stato», fasc. 10, 1934, pp. 641-649.

${ }^{34}$ L. Lachman, Integralismo fascista, «Lo Stato», fasc. 1, 1931, pp. 31-39. 
che come prosecutore di quanto nel socialismo era «principio rinnovatore utile, giusto e fecondo, rivendicazione umana, rispondente allo spirito dei tempi», come «continuazione» e «realizzazione logica, possibilista, concreta e fattiva delle grandi idee sociali che nel socialismo erano in germe $»^{35}$.

Non può poi sorprendere che un giovane come Modigliani, che non aveva vissuto direttamente il duro scontro sociale e politico dei primi anni Venti e lo squadrismo fascista, quello che culmina con il delitto Matteotti; un giovane che non aveva avuto esperienza diretta dell'applicazione delle leggi liberticide; non può sorprendere che un giovane che si affaccia alla vita civile durante gli anni 'ruggenti' del fascismo e della contemporanea crisi del capitalismo: non può sorprendere, dicevo, che un giovane appena ventenne non avesse coscienza, almeno da quanto si evince dai testi pubblicati, del contenuto retorico della giustizia sociale di cui il fascismo si dichiarava incarnazione. E non può sorprendere, del resto, che un giovane non considerasse anche gli aspetti inclusivi, sul piano sociale, del fascismo, chiamato con la crisi degli anni Trenta a rimodellare l'intervento pubblico in ambito economico e sociale. La repressione della libertà politica e sociale, il suo ingabbiamento non solo poliziesco attraverso la nascita di moderne corporazioni e della magistratura del lavoro si accompagnava, infatti, alla creazione di più o meno moderni istituti di assistenza sociale, nel quadro, parimenti analizzato su «Lo Stato»(con recensioni e brevi interventi con la penna di Aldo Buffa), di una nuova politica industriale veicolata da enti pubblici come l'IMI e l'IRI ${ }^{36}$.

Per riassumere: per valutare le aspirazioni sociali del fascismo non va dimenticato che uno dei suoi osservatori più acuti, Antonio Gramsci, che per altro scontava sulla propria esistenza il meccanismo repressivo del regime, nei suoi Quaderni, redatti nel carcere fascista, interpretò la parabola del regime come «rivoluzione passiva».

\section{La Grande Crisi}

Come ha osservato lo storico Aurelio Macchioro, era negli «ambienti di Fascismo populistico-nazionali che talune simpatie pel keynesismo erano riscontrabili, non foss'altro perché tanto Keynes che il Fascismo erano contrari al cosiddetto dogma del lasciar fare ${ }^{37}$. È sempre lo studioso a ricordare come nel 1936 lo storico economico Gino Luzzatto inserisce i due

35 Si tratta dell'articolo di apertura del secondo numero del 1927 della rivista, senza autore e dunque da attribuirsi alla direzione: Problemi e chiarimenti, «Gerarchia», n. 2, febbraio, 1927, p. 83.

${ }^{36}$ V. Andrioli, Caratteri giuridici dell'Istituto Mobiliare Italiano, «Lo Stato», fasc. 12, 1931, pp. 874-881; R. Fiorentini, La politica industriale del fascismo, «Lo Stato», fasc. 10, 1933, pp. 696-701.

37 A. Macchioro, J.M. Keynes e il keynesismo in Italia, in Id., Studi di storia del pensiero economico ed altri saggi, Feltrinelli, Milano 1970, p. 635. 
testi di Keynes La fine del lasciar fare e Autarchia economica in uno dei volumi della Nuova collana di economisti italiani ed esteri, un'iniziativa voluta da uno degli intellettuali di spicco del fascismo, Giuseppe Bottai ${ }^{38}$, che la dirige assieme a uno dei collaboratori de «Lo Stato», Arena. Il volume è quello dedicato alla Storia economica (Torino, Utet, 1936) e contiene una panoramica nazionale e internazionale di studiosi e/o promotori del mercantilismo vecchio e nuovo e del protezionismo, con scritti, nell'ordine, di Karl Bücher (L'origine dell'economia politica), Friedrich List (Il sistema nazionale dell'economia politica), i due testi di Keynes prima citati, Eli F. Heckscher (Il mercantilismo) e infine un lungo studio opera di una sorta di 'Schmoller italiano', il cattolico Jacopo Mazzei (Schema di una storia della politica economica internazionale nel pensiero dei secoli XVII, XVIII eXIX). Poiché il volume curato da Luzzatto è del 1936, e Modigliani, come vedremo, è molto interessato al filone di pensiero protezionista e autarchi$\mathrm{co}$, non è infondato ipotizzare che l'interesse per Keynes nasca in Modigliani per una comunanza di vedute circa la critica del liberismo: vedremo come nel testo L'autarchia economica egli utilizza tanto Keynes che List.

Il tema della crisi, naturalmente, è presente nelle pagine della rivista «Lo Stato». L'interpretazione che ne emerge, e le ricette che vengono proposte dagli economisti, sono indubbiamente 'classiche', per utilizzare l'espressione di Keynes; che però, timidamente, fa capolino.

Rosboch, che detta in materia di crisi economica la linea della rivista, scrive testi di interpretazione della grande crisi e di politica economica in linea con le tesi liberistiche inneggianti alla deflazione, alla diminuzione della spesa pubblica, alla stabilità del cambio ${ }^{39}$ e critica come inefficace e inflazionistica la politica economica di Roosevelt ${ }^{40}$. Gli economisti accademici che collaborano allo «Stato» sono anch'essi di questo avviso. Giuseppe Ugo Pagi scrive «Il costo della vita» e l'ordinamento corporativo, dove si auspica che la politica economica dell'«economa controllata» corporativa si traduca in una rapida riduzione di tutti i redditi avendo anche cura di tagliare la spesa pubblica e di mantenere il bilancio statale in pareggio ${ }^{41}$. Marco Fanno, in Considerazioni sull'economia corporativa, osserva come in un'economia ciclica i prezzi non si muovono tutti allo stesso momento: i salari sono molto vischiosi e questo amplifica il ciclo. Quando i prezzi sono alti, a salari costanti i profitti aumentano; quando invece i prezzi discendono, a salari costanti i profitti diminuiscono con conseguenze ne-

${ }^{38}$ Per un certo periodo è vicino alla stessa rivista, che apre nel primo numero proprio con un suo intervento: cfr. G. Bottai, Lettera-programma, «Lo Stato», fasc. 1-2, 1930, pp. 1-5.

${ }^{39}$ Tra gli altri cfr. E. Rosboch, Le crisi economiche, «Lo Stato», fasc. 5, 1931, pp. 321-328; Id., Economia politica e politica antieconomica, «Lo Stato», fasc. 1, 1932, pp. 1-7; Id., Come si può liquidare la crisi, «Lo Stato», fasc. 2, 1932, pp. 81-89.

${ }^{40}$ E. Rosboch, Contrasti monetari d'America, «Lo Stato», fasc. 6, 1932, pp. 408-411.

41 «Lo Stato», fasc. 1, 1931, pp. 40-50. 
gative sugli investimenti. Ebbene le fluttuazioni cicliche possono essere attenuate nell'economia corporativa, per l'occasione definita economia con "prezzi a movimento simultaneo», facendo muovere i salari con i prezzi. Nelle sue pagine A.C. Pigou, noto avversario delle teorie di Keynes, va a braccetto con la Carta del lavoro ${ }^{42}$.

Nel settembre 1931 Arena commenta i lavori della Commissione Mcmillan e anche la posizione di Keynes e di Mc Kenna. Essi «ritengono che uno sforzo per aumentare le possibilità d'impiego, riducendo i salari, avrebbe probabilmente in pratica, i risultati più sconfortanti: il beneficio che le industrie che producono esclusivamente per l'interno potrebbero realizzare abbassando i loro prezzi di costo, in seguito alla riduzione generale dei salari sarebbe compensato dalla diminuzione del potere di acquisto della loro clientela; e perfino le industrie che lavorano per l'esportazione non potrebbero avere la certezza che alle riduzioni dei salari imposte ai lavoratori inglesi, i principali concorrenti stranieri non rispondessero con analoghe riduzioni». Arena riporta la conclusione del memoriale, virgolettando che «il costo sociale» del tentativo di ridurre i prezzi «finirebbe in uno smacco, sarebbe incalcolabile». L'economista italiano non perde però occasione per ribadire il punto di vista 'classico' in un'ttica anti-inglese: l'Inghilterra, infatti, non vuole abbassare il proprio tenore di vita per «questione di egoismo ma anche di orgoglio patriottico». L'Inghilterra vuole difendersi dalla concorrenza straniera «cercando di imporre agli altri la propria politica. Non dunque riduzione dei salari». «Poco conta per l'inglese che il nuovo equilibrio sacrifichi eventualmente le altre economie che hanno provveduto con una saggia politica ad adeguare i salari e i costi interni al livello internazionale dei prezzi $»^{43}$.

Significativa, infine, la presa di posizione ufficiale della rivista in materia di Grande Crisi. In La crisi mondiale la direzione (Costamagna, dunque) si preoccupa di sottolineare come la crisi sia generale e non riguardi, dunque, solo l'Italia, che anzi grazie al fascismo ha approntato i prerequisiti politico-sociali per affrontarla, come finalmente va riconoscendo la pubblica opinione internazionale. Nel merito, il testo insiste nel definire la crisi una "crisi finanziaria», cioè una crisi dovuta ad un «abuso del credito» sia da parte dello Stato che dei privati. Nessun rimando, dunque, ai meccanismi dell'economia reale, alla distribuzione del reddito, alle leggi del risparmio e dell'investimento: è come se l'economia 'classica' di cui parlava Marx, e Marx stesso ovviamente, non fossero mai esistiti. Spicca, invece, la politica economica del fascismo, che «ha invece adottato fino dalle origini, una politica di austero realismo» ${ }^{44}$.

42 «Lo Stato», fasc. 4, 1931, pp. 271-274.

${ }^{43}$ C. Arena, Ribasso di salari o aumento generale dei prezzi?, «Lo Stato, fasc. 10, 1931, pp. 673-74.

${ }^{44}$ La direzione, La crisi mondiale, fasc. 10, 1931, pp. 730-731. 
Siamo in pieno 'classicismo', insomma, quello dal quale prende le distanze Keynes. Siamo in piena giustificazione dell'operato del governo fascista: che non aveva certo aspettato la Grande Crisi per scaricare sulle classi lavoratrici il reiterato salvataggio della nazione ${ }^{45}$.

Nel fascicolo del gennaio 1938 esce, però, anche una anonima discussione delle tesi di Keynes sulla crisi, pubblicate prima sul «Times» e poi riportare da un periodico italiano. Le sue idee sono definite «interessanti» e si riporta la sua opinione che il laissez-faire sia definitivamente tramontato. I problemi dell'economia, cerca di riassumere l'anonimo recensore, nascono perché «il pubblico dei consumatori, specialmente quando è in prosperità, non spende l'intero suo reddito nei consumi correnti» ${ }^{46}$. Come vedremo, Modigliani è interessato a questo tipo di ragionamento: la crisi del capitalismo può spiegare come un giovane ricerchi in modo disinteressato e a prescindere dalla famiglia politica di appartenenza, paradigmi economici nuovi per interpretarne le leggi evolutive e per prospettarne il governo o la trasformazione.

\section{La pianificazione}

Occuparsi delle cause della grande crisi implica proporre strumenti per uscirne.

Come è stato notato in sede storiografica, nei testi giovanili di Modigliani è evidente l'interesse per un intervento pubblico di natura ben differente da quello classico-liberale, tanto da arrivare a confondersi con quello proprio dell'economia socialista.

Il giovane studente approfondisce la teoria dei prezzi amministrati, che invece l'economia marginalista italiana, con Pareto, nelle pagine che in diverse opere e scritti dedica alla cosiddetta "plutocrazia demagogica», e soprattutto con Pantaleoni, aveva seccamente criticato in quanto riviviscenza antieconomica del mercantilismo. Era un'anti-economicità che tuttavia durante la Grande Guerra si era resa indispensabile per organizzare la difesa industrial-militare del Paese, come aveva suggerito durante il conflitto Enrico Barone, l'autore del celebre testo Il Ministro della produzione nello stato collettivista, del $1908^{47}$.

${ }^{45}$ Cfr. V. Castronovo, Storia economica d'Italia. Dall'Ottocento ai giorni nostri, Einaudi, Torino 2013, pp. 202, 204, 234-235.

46 Anonimo, Opinioni sulla crisi, «Lo Stato", fasc. 1, 1938, p. 57. Si tratta di un testo da aggiungere alla fondamentale ricognizione di P. Bini, P.F. Asso L'eco degli scritti di Keynes nelle riviste italiane, in Keynes in Italia. Catalogo bibliografi$c o$, a cura della Facoltà di Economa e Commercio, Università di Firenze, «Banca Toscana. Studi e informazioni». Quaderni 7, 1983, p. 96.

${ }^{47}$ Cfr. L. Michelini, Innovazione e sistemi economici comparati: il contributo di Enrico Barone e il pensiero economico italiano (1894-1924), «Società e storia», n. 110, 2005, pp. 741-797. 
«Lo Stato», in ogni caso, cercava di rivitalizzare questa linea di pensiero neo-mercantilistica: vi si cimentano l'economista Vincenzo Porri in Gl'interventi dello Stato nel sistema nazionale dei prezzi e Ferri con Lo Stato e $i$ prezzi nel sistema corporativo ${ }^{48}$. Si trattava di una linea di ricerca sviluppata anche su altre riviste organicamente legate al fascismo. Un esempio su tutti: uno dei contributi più antisocialisti e antiliberali di Pantaleoni era stato il saggio del 1911 Considerazioni sulle proprietà di un sistema di prezzi politici, che aveva fatto da architrave teorico a tutta la polemica "antiparassitaria» nella quale l'economista si profonde tra il 1911 e il 1924. Nei cinque celebri volumi Laterza (Tra le incognite, Note in margine della guerra, Politica. Criteri ed eventi, La fine Provvisoria di un'epopea, Bolcevismo italiano) che tra il 1917 e il 1922 raccolgono parte di questa polemica, Pantaleoni polemizza, da un lato contro lo statalismo di Nitti e di Giolitti e le cosiddette «bardature di guerra» (calmieri, razionamenti ecc.), dall'altro lato contro qualsivoglia riforma sociale che venisse incontro ai proponimenti del movimento socialista, soprattutto quello riformista. Si trattava, in ultima analisi, di una nuova forma di anti-economico neo-mercantilismo ${ }^{49}$. Pantaleoni diviene così l'eminenza grigia del primo fascismo, quello filo-liberista e 'manchesteriano' e 'austero' dei ministeri economici di Alberto De Stefani, che, è bene ricordarlo, trova il plauso di gran parte della cultura economica liberale e conservatrice (Barone, Pareto, che collabora alla rivista di Mussolini «Gerarchia», Luigi Einaudi, Giuseppe Prato ecc.). Ebbene, il già ricordato Arena sull'«Archivio di studi corporativi» utilizzerà il testo di Pantaleoni in termini esattamente opposti da quelli concepiti dal maceratese, e cioè cercando degli spunti teorici che potremmo definire neo-mercantilistici per teorizzare ed edificare 'l'economia nuova' del fascismo ${ }^{50}$. E lo «Stato» non mancherà di apprezzarne lo sforzo ${ }^{51}$.

D'altra parte, la Grande crisi e il profondo cambiamento che essa imprime al rapporto tra Stato e mercato spiegano l'interesse crescente per l'economia sovietica e la pianificazione propria ad una parte degli intellettuali fascisti. Impossibile ora richiamare la letteratura, ove spicca l'attività della casa editrice di Gentile, la Sansoni ${ }^{52}$. Anche «Lo Stato» segue l'evoluzione storica dell'Unione sovietica, soprattutto sul piano giuridico,

${ }^{48}$ Cfr. V. Porri, Gl'interventi dello Stato nel sistema nazionale dei prezzi, «Lo Stato», fasc. 2, 1930, pp. 165-175; C.E. Ferri, Lo Stato e i prezzi nel sistema corporativo, «Lo Stato», fasc. 4, 1930, pp. 446-453.

49 Come detto, il testo sui prezzi politici è ripubblicato, infatti, in M. Pantaleoni, La fine provvisoria di un'epopea, Laterza, Bari 1919, cit.

${ }^{50}$ C. Arena, La teoria dei prezzi politici e la nuova realtà corporativa, "Archivio di Studi Corporativi», vol. 4, 1933, pp. 495-532.

51 La Direzione, Realtà economica e teoria, «Lo Stato», fasc. 9, 1931, pp. 653-654.

52 Cfr. R. Romani, Il piano quinquennale sovietico nel dibattito corporativo italiano. 1928-1936, «Italia contemporanea», n. 155, giugno, 1984, pp. 27-41. 
anche se con forti accentuazioni polemiche e critiche ${ }^{53}$. La rivista, del resto, era molto preoccupata che la letteratura fascista che si interessava dell'esperimento sovietico potesse imprimere una svolta di natura socialista al fascismo, passando alla socializzazione dei mezzi di produzione. Sia Costamagna che Rosboch avevano una impostazione 'classica' in proposito: il primo non trascurava di sottolineare come la Carta del lavoro tutelasse l'iniziativa privata ${ }^{54}$; il secondo valutava il crescente intervento pubblico in economia tentando di riconnetterlo all'impostazione del maestro Pantaleoni, assolutamente ostile a qualsivoglia forma di pianificazione ${ }^{55} . \mathrm{Si}$ trattava di posizioni sottoposte a forte tensione, naturalmente, perché dovevano confrontarsi non solo con la pianificazione sovietica, ma anche con l'evoluzione economica della Germania nazista, sempre più pianificata ${ }^{56}$.

In tema di economia socialista la scienza economica italiana poteva vantare dei veri e propri pionieri, come Pareto e Barone, il cui già citato saggio del 1908 viene ripubblicato da F. Hayek in una famosa antologia nel 1935 per i tipi di Routledge, quando la pianificazione diventa non solo un esercizio libresco. Tra i giovani antifascisti e comunisti che avevano partecipato alle iniziative scientifiche del fascismo sul cosiddetto «Ordine nuovo» si annovera, p.es, Cesare Dami. Studiati i classici della pianificazione prima menzionati ${ }^{57}$, nell'immediato secondo dopoguerra sarà il primo economista italiano ad offrire uno studio non solo teorico, ma anche storico e scientifico dell'economia sovietica; tra l'altro, sarà eletto in Parlamento per il Partito comunista ${ }^{58}$.

53 Alcuni esempi: E. Paschukanis, La concezione sovietica del diritto internazionale, «Lo Stato», fasc. 2, 1931, pp. 101-121; A. Santoro, Diritto penale fascista e bolscevico, «Lo Stato», fasc. 6, 1931, pp. 416-422; T. Napolitano, Lo Stato sovietico e il diritto proletario, «Lo Stato», fasc. 4, 1936, pp. 210-222; G. D’Alò, La nuova costituzione della Unione Sovietica, «Lo Stato», fasc. 11, 1936, pp. 593-617.

54 Tra gli altri cfr. C. Costamagna, La validità della Carta del lavoro, «Lo Stato», fasc. 11, 1931, pp. 785-797.

55 Riassume bene le tesi di Rosboch un altro allievo di Pantaleoni, Lello Gangemi nella seguente recensione: E. Rosboch, La concezione fascista delleconomia, Quaderni di attualità, Edizioni Agugustea, Roma Milano 1930, «Lo Stato», fasc. 1-2, 1930, pp. 108111. Ispirato al maestro Pantaleoni, che aveva patrocinato la nascita dello 'Stato azionista' per quelle imprese in cui era necessario, per motivi tecnici, che lo Stato subentrasse ai privati, è il teso di E. Rosboch, Lazionariato di Stato nell'economia fascista: «La funzione economica dello Stato fascista ha il compito ben definito di integrare e sviluppare il più possibile l'operosità produttiva dei privati»: «Lo Stato», fasc. 3-4, 1930, p. 254.

${ }_{56}$ Cfr. F. Ermarth, Aspetti del piano economico nazista, «Lo Stato», fasc. 2, 1935, p. 82 .

57 Cfr. di C. Dami, Le caratteristiche ed i problemi dell'economia pianificata alla luce delle più recenti indagini, in Convegno per lo studio dei problemi economici dell'ordine nuovo, Pisa. 18-23 maggio 1942-XX. Atti. Volume I. Relazioni, Arti Grafiche Pacini Mariotti, Pisa 1942, pp. 41-74. Dami era clandestinamente iscritto al partito comunista dal 1941.

${ }_{58}$ Cfr. di C. Dami, Economia collettivista ed economia individualista, Einaudi, Torino 1947; Id., Esperienze di economia pianificata, Einaudi, Torino 1950. 
L'economia pianificata, insomma, nel secondo dopoguerra è argomento di grande attualità e di dibattito. Come dicevo in apertura, gli studiosi hanno opportunamente messo in luce la continuità della riflessione contenuta nei testi giovanili di Modigliani con il saggio L'organizzazione e la direzione della produzione in un'economia socialista, apparso sul «Giornale degli economisti» del 1947 (testo curiosamente espunto dalla raccolta di scritti di Modigliani approntata dal MIT), un torno di tempo durante il quale lo studioso italiano è impegnato a proporre un piano concreto di intervento settoriale al governo e alla comunità scientifica americani ${ }^{59}$.

${ }^{59}$ Cfr. M. Alacevich, P.F. Asso, S. Nerozzi, The Shaping of Public Economic Discourse in Postwar America ecc., cit., passim. 



\section{CAPITOLO TERZO}

\section{IL ‘RAZZISMO SPIRITUALE’ E L’ANTISEMITISMO}

\section{Fascismo e antisemitismo}

La collaborazione di Modigliani a «Lo Stato» e a «Dottrina fascista» apre un'altra problematica storiografica e biografica, che ritengo costituisca un importante contributo alla ricostruzione del rapporto tra il giovane Modigliani e il fascismo.

Non deve sorprendere troppo che un giovane universitario di origini ebraiche come Modigliani scriva su riviste fasciste, perché è noto che numerosi, ed anche con posizioni di rilievo, furono gli ebrei che aderirono al fascismo. Il caso di Modigliani e dello «Stato» merita, tuttavia, un approfondimento.

Anzitutto si deve ricordare come le leggi razziali non siano affatto un fulmine che cade a ciel sereno. Il fascismo, infatti, con alcuni dei suoi intellettuali più autorevoli, aveva cominciato una campagna antisemita ben prima dell'ascesa di Hitler al potere, e cioè fin dagli anni della Prima Guerra Mondiale. Va ricordato il caso emblematico di Pantaleoni, assiduo antisemita sulla rivista «La vita italiana», che già nel 1921 traduce e pubblica i famigerati Protocolli degli anziani savi di Sion ${ }^{1}$. Tra l'altro il direttore dello «Stato», Rosboch, era stato allievo di Pantaleoni e suo sodale nell'avventura politica di Fiume. Nonostante «il principe degli economisti italiani», come lo definisce Piero Sraffa nell'Obituary del 1924 pubblicato su «The Economic Journal», fosse tra i promotori più sistematici e autorevoli dell'antisemitismo politico - Pantaleoni, infatti, non credeva nel razzismo biologico -, numerosi, dicevo, furono gli ebrei fascisti. Possiamo ricordare l'economista di origine ebraica Gino Arias, una sorta di vera e propria voce ufficiale del fascismo, autore di riferimento della rivista «Gerarchia», fondata e diretta da Mussolini, seguito dai recensori dello «Stato» e suo autore ${ }^{2}$; ma non di meno perseguitato dalle leggi razziali del

${ }^{1}$ Cfr. L. Michelini, All'origine dell'antisemitismo nazional-fascista: Maffeo Pantaleoni e «La Vita italiana» di Giovanni Preziosi, 1915-1924, cit.; T. Maccabelli, L. Michelini, Economics and Anti-Semitism: The Case of Maffeo Pantaleoni, "History of Political Economy», mar. 2015, pp. 91-118.

${ }^{2}$ G. Arias, La proprietà privata e il diritto fascista, «Lo Stato», fasc. 5, 1935, pp. 332-335; Id., Economia generale, economia corporativa, economia politica, «Lo Stato», fasc. 8-9, 1935, pp. 575-580. 
$1938^{3}$. Tra gli economisti che collaborano a «Lo Stato» ho menzionato in precedenza Del Vecchio e Fanno.

Anche su «Lo Stato» il tema razziale e antisemita è presente prima e durante, oltre che dopo l'apparizione dei testi di Modigliani.

Fin dal 1935 la rivista comincia a scrivere di razzismo spirituale con la penna dell'antisemita Wilhelm Stapel, che pubblica La teoria razziale, che la direzione della rivista (Costamagna) commenta incitando alla costruzione di una teoria spirituale, oltre che biologica della razza ${ }^{4}$. Seguiranno poi i testi di O. Spann Senso e limiti del concetto di razza $a^{5}$ e di Costamagna Il problema della razza ${ }^{6}$. Sarà dunque la volta di Evola, che su «Lo Stato» del 1936 riprende, senza citarle, le tesi di Preziosi enunciate fin dal settembre 1921 sull'organo ufficiale del nazionalismo («L'idea nazionale») ${ }^{7}$, sottolineando come l'importanza dei Protocolli non risiedesse nella loro veridicità (erano un noto falso, infatti), quanto per il fatto che formulano un utile «mito» e una utile «ipotesi di lavoro»: «se quella congiura (...) non è vera, pure è come se lo fosse» (l'enfasi è dell'autore). Infatti «molti rivolgimenti della storia sociale e politica degli ultimi anni sono stati preveduti da detto documento con corrispondenza talvolta impressionante e quel mito vale dunque a farci ritrovare una specie di unità profonda dietro a molti avvenimenti e fenomeni apparentemente dispersi ${ }^{8}$.

Il testo di Modigliani La divisione internazionale del lavoro, uscito sul primo fascicolo del 1938 (lo stesso che ospita la discussione dei testi giornalistici di Keynes), è un saggio che si colloca tra un lavoro di Reinhard Höhn su Führer-Staat e repubblica parlamentare e uno di Evola su La selezione della futura classe politica dirigente in Germania, dove si osserva come esista, tra gli altri, il corpo "politico-militare» delle SS. Il «corpo nero», che "controlla molti fra i gangli più essenziali del nuovo Stato nazionalsocialista»: un corpo che «si presenta con caratteri non solo politico-militari, ma altresì biologici e razzistici» ${ }^{9}$.

È utile ricordare alcuni degli impegni di Evola sul finire degli anni Trenta: collabora con «La difesa della razza» e con «La vita italiana» di Preziosi, l'antisemita italiano più in vista del periodo nonché futuro ministro della razza nella Repubblica di Salò; firma l'introduzione all'edizione del

${ }^{3}$ O. Ottonelli, Zionism, fascism, racial laws: the case of Gino Arias, in «Research in the History of Economic Thougth and Methodology», 2014, pp. 83-125.

4 «Lo Stato», fasc. 1, 1935, p. 21.

5 O. Spann, Senso e limiti del concetto di razza, «Lo Stato», fasc. 3, 1935, pp. 161-169.

${ }^{6}$ C. Costamagna, Il problema della razza, «Lo Stato», fasc. 11, 1938, pp. 577-604.

${ }^{7}$ Cfr. L. Michelini, Alle origini ecc., cit., p. 14.

${ }^{8}$ J. Evola, Sviluppi della questione ebraica, «Lo Stato», fasc. 2, 1936, p. 110. Cfr. anche Id., Il problema della supremazia della razza bianca, «Lo Stato», fasc. 7, 1936, pp. 412-424.

\footnotetext{
9 «Lo Stato», fasc. 1, 1938, p. 39.
} 
1938 dei Protocolli riproposta dalla rivista di Preziosi; nell'ottobre 1937, sul numero dello "Stato» che contiene una discussione tecnica, come vedremo, delle riflessioni economiche proposte da Modigliani in alcuni numeri precedenti, Evola scrive Il problema ebraico dal punto di vista dell'Impero, dove il congresso antiebraico di Erfurt è l'occasione per ribadire che «effettivamente esiste un pericolo ebraico» ${ }^{10}$. Nello stesso numero la rivista propone il testo La difesa della razza nell'Africa orientale Italiana dove si disquisisce di due «importanti problemi», quello della «difesa della razza» e quello del «meticciato $»^{11}$.

Come è noto, Costamagna è tra i firmatari (non tra i primi dieci) del cosiddetto Manifesto della razza. Ma rimaniamo sulle pagine della rivista «Lo Stato». Essa saluta in modo entusiastico, e chiosa sul piano dottrinale, l'antisemitismo fascista nel numero di agosto-settembre del 1938 aprendo con il testo Valore e difesa della civiltà fascista. Quanto enunciato da Mussolini nel discorso di Trieste è «un passo decisivo della Rivoluzione verso il raggiungimento delle sue mete, che sono state allontanate e contrastate proprio dall'internazionalismo edonistico e dissolvente del giudaismo in parte ancora dominante, oltrecché in alcuni settori della cultura». Per quanto riguarda $\mathrm{i}$ "postulati essenziali della dottrina fascista» sarà comunque necessario approfondire il concetto di razza, ma subito la rivista vuole precisare che non potrà poggiare su una «concezione materialistica della vita», nonché positivistica, ben rappresentata da studiosi come Achille Loria e Sigmund Freud: «gli esponenti di tali pseudoscienze sono stati sempre ebrei». Quanto declamato da Mussolini a Trieste dimostra che il problema della «difesa della razza» riguarda questioni spirituali e morali, in ultima analisi della «stirpe $»^{12}$. E in una nota finale la direzione non solo appoggia l'epurazione degli ebrei dalle scuole come docenti e come discenti e dalle professioni, ma vuole la persecuzione delle «dottrine ebraiche», professate anche da non ebrei: come, nel diritto, gran parte dei gentiliani ${ }^{13}$. C'è poi un saggio dedicato a ricostruire la genesi della legislazione razzista, da connettere alla conquista dell'Impero, si valorizza l'antisemitismo della rivista «La Vita italiana $»^{14}$ e si discute di un testo di Arrigo Solmi apparso su «La difesa della razza» ${ }^{15}$.

Se leggiamo il testo di Costamagna Il problema della razza, uscito sul fascicolo decimo dello «Stato», possiamo renderci conto delle similitudini

10 «Lo Stato», fasc. 10, 1937, p. 533.

11 M. Mutinelli, La difesa della razza nell'Africa orientale Italiana, «Lo Stato», fasc. 10, 1937, pp. 543-544.

12 «Lo Stato», fasc. 8-9, 1938 , pp. 449-451.

${ }^{13}$ La Direzione, Professori ebrei e dottrina ebraica, "Lo Stato», fasc. 8-9, 1938, pp. 490-491.

14 B. Giannetti, Gli ebrei e i problemi della razza, «Lo Stato», fasc. 8-9, 1938, p. 495.

15 Anonimo, L'unità etnica della Nazione italiana, «Lo Stato», fasc. 8-9, 1938, pp. 507-508. 
con le tesi di Modigliani che analizzeremo tra breve. Largomentazione è molto più articolata e assai dotta, numerosi e circostanziati sono i riferimenti testuali, ma essa si fonda sulla distinzione tra nazione e nazionalità, rimarca il ruolo fondamentale dello Stato nel cementare o addirittura nel creare l'una e l'altra, esalta dunque la loro componente spirituale e culturale, critica le teorie del razzismo biologico nazionalista (e «alcuni 'eccessi' del razzismo tedesco» ${ }^{16}$ ), anche se non nega che vi sia una componente biologica di cui tener conto.

Non sorprenda che queste cautele e distinguo si accompagnino, come abbiamo visto, alla difesa dei provvedimenti governativi del fascismo. Il ragionamento sul razzismo spirituale non impedisce alla direzione della rivista di aderire alla politica fascista e di incitare all'epurazione degli ebrei dalle scuole di ogni grado. Si tratta di un dato originario dell'antisemitismo fascista. Pantaleoni non si dichiarava antisemita, non credeva, fatta una ricognizione dello stato delle scienze, nell'esistenza di razze umane differenti: ma non di meno era stato il fautore della campagna di stampa antisemita che invocava la pubblicazione di elenchi di ebrei, che a suo dire avrebbero occupato lo Stato e l'economia, invocandone l'epurazione.

Non sorprenda che lo Stato totalitario si incentri sulle decisioni del capo, incarnazione suprema della politica, del popolo e della nazione: che per agire si serve, strumentalmente, di qualsivoglia ideologia e di qualsivoglia tipologia di ideologi. Nel commentare il convegno giuridico italotedesco di Vienna del marzo 1939 il direttore dello «Stato» ribadisce la posizione dottrinaria sul razzismo fin qui esposta, e non di meno scrive che «il pericolo ebraico (...) è assai più grave in linea spirituale e sociale che non lo sia in linea biologica». A prescindere dalle differenze che in materia razziale esistono tra fascismo e nazismo, entrambi «negano che il concetto di 'umanità' possa servire alla costruzione di un sistema morale e scientifico. I 'fenomeni di insieme' devono essere considerati dal punto di vista del 'popolo' e non da quello dell'individuo'. Deve essere denunciata e combattuta, con una intensa opera di rieducazione culturale, la nefasta influenza che durante l'ultimo secolo l'ebraismo ha esercitato sulla civiltà europea sospingendola verso le posizioni estreme della concezione atomista e cosmopolitica $»^{17}$.

\section{Modigliani: Stato, nazione, razza}

La panoramica di testi razzisti e antisemiti dello «Stato» rende probabile l'ipotesi che Modigliani si illudesse fino all'ultimo, cioè fino al luglio 1938, che il razzismo italiano si sarebbe limitato per davvero ad una forma

16 C. Costamagna, Il problema della razza, «Lo Stato», fasc. 10, 1938, p. 604.

17 La Direzione, Razza e diritto al Convegno italo-tedesco di Vienna. Chiarificazione necessaria, «Lo Stato», fasc. 3, 1939, pp. 131-132. 
di 'razzismo spirituale', senza dunque avventurarsi nel campo del razzismo biologico e senza arrivare prima ad una codificazione legislativa discriminate (le leggi razziali del settembre 1938) e poi alla guerra di sterminio vera e propria, che in Italia data tra il 1943 e il 1945 ed è promossa dalla Repubblica sociale in stretta collaborazione con i nazisti. La lettura del testo Il valore e attualità del nazionalismo avvalora, ritengo, questa ipotesi. Questo testo consente di capire come le leggi razziali abbiano costituito una cesura fondamentale nel percorso intellettuale, oltre che umano, di Modigliani. Allo stato della documentazione, sul piano storiografico non si può non rilevare come i suoi scritti giovanili si presentino al lettore delle riviste di regime ben radicati nell'universo semantico fascista.

Il giovane studente disquisisce della tesi che il fascismo abbia un «valore universale» avversa a forme di internazionalismo e di «Super-Stato». A tal fine è importante «chiarire il concetto di Nazione». A suo giudizio il concetto è ormai assodato: si tratta di «un complesso di individui aventi una somma di elementi spirituali in comune», come «lingua, tradizione, cultura, coscienza di un comune compito da svolgere», "dai quali traggono unità, e soprattutto, coscienza di questa unità e che sono uniti nella realtà storica in un'unica organizzazione politica», cioè nello Stato. Il quale è indispensabile per distinguere il concetto di nazione da quello di nazionalità. «Solo quando è unificata a Stato la nazionalità diviene Nazione». Anzi, secondo Modigliani uno «Stato forte» può costituire il «crogiolo di fusione di nazionalità diverse» in un'unica nazionalità. «Se non si ammettesse questa seconda possibilità, che del resto è provata dalla storia, si negherebbe il valore formativo dello Stato totalitario da un lato, e dall'altro si escluderebbe il divenire nel mondo delle nazionalità». Perché insistere sul tema della coscienza dell'unità? Risposta:

perché questo elemento psicologico è indubbiamente il fattore costitutivo massimo e indispensabile perché si possa parlare di Nazione. Tutti gli altri elementi, che sono essenzialmente dati di fatto, possono nella concreta realtà storica ritrovarsi o non ritrovarsi fra i fattori spirituali che creano l'unità, e la mancanza di uno o più d'essi non impedisce l'esistenza di una Nazione. Così, mentre l'elemento tradizione e sentimento di un comune compito si trova quasi costantemente, meno costante è l'elemento lingua, mentre non è poi escluso che l'elemento unificatore sia riposto in un concetto meno spirituale: come ad esempio la razza ${ }^{18}$.

Poche parole, certo; ma è altrettanto certo che il giovane studente non esclude tra i dati di fatto che possono fondare nazione e nazionalità, l'esistenza di razze umane.

${ }_{18}$ F. Modigliani, Valore e attualità del nazionalismo, «Dottrina fascista», n. 2, giugno, 1938, p. 405. 
Il richiamo al darwinismo di Spencer e di Pareto si traduce nel giovane studente in una critica, tipica del fascismo, dell'egualitarismo liberalistico: «per quanto il liberalismo postulasse l'eguaglianza di tutti gli uomini e andasse ragionando di un individuo astratto e universale - ogni uomo continuava ad attingere le sue concrete caratteristiche dalla collettività nella quale era nato e viveva, e a differenziarsi come membro di quel gruppo dai membri di tutti gli altri» ${ }^{19}$. Il giovane autore ritiene che sul piano internazionale non possa che esservi lotta, anche militare tra nazionalismi. La lotta militare è «talvolta l'unica soluzione possibile di determinate situazioni di crisi non solo materiali, ma soprattutto morali», poiché, «checché ne dicano i materialisti storici, sta di fatto che ogni grande guerra chiude un periodo nella storia delle idee e delle costruzioni ideologiche, per aprirne un altro». «Ma la lotta più sana, più costruttiva, più feconda di risultati è quella di culture, di economie, in genere di tutti quei fattori sui quali più concretamente influisce l'elemento nazionale». Ecco dunque il valore positivo dell'autarchia. Il giovane, insomma, non inneggia ad «una lotta di distruzione» ${ }^{20}$.

Anche questa si rivelerà ben presto una tragica illusione. E non è da escludere che il rigetto della competizione internazionale bellica come sbocco inevitabile del nazionalismo sia una prova del distacco dalla politica estera imperiale di Mussolini, che Modigliani dirà, nell'autobiografia, essere avvenuto con la guerra di Spagna ${ }^{21}$. Infine, la riflessione sul nesso tra Stato e nazione non è necessariamente razzista, anche se può esserlo, come abbiamo visto in Modigliani. Sarebbe però difficile estrapolare completamente i ragionamenti di Modigliani da quelli proposti dal direttore dello «Stato» Costamagna in merito al rapporto tra razza, nazionalità, nazione e Stato.

Torniamo a «Dottrina fascista». Colpisce, e ritengo che avvalori la mia ipotesi interpretativa, che nel numero successivo a quello che ospita il testo di Modigliani esca uno scritto come Orientamenti spirituali della Germania dove si sottolinea come il concetto di "popolo» non possa che rimandare ad «una unità di sangue, nel senso dunque della comune origine razzistica $»^{22}$. Nel numero di agosto-settembre la rivista dedica molto spazio alla questione ebraica. Il direttore di «Dottrina fascista» Niccolò Giani si richiama ai Protocolli in Le due Europe $e^{23}$ e poi

19 Ibidem.

20 Ivi, p. 407.

${ }^{21}$ «Lo Stato» segue la guerra civile spagnola: cfr. E. Leva, Origini della rivoluzione spagnola, «Lo Stato», fasc. 3, 1937, pp. 148-158.

${ }_{22}$ W. Eicke, Orientamenti spirituali della Germania, «Dottrina fascista», n. 9, luglio, 1938, p. 441.

23 «Non è combinazione o caso che ieri come oggi in testa di questa Europa del toro sieno i semiti, gli ebrei, negli occhi dei quali arde sempre il sogno di tallonare il mondo dall'alto del loro trono d'oro. (...) E non sono forse semiti i teorici sia del liberalismo che del comunismo?»: N. Giani, Le due Europe, «Dottrina fascista», n. 10-11, agosto-settembre, 1938, pp. 461-462. 
seguono Cultura fascista senza giude $i^{24}$ e A proposito di certi confini nel problema della razza ${ }^{25}$.

Qualche cenno, infine, sui testi di economia ospitati da «Dottrina fascista», che inizia le pubblicazioni nel settembre 1937. Diretta da Giani, si presenta come espressione della Scuola di Mistica Fascista di Milano, che egli fonda insieme ad Arnaldo Mussolini, il fratello minore di Benito ${ }^{26}$. Nel 1934 Giani aveva pubblicato Lineamenti su l'ordinamento sociale dello Stato fascista (Milano, Giuffrè), prefato da C.E. Ferri, con il quale aveva dato vita ad una biblioteca internazionale sul fascismo. L'orizzonte problematico è quello che ritroviamo nello «Stato", anche se i testi hanno un taglio molto meno accademico. Tra gli altri autori impegnati sul piano scientificoeconomico troviamo, tra le firme più significative, C.E. Ferri (Ortodossia fascista, sett. 1937; Nessun controllo operaio ma conquista rivoluzionaria, gen. 1938) e i cattolici Amintore Fanfani (Autarchia, amicizie politiche e integrazione economica, nov. 1937) e Gino Barbieri (Economia corporativa, dic. 1937). Il programma della rivista, che non ripercorriamo nel dettaglio dei singoli articoli, «si compendia in una sola parola: servire $»^{27}$. Servire Mussolini. Il primo dei Quaderni della Scuola di Mistica fascista è Le leggi razziali italiane (legislazione e documentazione) ${ }^{28}$, Giani pubblica il libricino Perché siamo antisemiti ${ }^{29}$, poi il secondo numero dei Quaderni è Le leggi razziali tedesche $e^{30}$.

${ }^{24}$ G. Calendoli, Cultura fascista senza giudei, «Dottrina fascista», n. 10-11, agosto-settembre, 1938, pp. 477-479.

25 A.L. Arrigoni, A proposito di certi confini nel problema della razza, «Dottrina fascista», n. 10-11, agosto-settembre, 1938, pp. 490-491.

${ }^{26}$ Utile A. Grandi, Gli eroi di Mussolini. Niccolò Giani e la Scuola di mistica fascista, Milano, Rizzoli, 2004: il volume ricorda la collaborazione di Modigliani a «Dottrina fascista» senza analizzarne il testo.

27 Dottrina fascista, Il 'nostro' programma, «Dottrina fascista», n. 1, settembre 1937, p. 3. Per una spiegazione della «mistica fascista», che va intesa come radicale opposizione al razionalismo della cultura liberale e di quella socialista, cfr. N. Giani, La mistica come dottrina del fascismo, «Dottrina fascista», n. 6, aprile, 1937,pp. 287-301.

${ }_{28}$ Officine Grafiche A. Nicola e $C^{\circ}$, Milano-Varese, 1939; l'introduzione è firmata da R. Sertoli Salis.

29 Officine Grafiche A. Nicola e C ${ }^{\circ}$, Milano-Varese, 1939.

30 Officine Grafiche A. Nicola e C $C^{\circ}$, Milano-Varese, 1940; l'introduzione è di G. Ballarati. 



\section{CAPITOLO QUARTO}

\section{L'ECONOMIA NUOVA DI MODIGLIANI}

\section{Per la "progressiva regolamentazione di tutta l'economia»}

Ricostruito il contesto mediato e immediato nel quale si inserisce la riflessione del giovane Modigliani, non rimane che analizzarne il contenuto più specificamente economico.

Il primo articolo di Modigliani su «Lo Stato» è pubblicato nel numero di aprile del 1937 e si intitola Concetti generali sul controllo dei prezzi, che appare nella pagina come sottotitolo di una rubrica che recita Problemi dell'economia nuova.

Lautore parte dal dato di fatto della politica economica fascista in tema di controllo sui prezzi ma subito sottolinea come non si tratti di provvedimenti nuovi, poiché «si è profondamente rinnovato un istituto già da qualche tempo studiato e applicato e che concettualmente appartiene ad ogni sistema di economia corporativa e in genere di 'economia controllata'». Per controllo dei prezzi non si deve però intendere la politica del calmiere, ché altrimenti gli antecedenti sarebbero ben più remoti. Si tratta, invece, dell'intervento pubblico «sulla formazione del costo e la sorveglianza sull'andamento del mercato, per studiarne e prevederne le tendenze». Anche questo tipo di intervento ha però precedenti storici «numerosi ed autorevoli», non solo in Italia. Qui i precedenti risalgono già ai primi tempi «dell'era fascista»: partito e corporazioni, infatti, seguivano «l'andamento dei prezzi, per evitare gli abusi» e per non "perdere di vista i superiori interessi della Nazione». Ma è con la campagna d'Africa che questa politica prende vigore. Nascono infatti in ogni provincia i comitati intersindacali coordinati da un comitato centrale presieduto dal segretario del partito, rappresentanti delle pubbliche amministrazioni e «organi sindacali», con una evidente collaborazione tra partito e corporazioni.

All'estero il controllo è praticato non soltanto da «Stati a sistemi simili a quello italiano, ma anche a tendenze socialiste o addirittura liberali». In particolare, Francia e Germania hanno preceduto l'Italia su questa strada. In Germania il principio si ispirava al controllo dei «prezzi di produzione» e «vivacissime furono le critiche» sul «controllo politico dei prezzi». In Francia lo scopo è stato quello di evitare il processo inflazionistico «come conseguenza dei numerosi provvedimenti di carattere economico presi dal governo di Blum e soprattutto la svalutazione del franco, gli au- 
menti salariali», la riduzione delle ore di lavoro ecc. Ed è «indubbiamente notevole», scrive Modigliani, «che un paese a tendenze liberali riconosca l'insufficienza degli egoismi individuali ad assumere la condotta più utile per la collettività e riconosca invece la necessità che lo Stato controlli tale egoismo limitandolo ed impedendolo quando, come in pratica sempre avviene, esso si riduca all'oppressione del più debole da parte del più forte».

Quali sono le ragioni per cui in Italia questa politica si è intensificata? In primo luogo, perché si colpiva solo una «categoria economica», cioè «i venditori al minuto dei generi di prima necessità». Si trattava, dunque, di una politica inefficace e di «una evidente ingiustizia sociale assolutamente inammissibile con i principi etici del Fascismo». In secondo luogo, vi erano stati aumenti salariali e il riallineamento della lira. Si rischiava, cioè, una rincorsa inflazionistica. Bisognava cioè «evitare che un aumento di prezzo assorbisse gli aumenti dei salari e degli stipendi e magari li superasse» e «facessero sfumare le facilitazioni che l'allineamento avrebbe dovuto portare alla nostra esportazione». Ma quale è «la posizione che spetta al controllo dei prezzi di fronte ai principi economici del Fascismo»? Ebbene

il controllo dei prezzi è senza dubbio alcuno strettamente collegato e direttamente discendente dai principi economici del Fascismo. Come si può infatti pensare che il Fascismo, che vuole in qualunque campo e soprattutto in quello economico l'interesse individuale coordinato e subordinato a quello nazionale rilasci una funzione di così alta importanza quale quella di fissare i prezzi completamente in balìa degli interessi individuali? Possiamo credere che lo Stato fascista permette lo sfruttamento del consumatore da parte di un venditore, per esempio monopolista, lasciando che questi fissi il prezzo al punto che gli assicura il massimo beneficio di monopolio?

Il caso del monopolio è uno dei tanti possibili, anche se in «regime corporativo» è "particolarmente frequente data la tendenza ad eliminare la concorrenza per i suoi nocivi effetti».

Quali sono i principi del controllo dei prezzi? Esso deve essere «formativo». Non può cioè essere un «ancoramento», cioè limitarsi a constare quale sia oggi il livello dei prezzi per mantenerlo inalterato nel futuro «a malgrado di tutte le trasformazioni che possono avvenire». Ciò significherebbe concepire il controllo «in maniera completamente contraria a quello che è lo spirito del Fascismo che è incessante dinamismo racchiuso nella formula della 'Rivoluzione in marcia'». Il controllo, invece, deve assicurare una "organica formazione del prezzo». Il che significa, in primo luogo, seguire e controllare «lo sviluppo dei prezzi di un numero quanto più possibile esteso di merci, ed in tutti i passaggi che dette merci subiscono dalla produzione al consumo». Solo così si può evitare di controllare, come invece accaduto in Germania, i soli prezzi dei commercianti al minuto: e l'autore cita il giornale nazista «Volkischer Beobachter» come fonte dei dati che riporta. In secondo luogo, il 
controllo organico significa non limitarsi a prendere atto dei prezzi, ma «costruire» e «formare» il prezzo stesso a seconda del posto che una impresa ha nell'economia nazionale, che varia in continuazione «a seconda della diligenza, senso di responsabilità e abilità dei suoi dirigenti e della sua capacità di trasformarsi e adeguarsi ai tempi». In terzo luogo, ciò implica la «dinamicità del controllo». In conclusione, solo seguendo questi criteri il controllo «può non creare l'ingiustizia ma dividere i sacrifici su tutte le classi economiche. Solo così può stroncare l'azienda antieconomica ed assicurare all'azienda economica una vita non misera ma piena e rigogliosa» ${ }^{1}$.

Il testo di Modigliani suscita una discussione sulla rivista con l'intervento di Giuseppe Binello, nel fascicolo successivo. Autore più che minore, sconosciuto e di cui mi occupo solo in quanto consente di circostanziare meglio il profilo intellettuale di Modigliani. Binello ritiene che il controllo previsto dal governo fascista non sia, al contrario di quanto sosterrebbe Modigliani, «totalmente diverso dal sistema vincolistico di altri tempi», cioè sia da ascrivere al sistema dei calmieri e a quello di prezzo politico ${ }^{2}$.

Nel numero di luglio Modigliani risponde con Prezzo politico e prezzo corporativo. L'Autore è contrario a «inquadrare quella realtà nuova che è il sistema corporativo nei vecchi schemi dell'economia classica». "Certo se noi ammettessimo col Binello che la legge della domanda e della offerta è una legge rigida e matematica; che il tentare di modificarne sia pure leggermente, i termini sarebbe non solo vano ma anche fatale alla collettività; se noi ammettessimo che un prezzo per il solo fatto che si è formato nel libero gioco degli egoismi individuali è incondizionatamente il più utile per l'individuo, e quindi in base all'equazione individuo=collettività per la collettività stessa; che la realtà economica per il solo fatto che è, è sacra e non può essere valutata dal punto di vista morale in quanto una tale valutazione presuppone la volontà che invece di fronte a questa realtà è assolutamente impotente»: ebbene ammesso tutto ciò non si potrebbe che convenire che ogni tentativo di modificare il prezzo di mercato «non può che portare alla formazione di un 'prezzo politico'», o "corporativo», solo in omaggio ai tempi nuovi, cioè un prezzo «dannoso all'individuo=collettività». Se si fosse convinti «che l'equilibrio si ricompone da sé grazie alle forze autoregolatrici del sistema, purché non si tenti mai in alcun modo di intervenire perché qualunque intervento non fa che allontanare il ritorno dell'equilibrio, saremmo convinti anche noi che il controllo dei prezzi è un assurdo: ma allora perché non portare la questione alle sue logiche conclusioni ed affermare che tutto il sistema corporativo è un assurdo?». Le cose, però,

1 F. Modigliani, Concetti generali sul controllo dei prezzi, «Lo Stato», fasc. 4, 1937, pp. 220-232. Dopo la firma appare la dicitura «Littore dell'Anno XV».

2 Cfr. G. Binello, Il prezzo politico e il profitto commerciale, «Lo Stato», fasc. 6 , 1937, pp. 375-379. 
stanno ben altrimenti. «Alla rigida concezione fatalistica della cosiddetta economica classica, l'economia corporativa oppone una concezione fortemente volontaristica; l'equilibrio economico generale non 'si forma', va costruito; l'equilibro fra domanda ed offerta ed il livello del prezzo che esprime tale equilibrio non esiste al di fuori dell'uomo ma può e deve essere creato dalla sua volontà». «Salvataggi e calmiere sono interventi sporadici, per lo più dannosi, eseguiti per motivi politici che assolutamente esorbitano dal campo economico e che, come ha egregiamente posto in evidenza l'Arias, sono la smentita migliore dell'automatismo delle forze economiche». Il calmiere è opera di un'autorità che "vive fuori della vita economica», che non esamina la «realtà della situazione e che resta statico a malgrado del mutarsi delle condizioni». Ė un provvedimento che «resta isolato nel generale sistema del non intervento dello Stato». Tutt'altro il controllo corporativo dei prezzi: «non intervento isolato, ma coronamento di un sistema di interventi; non azione esteriore», bensì «azione squisitamente interna» dove le istituzioni coinvolte (categorie interessate in seno alla corporazione, poi consiglio provinciale della corporazione) cercano di influire sul prezzo, «sulle quantità offerte e persino domandate». Ecco dunque che per evitare i danni al commercio, sperequazioni e per raggiungere «maggior giustizia e benessere collettivo» ci vuole il "passaggio del controllo alle Corporazioni», capace di coinvolgere la «fase della distribuzione» e della «produzione», affrontando «la questione del costo di produzione e di distribuzione». Ci vuole, insomma, la "progressiva regolamentazione di tutta l'economia». D'altra parte, anche i provvedimenti parziali, come quelli francesi, hanno dimostrato la loro efficacia: perché «l'equilibrio una volta rotto non si ricompone più spontaneamente ed il campo resta aperto alle peggiori speculazioni, al disordine economico, alla rovina nazionale»?

Non priva di interesse risulta essere la stizzita risposta dell'interlocuto$\mathrm{re}^{4}$, poiché muove una critica a Modigliani richiamandosi ad un economista di formazione liberal-liberista approdato al fascismo: «Non è negazione del corporativismo (che è cosa ben più elevata del calmieramento) il rilevare talune impossibilità concrete; e non fanno neppure opera di teoria coloro che propugnano l'attuazione di astrazioni dannose, o emettono enunciazioni sovente fatte di nulla, senza la menoma sostanza, non delineanti che gli estremi di un'economia ridotta a gaia scienza, secondo l'efficace terminologia di Giuseppe Prato ${ }^{5}$. Il liberismo fascista, dunque (anche se con la penna di uno sconosciuto), attacca frontalmente Modigliani.

${ }^{3}$ F. Modigliani, Prezzo politico e prezzo corporativo, «Lo Stato», fasc. 7, 1937, pp. 439-442.

${ }^{4}$ Che scrive un volume sul tema: cfr. G. Binello, C. Tosca di Castellazzo, Il partito nella vita economica italiana: la politica fascista degli approvvigionamenti de dei prezzi, Giappichelli, Torino 1938.

${ }^{5}$ G. Binello, Ancora del prezzo politico, «Lo Stato», fasc. 10, 1937, pp. 564-566. 
Il testo con il quale Modigliani vince i Littorali consente di approfondire le idee del giovane studente di giurisprudenza. Emerge la giustizia sociale come obiettivo di politica economica da raggiungere insieme alla stabilità economica e sociale. La relazione da cui Modigliani parte è quella tra svalutazione e inflazione del caso francese, che non si vuole riproporre per l'Italia. La svalutazione comporta una redistribuzione della ricchezza, con danno «delle classi di popolazione a reddito fisso a tutto vantaggio di quelle a reddito variabile». «Laffannosa ricerca» di aumentare il proprio reddito variabile innesca la spirale inflazionistica «che non di rado supera la stessa percentuale della svalutazione». Come evitare questa svalutazione? Si potrebbero aumentare i redditi fissi, così colpendo, però, i vantaggi della svalutazione e poi si innescherebbe un «circolo vizioso", cioè «vi sarebbe una maggior spinta e ragione per l'aumento del costo della vita». La situazione finale sarebbe «insostenibile» e si genererebbe «il panico, la confusione, la speculazione più dannosa». Due sono le alternative che rimangono. La prima consiste nel non fare nulla, lasciando libero sfogo all'aumento dei redditi variabili: con il risultato di perpetrare «un'alta ingiustizia sociale». Infatti «una sola classe sociale e, per di più delle meno agiate, sopporta i sacrifici di un provvedimento preso nell'interesse di tutti». Si tratta della strada «che hanno sempre seguito i Governi liberali con i loro dogmi assenteistici che, in questo caso, come in mille altri, si traducevano nello sfruttamento del più debole da parte del più forte». Il «Regime Fascista che si prefigge l'avvento 'di una più alta giustizia sociale' non poteva certamente accettare questa via per il solo fatto che è la più facile». Ecco dunque la seconda strada, cioè «il mantenimento del valore interno della lira». Ecco lo scopo del controllo dei prezzi. Se si fosse in un regime di «assoluta libertà di scambi con l'estero» ciò sarebbe «assolutamente impossibile», enfatizza l'autore. Il contrario in caso di completo isolamento. In un regime intermedio, quale quello italiano, dove gli scambi con l'estero sono limitati e la moneta ha valore solo interno perché inconvertibile in oro, «il mantenimento dei prezzi è senz'altro possibile ma a costo di sacrifici anche gravi». Ma è qui che vi è la possibilità dell'intervento del partito, che dovrà «assicurare la equa ripartizione di questi sacrifici». Tutte le categorie devono sopportare l'aumento dei prezzi delle importazioni ${ }^{6}$.

${ }^{6}$ F. Modigliani, La funzione del partito nel controllo dei prezzi, «Il Ventuno. Rivista dei Littoriali», luglio-agosto 1937, pp. 30-31. A proposito di questo saggio è stato autorevolmente scritto: «Nel 1935 aveva partecipato ai littoriali della cultura e li aveva vinti, con un breve saggio su svalutazione e politica dei redditi, nel quale afferma la necessità della seconda, estesa esplicitamente non solo ai salari, ma anche ai profitti, se la svalutazione deve poter sortire effetti reali positivi e non effimeri. Un tema questo sul quale tornerà, con ben altri mezzi analitici, negli anni della maturità, giungendo alle stesse conclusioni di tanti decenni prima»: M. De Cecco, Gli economisti italiani e l'economia internazionale nel Novecento, cit., p. 6. 


\section{Protezionismo ed autarchia}

Il tema dell'autarchia diviene oggetto della riflessione di Modigliani in altri due articoli apparsi su «Lo Stato». Per quanto scritti da un giovane studente, si tratta di due testi dove la corposa tradizione dottrinale favorevole alle tesi protezioniste sono sintetizzate al meglio e dove esplicita è la presa di distanze dall'economia «pura», cioè dalla rivoluzione marginalista, che in Italia aveva avuto interpreti di valore mondiale come Pantaleoni, autore di Principi di economia pura (1889, poi tradotta in inglese nel 1898 con il titolo Pure Economics), e Pareto, che vi aveva dedicato i capitoli fondamentali sia del Cours (1896-97) sia del Manuale (1909). Nemmeno i testi sociologici o politici dei due autori italiani potevano costituire una base di riflessione: per esempio, sia negli Erotemi di economia di Pantaleoni (una raccolta di saggi uscita nel 1925), sia nel Trattato di sociologia generale (1916), l'interazione tra economia e le altre discipline era fatta sulle base della autonomia appunto dell'economia pura, che separava le «azioni economiche» da altri tipi di azioni umane, come le azioni politiche, morali, religiose, le azioni «non-logiche», tutte azioni umane che si potevano studiare con altrettante, autonome, discipline. Si apriva così il campo alla interazione tra azioni umane differenti e allo studio di «sistemi economici» differenti, caratterizzati da peculiari equilibri sociali e di cui si potevano comparare costi e benefici, sia sul piano economico, che sul piano storico generale.

Modigliani, pur non citando nessun autore in particolare, rifiuta di considerare l'autarchia solo dal punto di vista politico, dando per scontato, implicitamente, che sul piano economico sia antieconomica. L'intento va però oltre: «il principio autarchico», infatti, sarà dimostrato essere «il nuovo principio economico» (l'enfasi è dell'autore) che deve regolare gli scambi internazionali sostituendosi «al principio inapplicato e inapplicabile della 'divisione internazionale del lavoro'». Ma che cosa si deve intendere, si chiede in via preliminare l'autore, "per 'teoria economica' e per "economicità'»? Ebbene l'autore dichiara che "per teoria economica noi non riconosciamo quella costituita dall'economia classica' nelle sue varie posizioni fino ad oggi e non è dal punto di vista degli schemi da questa creati che intendiamo esaminare il problema». L'autore, cioè, vuole prendere le distanze da quell'economia che non solo assume "come modello un uomo che non persegue altro fine al di fuori di quello economico (homo oeconomicus), ma un uomo che per di più è fine a se stesso», cioè un individuo per il quale «la comunità non ha significato alcuno e che non ha alcun significato per la comunità». Partendo da questo punto di vista l'autarchia non può che risultare antieconomica, «è un assurdo». Ė per questo motivo, continua Modigliani, «che non può interessare e non può avere alcun significato per noi il giudizio dell'economia pura'», che non solo è "fuori» dalla realtà, ma «contro» di essa. Ecco perché l'economia pura «non può pretendere di giudicare né l'autarchia né il novanta per cento delle concrete azioni umane»; esse sono delle realtà «non puramente economiche, ma 
'spirituali' e quindi anche politiche». L'economia pura «o ignora lo Stato o lo considera come un elemento disturbatore: come può essa dare un giudizio su l'attività di un'esistenza che s'impernia tutta sullo Stato?». Ma non è nemmeno il punto di vista della politica economica che si vuole adottare: perché essa «non fa in sostanza che studiare i mezzi per raggiungere dati fini di carattere economico». Quale, allora, il punto di vista da adottare? Quello della «economia nuova», cioè di «quella economia che prende per base non l'individuo ma la comunità e che per 'utile' intende ciò che soddisfa non l'individuo ma la collettività intera come unità considerata nel tempo». Si tratta di un interesse "collettivo», «organico», che in alcuni casi può scostarsi o opporsi all'interesse individuale. Ė questo ciò che la realtà insegna, opponendosi a quasi tutte le scuole economiche, «dalla 'classica' alla 'psicologica' e all' 'equilibrista'». La domanda da porsi è se l'autarchia convenga alla collettività da un punto di vista economico. A tale domanda non può rispondere la scienza economica, perché è il compito della «politica» e della "morale», cioè è il compito delle "Scienze dello Stato"».

A questo punto dell'analisi Modigliani analizza e critica la teoria dei costi comparati di Ricardo, teoria che affondava le radici nel principio della divisione del lavoro, secondo la quale un individuo, o una "zona», «deve dedicarsi a quella attività e solo a quell'attività per la quale risulti obbiettivamente più portato». Nell'ipotesi di perfetta mobilità dei prodotti e dei fattori questo principio è certamente valido. Ma il problema è applicare questo principio a mercati differenziati, come ha fatto Ricardo, senza verificarne l'ipotesi di partenza e, al tempo stesso, passare alla fase «normativa», cioè patrocinare il libero scambio come quel sistema che garantisce il massimo individuale e collettivo ${ }^{8}$.

L'unico modo per Modigliani di verificare i presupposti di questa teoria è ricorrere alla «storia, allo scopo di accertare se questi presupposti esistano e quali risultati abbia dato o potrebbe dare l'applicazione dell'enunciata teoria». Nel 1817 questi presupposti esistevano realmente: l'Inghilterra aveva un vantaggio competitivo nella produzione industriale: gli altri paesi, d'America e d'Europa, sembravano potersi sviluppare solo in ambito agricolo. Ma dal punto di vista dei mercati nazionali si può affermare «che la specializzazione fosse conveniente o per lo meno conveniente egualmente per ognuno di essi?». "La risposta della storia è nettamente negativa». La divisione internazionale del lavoro avvantaggiava in modo preponderante la sola Inghilterra. In quarant'anni (1760-1800) lo sviluppo inglese è impetuoso e Londra diviene «il centro del mercato mondiale», mentre gli altri paesi si svilupparono molto meno o addirittura decrebbero (Spagna e Olanda). La Francia stessa non riesce ad industrializzarsi. L'Inghilterra godette, cioè, di un vero e proprio monopolio economico, che, tra l'altro,

7 F. Modigliani, La divisione internazionale del lavoro, «Lo Stato», fasc. 1, 1938, pp. 7-11.

${ }^{8}$ Ivi, pp. 11-12. 
le consentì di «concedersi il lusso di una politica 'liberale' mondiale». «Ma, il fatto più grave» è che su tali basi l'Inghilterra costruì una «vera e propria egemonia economico-politica». Attirati i paesi agricoli nella sua orbita, «e grazie soprattutto ai trattati di commercio, ai prestiti, agli investimenti finanziari, dal legame economico si passò presto al legame ed alla dipendenza politica». A questo tipo di argomentazione $\mathrm{i}$ «fautori del dominio inglese» ribattono che lo standard di vita degli altri paesi è migliorato: ma ciò fu dovuto non grazie alla divisione internazionale del lavoro «ma assai più» per le possibilità di industrializzazione che si aprirono. Gli economisti della prima metà dell'Ottocento non analizzarono la divisione internazionale del lavoro «in termini di 'organici nazionali'» e «compresero che attraverso il libero scambio si aguzzavano le armi non solo economiche, ma anche politiche in mano all'Inghilterra». Critiche furono mosse «ma assai più in base a vieti principi e pregiudizi mercantilistici che non con fondati ragionamenti». «Non si trovava ancora chiaramente espressa l'idea che, essendo l'emorragia dell'oro effetto e non causa dell'impoverimento del paese era vano tentare di mettervi fine coattivamente, mentre sarebbe occorso regolare e rinforzare l'economia del paese»?

La maggior parte degli economisti si mosse, invece, nel solco di Ricardo. Primo tra tutti Say, «che contribuì con lo stesso Ricardo all'elaborazione di una dottrina dell'economia mondiale secondo la utopistica concezione della teoria quantitativa della moneta». Al Say si deve anche la teoria degli sbocchi, che serviva anche a dimostrare come «fosse conveniente alle nazioni ricche di favorire in tutti i modi lo sviluppo delle nazioni più arretrate, specie con la concessione di prestiti». Una teoria che «ebbe il grande merito di sostenere» la «solidarietà economica tra le nazioni», «contro le concezioni mercantiliste», ma anche «il grande difetto di creare l'utopia dei 'consumi illimitati'». In sintesi, la prima metà dell'Ottocento è il periodo in cui «si credeva ciecamente all'assoluta identità» tra interesse individuale e collettivo e "la realtà sembrava dar conferma a simili concezioni». Il liberalismo in politica, poi, permetteva «la ascesa della borghesia, forza giovane ed effettivamente più adatta al governo» ${ }^{10}$.

La prima reazione venne da Napoleone e dal blocco continentale, che però adottò mezzi inadatti allo scopo, poiché era ancora «dominato» da «concezioni mercantilistiche». Voleva prosciugare l'Inghilterra del suo oro, infatti. Avrebbe invece dovuto fare altro: poiché l'Inghilterra era un paese altamente specializzato, "antiautarchico" al massimo grado», anche solo diminuendole fortemente esportazioni ed importazioni la si sarebbe gettata in una grave crisi economica interna. Se ne ebbe un esempio con l'aumento del prezzo del grano provocato dal blocco. Ma il blocco non ebbe mai un carattere "costruttivo", che invece distingue nettamente l'autarchia. Che tende a «creare' quelle attività economiche per le quali un paese è assog-

\footnotetext{
9 Ivi, pp. 13-16.

10 Ivi, pp. 16-18.
} 
gettato ad altri». Napoleone avrebbe dovuto rendere il continente indipendente sul piano economico. Anche se l'Europa non continentale non costituiva un mercato unico: perché «finché all'interno del blocco restano delle unità economiche distinte non è possibile parlare di autarchia $»^{11}$.

Finalmente nasce la corrente di pensiero protezionista. Ed è interessante osservare che il giudizio di Modigliani sul nesso esistente tra liberismo e liberalismo è prossimo ad un'intonazione socialista, anche se l'orizzonte esplicito è quello corporativo. La teoria ricardiana, infatti,

esprimeva una di quelle caratteristiche concezioni libertarie ed egualitarie, delle quali riboccano il liberalismo economico e il liberalismo politico, per il quale la libertà ed uguaglianza furono concetti senza valore concreto, ma astratti e formali dogmi giuridici. Furono la famosa uguaglianza costituzionale e correlativa libertà di contratto fra il datore di lavoro ricco e potente e il lavoratore povero e senza possibilità di resistere. Vale a dire una uguaglianza che si risolveva nella assenza di qualsiasi forza superiore che rettificasse la condizione delle due parti in contrasto. Alla medesima stregua la libertà del libero scambio internazionale era quella che poneva in gara a condizioni 'giuridiche' uguali un'industria organizzata ricca e potente ed un'industria nascente ed economicamente debole! $!^{12}$.

I protezionisti, infatti, sostennero che una divisione internazionale del lavoro ottima presupponeva "che le attività produttive fossero poste a confronto in condizioni di effettiva uguaglianza, cioè di uguale sviluppo». L'Inghilterra era più produttiva non per ragioni «naturali» ${ }^{13}$.

Secondo Modigliani «non è possibile dubitare» della «esattezza» della «obbiezione protezionista», che aprì una «duplice breccia»: dimostrò che «dalla spontanea e libera gara degli interessi 'individuali' non derivava necessariamente il massimo interesse 'collettivo'; "confermò che l'intervento dello Stato non è sempre un elemento perturbatore ed antieconomico». Intervenendo «a fianco, non contro, l'individuo» lo Stato può farsi «propulsore di un risultato più economico di quello che potrebbe ottenere l'individuo stesso abbandonato al gioco degli istinti egoistici». Ma c'è di più, perché il protezionismo giunge a negare i principi dell'economia classica, perché, da List fino ai protezionisti americani, si scoprì che è «inutile parlare di un interesse individuale generico ed avulso da quello nazionale» ${ }^{14}$.

Fu così che Germania e Stati Uniti presero la via dell'industrializzazione, dell'arricchimento individuale, dell'elevamento dello standard di vita, del «potenziamento politico». Perché i paesi politicamente più forti sono appunto

11 Ivi, pp. 18-20.

12 Ivi, p. 21.

13 Ivi, p. 21.

14 Ivi, pp. 22-23. 
quelli industrializzati, non quelli abbondanti di popolazione e di ricchezze naturali. E poi le industrie «nuove» cresciute all'ombra dei dazi riescono a fare concorrenza anche sul mercato mondiale alla stessa industria inglese ${ }^{15}$.

Tra i «punti più vulnerabili» della teoria liberista vi è la teoria quantitativa della moneta. Tra le critiche spicca la seguente: «se anche, grazie al meccanismo previsto da questa teoria, l'equilibrio torna a ristabilirsi, ciò avviene a costo di gravi crisi che sconvolgono il sistema dei prezzi, e del credito, portano ad ingiuste redistribuzioni di ricchezza, in una parola, scuotono le cose economiche e politiche di una nazione». E poi «le grandi migrazioni di ingenti quantità di oro vagante, che, più per ragioni politiche che per sane ragioni economiche, vanno verificandosi in questi ultimi anni, rendono ancor più difficile il già ipotetico funzionamento del meccanismo» ${ }^{16}$.

Modigliani insiste nell'elencare i punti critici della divisione del lavoro: eccessiva specializzazione, che espone il paese a crisi e squilibri; ingiusta distribuzione internazionale delle specializzazioni. Poiché il massimo utile collettivo può non corrispondere alla somma delle utilità individuali, il principio vale anche in campo internazionale: ciò significa che «una 'somma maggiore di benessere' iniquamente distribuito dà una 'benessere collettivo' minore che non una somma minore ma più equamente distribuita». Richiama, poi, la critica di Pareto alla teoria dei costi comparati. In generale Ricardo non si è accorto "che accanto e al di sopra degli interessi individuali esistono interessi nazionali ai quali quelli individuali sono condizionati ${ }^{17}$. Infine la teoria dei costi comparati «non è stata mai applicata né tenuta presente nella realtà economica internazionale». In Ricardo, infatti, non vi è alcun «dinamismo». E poi i teorici successivi non hanno parlato di costo comparato come voleva Ricardo, ma di prezzi ed «è evidente che la capacità attuale di produrre al minimo prezzo non è certo indice della capacità naturale di produrre con la minima quantità di sforzo produttivo»; il prezzo di capitale e lavoro variano, infatti, da mercato a mercato ${ }^{18}$. Senza poi contare le imposte, diverse in ogni Stato. Insomma, è possibile che una nazione che produce al minimo prezzo «impieghi nella produzione uno sforzo produttivo assai maggiore di quello che un'altra impiega o potrebbe impiegare nella stessa produzione, grazie alle sue 'doti naturali'». Se cioè si ammette "che il costo in lavoro non ha importanza decisiva, si dovrà anche ammettere che manca qualsiasi base fissa per una specializzazione». Allora «tutto si riduce a organizzazione e volontà». Di fatto nessuna nazione ha cercato le proprie doti naturali, ma si è specializzata ad «incrementare tutte le produzioni che potevano contribuire a dare potenza al paese» ${ }^{19}$.

\footnotetext{
15 Ivi, p. 24.

16 Ivi, p. 25.

17 Ivi, pp. 25-26.

18 Ivi, p. 27.

19 Ivi, p. 28.
} 


\section{L'utopia dell'economia pura', Costamagna, Keynes e Mussolini}

Nel secondo fascicolo del 1938, di febbraio, Modigliani pubblica L’Autarchia nazionale. Il testo si divide in due parti. Nella prima i ragionamenti di Modigliani dimostrano di aver già avuto un primo confronto con i testi di Keynes, anche se non sappiamo quali di preciso, se non che la Teoria generale è stata affrontata direttamente solo in America, stando alla testimonianza autobiografica. Questo confronto è interessante perché i ragionamenti in tema di sperequazione che riguardano il mercato internazionale non possono non apparire anche nella loro valenza per il mercato interno. Si tratta, insomma, di un'analisi che rimanda, anche esplicitamente, al potere di acquisto delle classi lavoratrici. La seconda parte dell'articolo è invece scritta all'insegna del dottrinarismo di Costamagna e di Carli, ma, come vedremo, denotano un punto di vista peculiare.

Veniamo alla prima parte dell'articolo. Modigliani si domanda quali siano le cause della crisi dell'economia «individuale mondiale» ${ }^{20}$. Esse sono cinque.

In primo luogo si è verificata «una lotta economica esasperata» tra le economie nazionali. In altre parole è stato proprio il libero scambio a scatenare «la più aspra lotta economica che la storia ricordi». L'individualismo economico ha messo a tacere «ogni temperamento politico» $\mathrm{e}$ «freni morali» tipici di coloro che appartengono ad una «medesima nazione». $\mathrm{Ne}$ conseguono ingenti «danni» e «sperperi». «Di fatto la concorrenza mondiale ha determinato il fenomeno delle intese internazionali e supernazionali capitaliste, le quali sono riuscite ad attirare gli stessi Stati nelle proprie manovre e della forza politica si sono fatte strumento per sfruttare le masse operaie con bassi salari, per colpire le masse consumatrici con premi di produzione di esportazione, per taglieggiare il risparmio mediante la svalutazione e l'inflazione» ${ }^{21}$.

In secondo luogo il mercato mondiale era tutt'altro che unificato. Il sistema individualista non ha portato alla pace, come invece sostenevano i

${ }^{20}$ Nel valorizzare queste pagine di critica dell'individualismo economico, Marcello De Cecco ha testimoniato come Modigliani, nel discuterne con lui, ripudiasse questi articoli. Vale la pena citare De Cecco: «quando in più di un'occasione ebbi a congratularmi con Franco per quegli scritti giovanili tanto precocemente acuti, e tanto vicini, per la parte economica, a quel che io pensavo e penso, egli non gradì che lo facessi e mi disse che quegli scritti li aveva ripudiati. Al contrario, credo che essi, se si dimenticano le parti nelle quali si glorificano l'Autarchia, e la Carta del Lavoro, come conquiste del fascismo, testimoniano una visione del mondo assai perspicace, da parte di un giovane di talento, capace di coniugare storia economica e politica e teoria economica e di comprendere fino in fondo la bancarotta della teoria che postula l'individualismo metodologico e trasforma gli interessi del paese egemone del secolo diciannovesimo in una teoria economica che si pretende valida per tutti i tempi e tutti i paesi.»: M. De Cecco, Gli economisti italiani e l'economia internazionale nel Novecento, cit., pp. 6-7.

${ }^{21}$ F. Modigliani, L'Autarchia nazionale, «Lo Stato», fasc. 2, 1938, p. 78. 
suoi teorici: come ha dimostrato la Prima Guerra Mondiale ${ }^{22}$. Il mercato mondiale non può costituire una unità economica in quanto non vi è né unità morale, né politica. Le comunità politiche esistenti tendono poi ad approfondire le divisioni. L'unità del mercato, insomma, presuppone l'unità politica: «voler costruire un sistema economico ed un equilibrio unitario sull'ipotesi della concorrenza individuale è un'impresa assolutamente folle ${ }^{23}$. Ciascun mercato di consumo, per esempio, può essere improvvisamente chiuso dall'autorità politica e le violente oscillazioni dei cambi «riducono il commercio internazionale ad un gioco d'azzardo e di speculazione». In questa condizione «le crisi di sovrapproduzione si inseguono e rendono inevitabili terribili sperperi e perfino deliberate distruzioni di ricchezza», con industrie che producono al cinquanta, o addirittura al venti per cento delle proprie possibilità ${ }^{24}$.

In terzo luogo si sono verificati «trasferimenti disordinanti di capitali» e accaparramenti della riserva aurea. Mentre in una prima fase gli investimenti esteri ebbero un effetto positivo, come quelli che si indirizzarono verso le terre vergini, in seguito le dinamiche sono cambiate: si verifica il fenomeno della «emigrazione in massa di ingenti quantità di capitali» dei maggiori paesi capitalistici non per scopi economici, «ma a seconda della situazione politica», preferendo così indirizzarsi ai paesi già ricchi. In ogni caso, sia nel paese d'entrata che in quello d'uscita questi movimenti di capitali «provocano una serie di fenomeni patologici», come l'inflazione, finendo per indurre alla «sterilizzazione dell'oro». I capitali sono cioè diretti verso paesi dove sono inutili e sono «impegnati solo in investimenti brevissimi per avere la massima libertà, più propensi alla speculazione che al sano investimento» ${ }^{25}$.

In quarto luogo l'economia liberista è entrata in crisi a causa delle «sperequazioni eccessive» esistenti tra i popoli. «Capitalismo e liberalismo come hanno provocato all'interno delle nazioni la divisione in classi, secondo la famosa antitesi marxista, così sul piano internazionale, hanno provocato la divisione, sempre più netta, delle nazioni in capitaliste e proletarie», come l'Italia (il riferimento implicito è, ovviamente, alle pagine di Enrico Corradini, il patriarca del nazionalismo italiano). «Ora, se rappresenta un male l'eccessiva sperequazione fra le classi sociali e l'esistenza in un paese di una massa ingente di individui con potere d'acquisto bassissimo, a maggior ragione costituisce un male economico la sperequazione di ricchezza fra le nazioni e la presenza sul mercato internazionale di popoli che non sono in grado di assorbire la produzione altrui $»^{26}$. Vale la pena riportare una lunga citazione del testo di Modigliani, ove è eviden-

\footnotetext{
${ }^{22}$ Ivi, p. 78.

${ }^{23}$ Ivi, p. 79.

24 Ivi, pp. 79-80.

25 Ivi, pp. 80-81.

26 Ivi, p. 81.
} 
te il richiamo al pensiero di Keynes, sia sul piano analitico che su quello della filosofia sociale:

Le crisi di sovrapproduzione verificatesi con intensità spaventosa in questi ultimi anni trovano una delle principali ragioni nella circostanza della difettosa ripartizione internazionale del potere di acquisto. Se è vero che tali crisi sono contraddistinte da una scarsità di domanda è anche vero che tale scarsità va intesa 'in senso relativo'. Essa non indica già che tutto il consumo sia sazio e tutta l'umanità crepi di indigestione; bensì che è sazia quella parte del consumo il cui potere d'acquisto è sufficientemente alto per chiedere le merci a prezzo remunerativo. Il resto del consumo, anziché sazio, sarebbe bisognoso di quelle merci, ma il suo potere d'acquisto è talmente scarso che non è in grado di concorrere alla domanda. Si deve così permettere, in onta a un concetto elementare di umanità, che vengano distrutte ingenti quantità di beni e che grandi fabbriche restino inoperose, mentre nello stesso momento si verifica la più spaventosa miseria e la carenza delle cose più necessarie ${ }^{27}$.

Anche il ragionamento che segue sembra diretto alla realtà del mercato interno: secondo «i fautori del capitalismo mondiale» i turbamenti dell'economia dipenderebbero dal «desiderio di guerra di certe nazioni. Bisogna capovolgere la questione. Ė l'esistenza di nazioni povere ed insoddisfatte che spinge al disordine ed alla guerra $»^{28}$. Conclusione: «Si può affermare onestamente (...) che sia 'economico' un sistema che porta a tali assurdi casi, o non piuttosto si deve lavorare con ogni sforzo per raggiungere un sistema che, attuando una più equa distribuzione di ricchezza, cioè diminuendo le sperequazioni da nazione a nazione aumenti il potere d'acquisto delle masse, e renda possibile l'assorbimento di una produzione sempre crescente da parte di un crescente consumo, col risultato di un maggior benessere generale ${ }^{29}$.

La quinta causa del fallimento del sistema individualista risiede nel fatto che è stata offerta una "soluzione negativa» al problema dell'emigrazione. Mentre nel passato essa ebbe una causa politica, nel capitalismo individualistico si tratta di individui in cerca di lavoro, privi di diritti politici e di tutele, «facile preda dello sfruttamento», che suscitano «la preoccupazione dei lavoratori indigeni, ai quali muovevano concorrenza sul mercato del salario $»^{30}$. Questo problema non ebbe soluzione alcuna ed anzi si pensò che una soluzione non si dovesse trovare, essendo l'emigrazione un fatto economico in sé. Si trascurava il fatto che ciò presupponeva una unità politica del mercato mondiale, così da distribuire costi

27 Ivi, p. 81.

${ }^{28}$ Ivi, p. 82.

29 Ivi, p. 82.

30 Ivi, p. 83. 
e benefici del fenomeno sull'intera comunità nazionale. In un secondo momento il problema fu affrontato, impedendo o limitando l'immigrazione: e così gettando in rovina i paesi che si basavano sull'emigrazione, come Italia e Germania.

L'obiettivo di questa analisi è chiaro: il problema non è domandarsi quanto costi economicamente l'autarchia, ma quanto costi il libero scambio.

A questo punto il testo di Modigliani propone una seconda parte dal titolo «L'autarchia ed 'il bene comune'». Qui il giovane autore vuole oltrepassare i temi economici, nazionali ed internazionali, per proporre una riflessione di carattere politico e morale.

Con l'economia mondiale è infatti franato «tutto un sistema»: «il sistema che credeva ciecamente nella equazione somma dei massimi interessi individuali = massimo interesse collettivo; il sistema dell'agnosticismo politico e morale», cioè quel sistema «che intendeva ridurre i fenomeni dello spirito a quelli dell'economia e costruire una società economica, prescindendo dalla società politica o 'Stato'». Con la fine dell'epoca liberista crolla la «concezione filosofica» che considera «l'individuo fine a sé stesso» e quindi crolla anche «la nozione razionalistica dello Stato semplice appellativo di garanzia e tutele dei diritti individuali» ${ }^{31}$.

Nel prospettare la soluzione alla crisi del liberalismo Modigliani si richiama alle pagine di Dottrina del fascismo di Costamagna (Torino, Utet, 1938) e a quelle di Filippo Carli Le basi storiche e dottrinarie dell'economica corporativa (Padova, Cedam, 1938) 32 . Per ricostruire «un nuovo sistema economico teorico e pratico» bisogna ridare allo Stato «il suo vero valore che non è la funzione assegnatagli dal liberalismo», poiché la sua «essenza» è tale per cui in esso «si realizza 'il bene comune"», cioè «i fini che sono propri del 'Popolo come unità' e che come tali trascendono quelli dei singoli individui» che lo compongono. Il concetto di autarchia ha dunque un «significato integrale»: per raggiungere il bene comune lo Stato «ha bisogno di essere autarchico, di avere cioè un' indipendenza integrale, una concreta ed effettiva capacità di auto-determinazione». Lautarchia si contrappone così al "concetto teorico-giuridico di 'sovranità'», che è solo «una semplice capacità teorica ed astratta di autodeterminazione». Autarchia significa, insomma, «realizzare l'unità etica, cioè l'unità assoluta, e lo stesso ideale collettivo di una comunità nazionale». L'unità è del re-

31 Ivi, p. 84.

${ }^{32}$ Entrambi gli autori menzionano Keynes. Costamagna solo di seconda mano e tra gli autori che dimostrano la confusione che regna nella scienza economica inglese: C. Costamagna, Dottrina del fascismo, Utet, Torino 1938, p. 374. Carli cita Keynes tra gli autori che dimostrano come lo Stato «non esercita più un'azione di carattere occasionale ed empirico» in economia, «bensì necessaria e logica (...) e che quindi esso rientra per ragioni di necessità logica nel quadro della teoria pura»: F. Carli, Le basi storiche e dottrinali della economia corporativa, Cedam, Padova 1938, p. 147. 
sto a fondamento della Carta del Lavoro, che afferma che «la produzione è unitaria dal punto di vista nazionale» ${ }^{33}$.

L'Autarchia va considerata sotto due aspetti: quello dell'equilibrio economico nazionale e quello dell'indipendenza economica.

Il primo costituisce «la negazione» di quello «individuale-mondiale». Esso è «volontario» e non «meccanico», è «economico-statale» e non «economico-individuale», è «nazionale», perché si stabilisce in contrapposizione all'equilibrio «realizzantesi per virtù delle libere scelte individuali al di fuori, se non contro lo Stato». Anche gli economisti tradizionali hanno dovuto ammettere, secondo Modigliani, che «la libera concorrenza degli egoismi individuali» non genera equilibro, ma «un susseguirsi di squilibri e di oscillazioni perturbanti che nella forma più violenta costituiscono la crisi». E hanno dovuto ammettere che l'interesse collettivo non è uguale alla somma degli interessi individuali, ed anzi i due interessi sono in contrasto. Ecco dunque che la politica non è più un fattore «deleterio e perturbatore» ma «è indispensabile per far adottare all'individuo la condotta più 'razionale'», cioè per ottenere un risultato "più economico», «anche dallo stesso punto di vista individuale». E a questo punto che l'autore cita il testo di Carli, che vorrebbe «istituire un calcolo economico collettivo mirante a stabilire quale sarebbe l'azione che conviene di più» allo Stato, sostenendo che «è necessario limitare, attraverso l'intervento dello Stato, l'iniziativa individuale eliminando istituzionalmente il dissidio tra interesse individuale e interesse collettivo ${ }^{34}$.

Modigliani, insomma, è alla ricerca di un termine medio capace di mettere d'accordo economisti «ortodossi» ed economisti «eterodossi». I primi «si limitano a sostenere il concetto che l'ordinamento giuridico costituisce un utile fattore di integrazione dell'iniziativa individuale, la quale diviene 'più economica' quando sia guidata e controllata secondo direttive di insieme invece che abbandonata a sé stessa $»^{35}$. Ma qualsivoglia ordinamento giuridico, ribadisce Modigliani, non può che avere una base statuale e politica. E dunque l'equilibrio economico mondiale non potrà che avere come presupposto un accordo tra Stati.

Le caratteristiche dell'equilibrio nazionale sono le seguenti: essere «integrale» e «dinamico». Integrale, cioè economico e politico, spirituale ed etico. Modigliani fa l'esempio del monopolio: se libero di operare le proprie scelte, esso giungerà a certi risultati di prezzo, profitto e quantità prodotte; ma perché l'equilibrio raggiunto possa dirsi «integrale» deve essere «morale», cioè raggiungere «la giustizia fra le parti contraenti, impedendo che una di esse (in questo caso il monopolista) approfitti della sua situazione per imporsi e, come osserva il Carli, questa situazione sarà realizzata quando ognuna delle parti fosse disposta a prendere il posto dell'altra

33 F. Modigliani, L'Autarchia nazionale, cit., pp. 84-85.

34 Ivi, pp. 86-87.

35 Ivi, p. 87. 
e ad essere indifferente compratore o venditore $»^{36}$. L'equilibrio nazionale deve essere dinamico in quanto deve garantire l'aumento sia dell'offerta che della domanda: «l'elevazione delle classi meno favorite» ${ }^{37}$.

Come raggiungere questo tipo di equilibrio? Modigliani avverte che limiti di spazio non gli consentono di approfondire il pur importante problema; si limita a sottolineare che tale equilibrio «deve sempre avere quale presupposto l'iniziativa individuale e la proprietà privata, in una concezione funzionale del diritto individuale», tale per cui esso è «un attributo del singolo che va esercitato a beneficio della comunità oltre che del singolo» ${ }^{38}$. Questo risultato si raggiunge per due vie: «col porre le forze contrarie, in cerca di equilibrio, in condizioni di uguaglianza concreta ed effettiva, e non soltanto teorica e virtuale come le poneva il sistema liberale»; e circoscrivendo «il campo nel quale le forze economiche contrastanti sono libere» di cercarsi un equilibrio. L'unico esempio storico richiamato è il riconoscimento giuridico delle organizzazioni dei lavoratori e dei datori di lavoro, così che è impedito che «l'una parte si possa valere del peso della sua ricchezza, l'altra del peso della sua massa ${ }^{39}$.

Veniamo ora all'indipendenza economica, uno degli aspetti dell'autarchia. L'obiettivo, secondo Modigliani già chiaramente individuato da List, è di raggiungere «un mercato fornito di assoluta libertà di circolazione dei fattori produttivi, armonicamente sviluppato», in grado di «soddisfare le proprie necessità con produzioni interne»e di trovare «nel consumo interno sufficiente sbocco alle produzioni proprie» ${ }^{40}$. Solo così lo Stato raggiunge «l'indipendenza politica» e la capacità di «autodeterminazione», altrimenti impossibile. Solo così si eviterebbero gli «imperialismi economici delle grandi potenze monopoliste» ${ }^{41}$. Perché così si stabilisce una «effettiva e concreta equivalenza», enfatizza l'autore, tra le nazioni, «che il libero scambio non assicurava per nulla». Solo così si gettano le basi per «una collaborazione di Popoli». Solo così si raggiunge un ideale «distributivo», che Modigliani definisce, senza però citare la fonte, usando una terminologia di un noto discorso di Mussolini ${ }^{42}$ : «il lavoro continuerà ad essere merce, e non sog-

36 Ivi, p. 88.

37 Ivi, p. 89.

38 Ivi, p. 89.

39 Ivi, p. 90.

${ }^{40}$ Ivi, p. 90. Assurdo, perciò, pensare, come W. Heinrich, di volere scomporre in altrettanti mercati provinciali autarchici il mercato interno: cfr. F. Modigliani, Ancora introno al principio di autarchia, «Lo Stato», fasc. 3, 1938, pp. 174-176.

${ }^{41}$ F. Modigliani, L’Autarchia nazionale, cit., p. 91.

42 «Nello Stato corporativo il lavoro non è più l'oggetto dell'economia, ma il soggetto poiché è il lavoro che forma e accumula il capitale»: B. Mussolini, Sintesi del regime, discorso del 18 marzo 1934, in Id., Scritti e discorsi, vol. 9, Hoepli, Milano 1935, p. 33. Per gli sviluppi del filone di pensiero fascista incentrati su questo tema cfr. G. Parlato, La sinistra fascista. Storia di un progetto mancato, Bologna, Il Mulino, 2008, pp. 177-223. 
getto dell'economia, fintantoché l'altezza del salario dovrà mantenersi adeguata al livello meccanico creato sul mercato mondiale dalle modificazioni di domanda e di offerta di mano d'opera determinate dalle forze monopoliste internazionali». Ė la «necessità di resistere o di battere la concorrenza straniera» che "costringe a sacrificare or questa or quella classe sociale». Solo così il sistema economico diventa stabile. Fintanto che l'equilibro tra produzione e consumo, fra offerta e domanda di lavoro e capitali «dipende da forze che sono fuori dello Stato e risultano integrate in un sistema estraneo e inorganico» un equilibro stabile non è raggiungibile. In altri termini si avrà una «situazione potenziale di crisi e di squilibrio di forze» ${ }^{43}$.

Autarchia, dunque, non significa «isolamento assurdo e dannoso» ${ }^{44}$ : esportazioni ed importazione vanno anzi potenziate, secondo sistemi di scambio internazionale che Modigliani dichiara di non avere spazio per illustrare. Rivolge, invece, la propria attenzione al mercato interno, affrontando il tema del «costo dell'autarchia».

Il monopolio naturale è una eccezione, non una regola: i costi dipendono «quasi esclusivamente dal fattore dell'organizzazione e non dal luogo in cui le fabbriche sono poste». Anche in agricoltura è crescente il dominio dell'uomo sulla natura. Il progresso tecnico mostra "possibilità inesauribili». I prodotti stranieri possono così essere sostituiti da prodotti nazionali. L'autarchia è dunque un «ideale dinamico», tanto più che il costo dipende dalla dimensione del mercato interno, come dimostra l'Inghilterra con il suo Impero. Nazioni come il Belgio o la Svizzera non possono ambire all'autarchia. Ecco perché è allora necessario allargare il mercato e costruire "più ampi sistemi federali di economie nazionali»: a «simili formazioni, sia pure attraverso soste e ritorni sembra conduca inevitabilmente l'evoluzione della civiltà europea». «Il liberismo è stata un'utopia, storicamente sfruttata da qualche economia nazionale più fortunata. In sostanza il protezionismo e l'autarchia sono il portato del libero scambio, per quanto ne costituiscano la negazione» ${ }^{45}$.

Naturalmente, quella dello spazio economico europeo unificato era un'idea che fascismo e nazismo andavano coltivando e praticando. Colpisce, però, la mancanza in questi testi di Modigliani di accenti bellicisti: che, invece, costituivano una delle componenti essenziali e del fascismo e del nazismo.

\section{La tesi di laurea}

Nella tesi di laurea Modigliani constata il cambiamento occorso all'economia capitalistica. Gli autori di riferimento sono l'Alfred Marshall di

${ }^{43}$ F. Modigliani, L'Autarchia nazionale, cit., pp. 91-93.
${ }_{44}$ Ivi, p. 93.
${ }^{45}$ Ivi, pp. $93-95$. 
Industry and Trade, Guglielmo Masci, relatore della tesi, e Werner Sombart ${ }^{46}$. Il cambiamento suscita «un grande numero di problemi nuovi, in gran parte non previsti dai teorici del capitalismo». Lo scopo della tesi è mostrare che «la uniformizzazione delle contabilità e del calcolo del prezzo di costo» sul piano contabile possa costituire uno strumento per risolvere questi problemi. Come vedremo, in tale direzione spinge il crescente intervento pubblico in economia.

Le prime fasi del capitalismo erano caratterizzate da concorrenza perfetta, prevaleva, cioè, «l'individualismo assoluto»: per molti aspetti si trattava della «esatta negazione» del capitalismo contemporaneo ${ }^{47}$. Modigliani elenca i presupposti della libera concorrenza: una "possibilità di produzione» tendenzialmente «illimitata»; sostituibilità e perfetta mobilità dei prodotti; necessità «che la domanda sia ugualmente mobile e trasferibile»; perfetta mobilità di capitale e lavoro; «soprattutto che la produzione sia esercitata da un numero rilevantissimo di imprese piccole e indipendenti» così che nessuna di esse possa influenzare il prezzo dei prodotti e dei fattori della produzione; si presuppone che «ogni produttore abbia una conoscenza perfetta del mercato ${ }^{48}$.

Sebbene si tratti di condizioni irrealizzabili, il primo capitalismo tendeva a realizzarle e dunque il prezzo assicurava «il massimo edonistico» individuale; d'altra parte, «la liquidità del mercato permette adattamenti rapidi e poco costosi attraverso squilibri poco profondi». È per questi motivi che l'intervento pubblico in economia è il più limitato possibile e nascono i canoni del liberismo economico. In questa situazione non vi sono problemi di «regolamentazione giuridica o convenzionale della contabilità» perché il mercato non va regolamentato né controllato dallo Stato, né si deve proteggere il risparmio o altre categorie ${ }^{49}$.

Sotto la spinta di leggi immanenti il capitalismo subisce una profonda trasformazione. La tendenza al monopolio si rafforza per due motivi, l'uno finanziario l'altro tecnico. Lo sviluppo del credito bancario e delle società per azioni può consentire di superare il problema della limitatezza dei capitali tipico delle imprese individuali. Si sviluppano così imprese colossali, che possono lavorare a costi decrescenti, e si avvia il processo di integrazione verticale ed orizzontale. Naturalmente si tratta di processi

${ }^{46}$ Il testo di Marshall è tradotto in Organizzazione industriale, vol. VII della Nuova collana di economisti italiani e stranieri, Utet, Torino 1934; nello stesso volume cfr. G. Masci, Alcuni aspetti odierni dell'organizzazione e delle trasformazioni industriali; infine W. Sombart, Il capitalismo moderno, Vallecchi, Firenze 1925.

${ }^{47}$ F. Modigliani, La regolamentazione e la standardizzazione dei bilanci della contabilità e del calcolo del prezzo di costo nei suoi aspetti teorici e nelle sue attuazione all'estero. Tesi di Laurea, Regia Università degli Studi de Roma Facoltà di Giurisprudenza, circa 1939, in Franco Modigliani Papers, David M. Rubenstein Rare Book \& Manuscript Library, Duke University, p. 1.

48 Ivi, pp. 1-2.

49 Ivi, p. 3. 
che trovano degli ostacoli: i guadagni tendono a diminuire, i costi prima o poi salgono, soprattutto quello dei trasporti. In secondo luogo, la «crescente costosità degli impianti e l'aumento del capitale fisso» e la «crescente specializzazione degli impianti e della mano d'opera» allontanano dalle condizioni di libera concorrenza; «il mercato perde molta della sua elasticità, sia sotto l'aspetto dell'immediato adattamento alle oscillazioni della domanda, sia sotto quello dell'eliminazione delle imprese marginali». Le imprese che lavorano a costi decrescenti, per adattarsi ad una diminuzione della domanda incontreranno costi crescenti, inducendo un'ulteriore diminuzione della domanda. Ecco dunque che vendono in perdita o accumulano merci in magazzino in previsione di tempi migliori. Così facendo, però, rovinano il mercato e la diminuzione dei prezzi invece che avvenire in un periodo breve "tende a perpetuarsi in un periodo più lungo», infine la produzione non si riduce ${ }^{50}$. In questo modo si creano «depressioni (...) lunghe e gravi», il ribasso dei prezzi avviene in maniera violenta, eliminando così imprese anche sane; ma anche la ripresa è tumultuosa, «spesso violenta e caotica come la discesa». Mentre nel capitalismo individualistico, come teorizza la legge di Say, non vi potevano essere ingorghi data la perfetta mobilità dei fattori di produzione, in seguito la situazione cambia: il capitale "più facilmente realizzabile», «liquido», è quello circolante, ma nel capitalismo contemporaneo a prevalere è quello fisso, dunque «lo smobilitamento diviene sempre più difficile»; anche l'elevata specializzazione delle macchine contribuisce al fenomeno ${ }^{51}$. La specializzazione della mano d'opera irrigidisce il mercato, anche se alcuni teorici ritengono che la crescente razionalizzazione del lavoro e il crescente impiego di «macchine automatiche non richiedano dalla massa degli operai una speciale qualificazione $\aleph^{52}$. In ogni caso, l'irrigidimento del mercato provoca ulteriore irrigidimento: più l'impresa è grande è più resistenza farà ad accettare di essere diventata una impresa marginale.

Riassumendo. La «crescente difficoltà di adattamento spontaneo della produzione alle condizioni del mercato»; «l'aumento degli effetti negativi della lotta economica spinta»; «la tendenza della lotta economica ad aggravarsi poiché l'impresa tende con ogni mezzo al raggiungimento delle dimensioni più economiche»: tutto ciò, dovuto in gran parte all'aumento degli investimenti in capitale fisso e ad "una sproporzione sempre maggiore fra profitto e rischio del capitale», spinge al formarsi di coalizioni industriali, cioè al superamento dell'individualismo economico ${ }^{53}$.

Le trasformazioni conosciute dal capitalismo pongono su basi del tutto nuove il rapporto tra Stato e mercato. In altre parole «aumentano i casi nei quali l'intervento dello Stato per ragioni economiche, politiche o so-

\footnotetext{
50 Ivi, pp. 13-14.

51 Ivi, pp. 14-15.

52 Ivi, p. 17.

53 Ivi, p. 17.
} 
ciali diventa necessario o almeno utile»: «Quanto poi alle ragioni positive in favore dell'intervento dello Stato (...) esse sono infinite e sono state ampiamente studiate in Italia, specie dopo l'avvento al potere del Fascismo e la creazione del sistema corporativo che, fra l'altro, è stato definito come regime d'intervento organizzato e metodico dello Stato nel campo economico» ${ }^{54}$.

Modigliani dichiara di non potersi occupare di tutti i compiti a cui è chiamato lo Stato. Si limita ad approfondire quelli di «controllo», a favore di categorie o della collettività, e alle «funzioni direttive» ${ }^{55}$.

Per quanto riguarda i controlli a favore di determinate categorie, l'autore ricorda quelle dei consumatori, dei risparmiatori e il controllo dei prezzi in regime di monopolio e anche il controllo generale dei prezzi. Lo Stato deve poi proteggere «il salariato»: si tratta di uno dei «primi campi» in cui si è cimentato l'intervento pubblico. Infatti, «i danni sociali che derivano dal deprezzamento della merce lavoro, sono incalcolabili; per di più essi si accumulano pesando sulla generazione seguente e non possono in alcun modo essere riparati $»^{56}$. La proposta di Modigliani avrà come risultato utile, fra l'altro, «di permettere una maggiore collaborazione fra datori di lavoro e lavoratori; questi infatti saranno messi in grado di conoscere la situazione economica e l'andamento della loro impresa. Ora, com'è noto, la conoscenza dei risultati della propria attività è un forte stimolo al lavoro e al rendimento, e farà gli operai più disposti agli eventuali sacrifici quando ne comprenderanno la necessità e sapranno che parteciperanno anche agli utili del buon andamento dell'impresa ${ }^{57}$.

Per quanto riguarda gli interessi collettivi Modigliani sottolinea «l'ingigantirsi delle imprese fino a divenire un fatto sociale» e poi «l'uso dei capitalisti di chiedere allo Stato un crescente aiuto di carattere legislativo e perfino finanziario», «prova questa del progressivo esaurirsi del sistema capitalista e dell'individualismo economico ${ }^{58}$.

Veniamo ora alle funzioni direttive. Lo Stato può «provocare» la fusione tra imprese concorrenti, può limitare la lotta economica, può controllare e disciplinare la creazione di nuovi impianti, sul piano finanziario lo Stato può manovrare il tasso ufficiale di sconto, infine si può avere la "gestione diretta di imprese, detta socializzazione delle imprese», la quale, «benché trovi degli oppositori, in certe condizioni è certamente economica ed utile» ${ }^{59}$.

La parte dedicata alla proposta di Modigliani è interessante sia perché risulta finalizzata a razionalizzare i fenomeni di coalizione e di interven-

\footnotetext{
54 Ivi, pp. 20-21.

55 Ivi, p. 21.

56 Ivi, p. 24.

57 Ivi, p. 51.

58 Ivi, p. 25.

59 Ivi, p. 27.
} 
to pubblico analizzati, sia perché dimostra curiosità anche per esperienze di paesi che si sono avviati su questo sentiero. Menziona il caso tedesco, il sovietico, il francese, che gli appare il più avanzato, l'inglese, quello americano. Gli Stati Uniti, «per lungo tempo la roccaforte del liberalismo e dell' individualismo spinto», con Roosevelt si sono incamminati su una via nuova, quella del controllo dei prezzi. La grande crisi del '29, infatti, aveva spinto i produttori a vendere sotto costo: «è facile intendere le conseguenze di simili procedimenti; la riduzione dei prezzi iniziata da un concorrente veniva ripresa ed allargata dagli altri, col risultato che il dumping non riusciva a nessuno dei produttori, mentre tutti restavano ugualmente danneggiati dal sistema: i profitti (...) sparivano ${ }^{60}$. Il lettore noterà la visione critica di Modigliani nei confronti dei meccanismi deflattivi di un mercato lasciato operare liberamente in periodo di crisi economica violenta. 



\section{CONCLUSIONI}

È venuto il momento di trarre le conclusioni della nostra analisi. Mi limito ad alcune osservazioni.

La prima è che ritengo importante ribadire che Modigliani nella prima parte del testo L'Autarchia nazionale abbia ben presente alcuni dei ragionamenti di Keynes ${ }^{1}$ e che essi abbiano un'accentuazione, per quanto riguarda le sperequazioni (affrontate di petto anche nel testo che gli fa vincere i Littoriali), quasi più rilevante per il mercato interno, che per $i$ rapporti internazionali. Mi sembra, in altri termini, che ne emerga una filosofia sociale con intonazioni di stampo latamente socialista e tendenzialmente pacifista. Tuttavia, ricordando la radice ideologica e analitica all'interno della quale Modigliani propone questi ragionamenti, che è quella del nazional-fascismo economico delle riviste «Lo Stato» e «Dottrina fascista», come ho già evidenziato, Modigliani può essere inserito all'interno del fascismo sociale ${ }^{2}$.

Il paragone del testo di Modigliani con quello di altri economisti della rivista «Lo Stato» che si occupano della crisi, come Arena, Fanno e Papi o Rosboch, che detta la linea dello «Stato», evidenzia, in secondo luogo, come il giovane studente universitario sia fermamente ostile alle politiche deflattive, è cioè sia decisamente critico nei confronti di coloro che ritengono che per uscire dalla crisi sia necessaria una compressione dei salari. Nella tesi di laurea, come abbiamo visto, Modigliani enfatizza il «danno sociale» derivato dal «deprezzamento della merce lavoro»;

1 Scrive R.M. Solow che Modigliani aveva letto prima della Teoria generale i celebri saggi di Hicks, del 1937, e di Lange, 1938, che ne riassumevano il contenuto: Modigliani e Keynes, "Moneta e Credito», giugno-settembre 2015, p. 11. Più in generale, i riferimenti a Keynes sono numerosi anche nella letteratura economica italiana. Per gli anni 1936-1938 cfr. S. Bartolozzi Batignani, Keynes nei volumi degli economisti italiani. Un saggio bibliografico, in Keynes in Italia, cit., pp. 135-139.

2 Affonda dunque qui il passaggio alla fase socialista di Modigliani, durata per il breve periodo francese e dalla quale si distacca in America grazie alla frequentazione di Gaetano Salvemini? Cfr. quanto scrive P.F. Asso in Viaggio attraverso la storia ecc., cit., p. 154. 
i danni sono «incalcolabili», anche perché «si accumulano pesando sulla generazione seguente e non possono in alcun modo essere riparati». Ed enfatizza l'inutilità per il rilancio occupazionale degli effetti deflattivi di un mercato che si affida ai propri meccanismi di autoregolazione.

In terzo luogo si deve sottolineare come, stando ai testi pubblicati da Modigliani prima dell'arrivo negli Stati Uniti d'America, l'avversità alla deflazione salariale ha un fondamento che possiamo definire di carattere sociale e politico, perché non vi è alcun esplicito ragionamento prettamente economico che la supporta, né vi è alcun collegamento agli effetti che la deflazione salariale ha, o non ha, sugli investimenti, come invece nella riflessione di Keynes.

Si tratta di conclusioni che sono rilevanti, ritengo, per quegli storici che volessero approfondire, sulla base dello studio dei testi italiani, i contributi teorici di Modigliani proposti una volta arrivato negli Stati Uniti d'America. Con il saggio del 1944, come noto, egli proporrà un duplice modello macroeconomico, l'uno che si riconnette all'impostazione classica e incentrato sull'ipotesi di flessibilità verso il basso dei salari, l'altro invece, ricondotto all'impostazione di Keynes, fondato sulla rigidità salariale. Nel teso del 1944, inoltre, Modigliani sottolineerà come vi sia un caso specifico, contemplato da Keynes, in cui la deflazione salariale, tipica del modello classico, non ha alcun potere di stimolare gli investimenti: il cosiddetto caso della trappola della liquidità ${ }^{3}$. Sarebbe allora interessante ricostruire la sequenza di argomentazioni che Modigliani proporrà, dopo lo sbarco in America e nel corso di tutta la sua carriera scientifica, a fondamento della sua interpretazione di Keynes a questo proposito. Saranno le ricerche storiche future a verificare se la teoria dell'economista italiano si limiterà a proporre i ragionamenti di Keynes oppure se, sulla base del pensiero di Keynes, svilupperà anche riflessioni originali, appoggiandosi al pensiero anche di altri autori. Saranno le ricerche future a circostanziare la rilevanza storica, sociale e politica che Modigliani attribuirà a questo caso specifico. Sarebbe altresì interessante, e sarebbe altrettanto fondamentale, ricostruire il contesto economico, sociale e politico, oltre che le riflessioni sociali e politiche dello stesso Modigliani, che accompagneranno i suoi ragionamenti teorici volti a sviluppare, nel corso della sua carriera, l'altra linea di pensiero e cioè proprio l'ipotesi classica di flessibilità verso il basso dei salari monetari, tipica degli economisti italiani di tradizione classica.

Se si potesse comprovare, sul piano documentale, che Modigliani fosse già antifascista quando scriveva i tesi per lo «Stato» e per «Dottrina fascista», e che quindi questi testi devono avere una doppia lettura, l'una di facciata, fascista, l'altra, nascosta, favorevolmente orientata diciamo verso il socialismo o il liberalsocialismo, allora si potrebbe far risalire la

${ }^{3}$ Cfr. F. Modigliani, La preferenza per la liquidità e la teoria dell'interesse e della moneta, (gennaio 1944), in Id., Consumo, risparmio, finanza, cit., pp. 66-67. 
refrattarietà di Modigliani alle teorie che inneggiavano alla flessibilità verso il basso dei salari monetari in qualunque situazione economica e dunque compreso il caso della cosiddetta trappola della liquidità, anche alla ferma consapevolezza che queste teorie erano state quelle proprie del fascismo. Se Modigliani fosse ritornato a riflettere, nella maturità, sul contenuto e sull'occasione dei suoi saggi giovanili argomentando quanto sostiene nell'autobiografia, risulterebbe che tutto ciò che il fascismo declamava in merito alla giustizia sociale e all'esistenza di uno Stato capace di non essere asservito ad una sola classe sociale, quella capitalisti$\mathrm{Ca}^{4}$, ai suoi occhi risultava pura retorica. Nei testi giovanili è già chiaro, anche senza ricorrere al caso della trappola della liquidità, che mostra l'inanità della deflazione salariale nello stimolare gli investimenti date certe condizioni economiche, è già chiaro, dicevo, che la compressione di consumi già ridotti all'osso per mancanza di capacità pagante, non può certo rimettere in moto l'economia. Ed è chiaro, dalla lettura dello «Stato», che coloro i quali proponevano come rimedio alla crisi una politica economica deflattiva capace di far prontamente abbassare i salari, avevano, almeno da quanto si evince dalla lettura dello «Stato» (ogni singolo economista, infatti, merita un approfondimento storiografico a sé stante), una filosofia sociale decisamente fascista, come quella di Arena, Fanno, Papi, Rosboch, che con i loro scritti assecondavano la politica economica del regime. Il fascismo ne emergerebbe come un regime del tutto insensibile ai problemi di giustizia sociale, di perequazione e di piena occupazione e apparirebbe come baluardo dittatoriale, totalitario e classista del capitalismo, un regime votato inevitabilmente a distruggere la convivenza sociale. E al lettore che si scandalizzasse dell'uso di tale terminologia - classista - ricorderei il passaggio, in precedenza citato, che il giovane Modigliani dedica a Marx. Era appunto la tradizione 'classica', che in Italia poteva vantare autori come Pantaleoni, tra i più duri fautori dello squadrismo fascista, del suffragio censitario e corporativo, della limitazione della libertà di stampa e di una politica economica fatta all'insegna dell'ortodossia finanziaria: e cioè incentrata sul pareggio di bilancio, sulla limitazione delle spese pubbliche, sulle privatizzazioni, sull'abolizione delle tasse di successione, sull'introduzione della tassazione sul salario, sulla distruzione, in nome della libertà di associazione a venire, di qualsivoglia sindacato.

4 Tra gli esempi: «Lo Stato fascista e lo Stato nazional-socialista si presentano (...) come un superamento dello Stato liberale democratico. Mentre quest'ultimo, in nome dei principi della libertà individuale, negava o ostacolava alle categorie dei lavoratori il diritto alla coalizione» e «non si accorgeva che il capitale aveva grande facilità di influire (...) sulla vita sociale e sullo Stato", Lo Stato fascista e il nazionalsocialista «hanno posto la legge del lavoro a base della consociazione nazionale e hanno dato vito allo ordinamento corporativo»: A. Solmi, L'intesa italo-germanica per gli studi legislativi, «Lo Stato», fasc. 10, 1937, p. 514. 
Tuttavia, per proporre questa ipotesi interpretativa non è necessario pensare a un Modigliani già antifascista. Sul piano biografico abbiamo scarsi elementi per approfondire l'ipotesi, che indica l'autobiografia, che Modigliani si fosse già staccato dal fascismo quando scriveva i testi che abbiamo analizzato; anzi, i suoi contributi indicano un'appartenenza scientifico-politica precisa, che solo le leggi razziali sapranno cambiare. Questo non toglie, tuttavia, che la filosofia sociale che emerge dalle pagine del giovane che vuole dare un contributo alla costruzione della scienza nuova appartiene all'alveo di quel fascismo che tanto preoccupava Costamagna; cioè quel fascismo che, per dirla con la parola che Modigliani prende a prestito da Mussolini, voleva che il lavoro diventasse «soggetto». D'altra parte, nella tesi di laurea, scritta dopo le leggi razziali e il soggiorno in Francia, abbiamo visto che il tema dell'intervento pubblico in una cornice tutt'altro che liberista è confermato, così come confermata è l'avversione alla deflazione salariale.

Può darsi che la mia sia una impressione dettata dalla simpatia per alcune delle tesi economiche di Modigliani: quelle cioè proto-keynesiane, protezioniste, perequative, europeiste e pianificatrici. In ogni caso, credo che al lettore contemporaneo venga naturale eliminare la parte caduca - così almeno risulta ai miei occhi - dei ragionamenti di Modigliani, cioè quelli fascisti compreso l'accenno alla razza, dal resto del discorso. È ciò che fece, del resto, di fatto, lo stesso Modigliani. Ed è ciò che fecero altri economisti e studiosi di altre discipline. Ci fu, infatti, una generazione di studiosi che, dopo aver preso coscienza della natura del fascismo e del suo fallimento, in tempi e secondo esperienze e circostanze differenti, si pose il problema di coniugare giustizia sociale e progresso economico, politico e civile. Si tratta di una generazione che aveva preso coscienza che per realizzare questi obiettivi andava radicalmente modificato il capitalismo, che aveva generato la Prima Guerra Mondiale e il fascismo. Andava cambiato fino a lambire, nei più audaci, un sistema economico nuovo, dove la rivoluzione da passiva si poteva fare, anche gradualmente e pacificamente, attiva. E la direzione del cambiamento era chiara perché imperniata su profonde trasformazioni strutturali dell'economia: quanto fatto dal fascismo del rapporto tra Stato e mercato era parte di cambiamenti epocali che avevano investito tutto l'Occidente capitalistico. Lo 'Stato industriale', lo 'Stato sociale' il 'keynesismo' teorico e pratico, i propositi di pianificazione dell'economia troveranno continuità e ampio sviluppo nell'Italia repubblicana. Anche i ragionamenti sociologici e politologici paretiani sulla nazione, possono avere una inflessione differente da quella impressa dal fascismo: per molti degli anni successivi alla Seconda Guerra Mondiale, in Italia si è appunto cercato di costruire una «Scienza dello Stato», nonché una nazione, che fossero democratici e tendenzialmente socialisti. E nel carcere fascista ci fu chi progettò anche uno spazio politico ed economico europeo ispirato alla medesima filosofia sociale. 
Non è scopo di questa pagine, tuttavia, ricostruire se e in quali termini Modigliani abbia contribuito a questa costruzione dopo lo sbarco in America. 



\section{INDICE DEI NOMI}

Alacevich, Michele 14 e n, 15n, 35n

Amoroso, Luigi 22 e $n$

Andrioli, Virigilio 29n

Arena, Celestino 24, 30, 31 e n, 33 e $\mathrm{n}$

Arias, Gino 5, 17, 37n, 48

Arrigoni, Angelo Luigi 43n

Asso, Pier Francesco 11, 14 e n, 15n, $32 \mathrm{n}, 35 \mathrm{n}, 67 \mathrm{n}$

Augello, Massimo Mario 11

Ballarati, Giancarlo 43n

Barbieri, Gino 43

Barone, Enrico 1, 3 e n, 4 e n, 6, 32, 33, 34

Bartolozzi Batignani, Simonetta $67 n$

Barucci, Piero 11, 14n

Benvenuti, Marco 21n

Bientinesi, Fabrizio 11, 14 e n, 16, 17

Binello, Giuseppe 47 e n, 48 e n

Bini, Piero 32n

Blum, Léon 45

Bonaparte, Napoleone 52

Borgatta, Gino 23n

Bottai, Giuseppe 30 e n

Brancaccio, Emiliano 11

Bücher, Karl 30

Buffa, Aldo 23n, 29

Calendoli, Giovanni 43n

Camurri, Renato 15 e n

Carli, Filippo 4, 5, 6, 17, 58 e n, 59

Castronovo, Valerio 32n

Cattabrini, Francesco $14 n$
Cini, Marco 11

Corradini, Enrico 2, 56

Costa, Pietro 21n

Costabile, Lilia $14 \mathrm{n}$

Costamagna, Carlo 10, 16, 17, 19, 21 e n, 22 e n, 23 e n, 25 e n, 26n, 27 e n, 28, 31, 34 e n, 38 e n, 39, 40n, 55,58 e $n, 70$

Cristiano, Carlo 11

Curcio, Carlo 23n, 24 e n

D'Adda, Carlo 14 e n

D’Alò, Giovanni 34n

D’Annunzio, Gabriele 6

Dami, Cesare 34 e n

De Ambris, Alceste 6, 28

De Cecco, Marcello 16 e n, 49n, 55n

De Francisci, Pietro 23n

de Molo Aliprindi Veillon, Jacqueline 11

De Stefani, Alberto 1, 4, 33

De Viti De Marco, Antonio 2

Del Vecchio, Gustavo 22n, 23n, 26 e n, 38

Di Matteo, Massimo 14n

Eicke, Werner $42 \mathrm{n}$

Einaudi, Luigi 7, 33

Ermarth, Fritz 24n, 34n

Evola, Julius 24 e n, 25 e n, 38 e n, 39

Fabbri, Sileno 23n

Fanfani, Amintore 43

Fanno, Marco 30, 38, 69 
Ferri, Carlo Emilio 23n, 25 e n, 33 e n, 43

Fiorentini, Ruggero 29n

Fiorito, Luca 11

Flores, Marcello 19n

Forget, Evelyn 17n

Freud, Sigmund 39

Gangemi, Lello 34n

Garino-Canina, Attilio 26n

Gemelli, Agostino 9

Gentile, Giovanni 23, 27, 33

Giani, Nicolò 42 e n, 43 e n

Giannetti, Berlindo 39n

Gigliobianco, Alfredo 11

Gini, Corrado 5 e $n$

Giocoli, Nicola 11

Giolitti, Giovanni 33

Glaesser, Gustavo 24n

Gramsci, Antonio 29

Grandi, Aldo 43n

Hagemann, Harald 15 e n

Hayek, Friedrich 34

Heckscher, Eli Filip 9, 30

Heinrich, Walter 27, 60n

Hicks, John 67n

Hitler, Adolf 37

Höhn, Reinhard 38

Jannaccone, Pasquale 25

Keynes, John Maynard 8, 9, 10, 17, $27,28,29,30,31,32$ e n, 38, 55, 57, 67 e n, 68

Kourri, Pentti Juha Kalervo $15 n$

Lachman, Ludwig 28 e $\mathrm{n}$

Leonardi, Valentino 23n

Leva, Enrico $42 n$

Levis Sullam, Simon 19n

List, Friedrich 9, 30, 60

Loria, Achille 39

Luzzatto, Gino 30

Macchioro, Aurelio 29 e n
Maiocchi, Roberto 14 e n, 16, 17

Manoilescu, Mihail 27

Marshall, Alfred 61,62n

Marx, Karl 25, 31, 69

Masci, Guglielmo 62 e n

Matard-Bonucci, Marie-Anne 19n

Matteotti, Giacomo 1, 29

Mazzei, Jacopo 9, 30

Mc Kenna, Reginald 31

Michelagnoli, Giovanni 11

Michelini, Luca 1n, 7n, 8n, 9n, 22n, 23n, 26n, 32n, 37n, 38n

Michels, Roberto 25 e $\mathrm{n}$

Modigliani, Franco 8, 9, 10, 13 e n, 14 e n, 15 e n, 16 e n, 17, 21, 27 e n, $28,29,32,35,37,38,39$, 40,41 e n, 42, 43n, 45, 46, 47 e n, 48 e n, 49 e n, 50,51 e n, 53, 54,55 e n, 56, 58, 59 e n, 60 e n, 61n, 62 e n, 64, 65, 67 e n, 68 e n, 69, 70, 71

Mussolini, Arnaldo 43

Mussolini, Benito 6, 16, 17, 23 e n, $28,33,37,39,60$ e n, 70

Mutinelli, Marino 39n

Napolitano, Tomaso 34n

Nerozzi, Sebastiano 14 e n, 15n, 35n

Nitti, Francesco Saverio 33

Ottonelli, Omar 38n

Padoa-Schioppa, Fiorella 14 e $n$

Padoa-Schioppa, Tommaso 14 e $n$ Pantaleoni, Maffeo 1, 2 e n, 3 e n, 4 e $n, 6,7,8,10,23,32,33$ e n, 34 , $37,40,50$

Panunzio, Sergio 27

Papi, Giuseppe Ugo 30, 67, 69

Pareto, Vilfredo 1, 2, 3 e n, 4 e n, 6 , $7,8,26,33,34,42,50,54$

Parisi, Daniela 13 e n, 14, 15 e n, 16 Parlato, Giuseppe 60n

Paschukanis Evgeny. 34n

Pasinetti, Luigi 27n

Pavesi, Mazzini 23n 
Peluffo, Paolo 16n

Pigou, Arthur Cecil 31

Porri, Vincenzo 33 e $n$

Prato, Giuseppe 33, 48

Preziosi, Giovanni 8, 38, 39

Rancan, Antonella 14n

Ricardo, David 51, 52

Rocco, Alfredo 1, 4, 6, 7, 23

Romani, Roberto 11,33n

Roosevelt, Franklin Delano 17, 30, 65

Rosboch, Ettore 21n, 30 e n, 34 e n, 37, 67, 69

Rosemberg, Alfred 24

Salvadori, Neri 11

Salvemini, Gaetano 67n

Santoro, Arturo 34n

Say, Jean-Baptiste 28, 52, 63
Schmitt, Carl 23n, 24 e n

Schmoller, Gustav 30

Sensini, Guido 26 e $n$

Serafini, Gabriele 11

Solmi, Arrigo 23n, 39, 69n

Solow Robert M. 67n

Sombart, Werner 62 e n

Spann, Othmar 23n, 27, 38 e n

Spencer, Herbert 42

Spirito, Ugo 25, 27

Sraffa, Piero 37

Stapel, Wilhelm 38

Toraldo di Francia, Monica 21n

Tosca di Castellazzo, Carlo 48n

Vacca, Giuseppe 11

Volpicelli, Arnaldo 27

Weintraub, Eliot Roy 17n 



\section{STUDI E SAGGI}

Titoli Pubblicati

\section{ARCHITETTURA, STORIA DELL'ARTE E ARCHEOLOGIA}

Acciai S., Sedad Hakki Eldem. An aristocratic architect and more

Bartoli M.T., Lusoli M. (a cura di), Le teorie, le tecniche, i repertori figurativi nella prospettiva d'architettura tra il '400 e il '700. Dall'acquisizione alla lettura del dato

Bartoli M.T., Lusoli M. (a cura di), Diminuzioni e accrescimenti. Le misure dei maestri di prospettiva

Benelli E., Archetipi e citazioni nel fashion design

Benzi S., Bertuzzi L., Il Palagio di Parte Guelfa a Firenze. Documenti, immagini e percorsi multimediali

Biagini C. (a cura di), L’Ospedale degli Infermi di Faenza. Studi per una lettura tipomorfologica dell'edilizia ospedaliera storica

Bologna A., Pier Luigi Nervi negli Stati Uniti 1952-1979. Master Builder of the Modern Age

Eccheli M.G., Pireddu A. (a cura di), Oltre l'Apocalisse. Arte, Architettura, Abbandono

Fischer von Erlach J.B., Progetto di unarchitettura istorica / Entwurff einer Historischen Architectur, traduzione e cura di G. Rakowitz

Frati M., "De bonis lapidibus conciis": la costruzione di Firenze ai tempi di Arnolfo di Cambio. Strumenti, tecniche e maestranze nei cantieri fra XIII e XIV secolo

Gregotti V., Una lezione di architettura. Rappresentazione, globalizzazione, interdisciplinarità

Gulli R., Figure. Ars e ratio nel progetto di architettura

Lauria A., Benesperi B., Costa P., Valli F., Designing Autonomy at Home. The ADA Project. An Interdisciplinary Strategy for Adaptation of the Homes of Disabled Persons

Lisini C., Lezione di sguardi. Edoardo Detti fotografo

Maggiora G., Sulla retorica dell'architettura

Mantese E. (a cura di), House and Site. Rudofsky, Lewerentz, Zanuso, Sert, Rainer

Mazza B., Le Corbusier e la fotografia. La vérité blanche

Mazzoni S. (a cura di), Studi di Archeologia del Vicino Oriente. Scritti degli allievi fiorentini per Paolo Emilio Pecorella

Messina M.G., Paul Gauguin. Un esotismo controverso

Paolucci F. (a cura di), Epigrafia tra erudizione antiquaria e scienza storica

Pireddu A., In abstracto. Sull'architettura di Giuseppe Terragni

Pireddu A., The Solitude of Places. Journeys and Architecture on the Edges

Pireddu A., In limine. Between Earth and Architecture

Rakowitz G., Tradizione Traduzione Tradimento in Johann Bernhard Fischer von Erlach

Tonelli M.C., Industrial design: latitudine e longitudine

\section{CULTURAL STUDIES}

Candotti M.P., Interprétations du discours métalinguistique. La fortune du sūtra A 1.1.68 chez Patañjali et Bhartrhari

Nesti A., Per una mappa delle religioni mondiali

Nesti A., Qual è la religione degli italiani? Religioni civili, mondo cattolico, ateismo devoto, fede, laicità

Pedone V., A Journey to the West. Observations on the Chinese Migration to Italy

Pedone V., Sagiyama I. (edited by), Perspectives on East Asia

Pedone V., Sagiyama I. (edited by), Transcending Borders. Selected papers in East Asian studies 
Rigopoulos A., The Mahānubhāvs

Squarcini F. (a cura di), Boundaries, Dynamics and Construction of Traditions in South Asia Sagyiama I., Castorina M. (edited by), Trajectories: Selected papers in East Asian studies 軌跡 Vanoli A., Il mondo musulmano e i volti della guerra. Conflitti, politica e comunicazione nella storia dell'islam

DIRITTO

Allegretti U., Democrazia partecipativa. Esperienze e prospettive in Italia e in Europa

Bartolini A., Pioggia A. (a cura di), A 150 anni dall'unificazione amministrativa italiana. Studi. Vol. VIII. Cittadinanze amministrative

Cafagno M., Manganaro F. (a cura di), A 150 anni dall'unificazione amministrativa italiana. Studi. Vol. V. L'intervento pubblico nell'economia

Cavallo Perin R., Police A., Saitta F. (a cura di), A 150 anni dall'unificazione amministrativa italiana. Studi. Vol. I. L'organizzazione delle pubbliche amministrazioni tra Stato nazionale e integrazione europea

Chiti E., Gardini G., Sandulli A. (a cura di), A 150 anni dall'unificazione amministrativa italiana. Studi. Vol. VI. Unità e pluralismo culturale

Cingari F. (a cura di), Corruzione: strategie di contrasto (legge 190/2012)

Civitarese Matteucci S., Torchia L., A 150 anni dall'unificazione amministrativa italiana. Studi. Vol. IV. La tecnificazione

Comporti G.D. (a cura di), A 150 anni dall'unificazione amministrativa italiana. Studi. Vol. VII. La giustizia amministrativa come servizio (tra effettività ed efficienza)

Curreri S., Democrazia e rappresentanza politica. Dal divieto di mandato al mandato di partito

Curreri S., Partiti e gruppi parlamentari nell'ordinamento spagnolo

De Giorgi Cezzi, Portaluri Pier Luigi (a cura di), A 150 anni dall'unificazione amministrativa italiana. Studi. Vol. II. La coesione politico-territoriale

Federico V., Fusaro C. (a cura di), Constitutionalism and Democratic Transitions. Lessons from South Africa

Fiorita N., L'Islam spiegato ai miei studenti. Otto lezioni su Islam e diritto

Fiorita N., L'Islam spiegato ai miei studenti. Undici lezioni sul diritto islamico

Fossum J.E., Menéndez A.J., La peculiare costituzione dell'Unione Europea

Gregorio M., Le dottrine costituzionali del partito politico. L'Italia liberale

Marchetti B., Renna M. (a cura di), A 150 anni dall'unificazione amministrativa italiana. Studi. Vol. III. La giuridificazione

Palazzo F., Bartoli R. (a cura di), La mediazione penale nel diritto italiano e internazionale

Ragno F., Il rispetto del principio di pari opportunità. L'annullamento della composizione delle giunte regionali e degli enti locali

Sorace D. (a cura di), Discipine processuali differenziate nei diritti amministrativi europei Trocker N., De Luca A. (a cura di), La mediazione civile alla luce della direttiva 2008/52/CE Urso E., La mediazione familiare. Modelli, principi, obiettivi

Urso E., Le ragioni degli altri. Mediazione e famiglia tra conflitto e dialogo. Una prospettiva comparatistica e interdisciplinare

ECONOMIA

Bardazzi R. (edited by), Economic multisectoral modelling between past and future. A tribute to Maurizio Grassini and a selection of his writings

Bardazzi R., Ghezzi L. (edited by), Macroeconomic modelling for policy analysis

Barucci P., Bini P., Conigliello L. (a cura di), Economia e Diritto durante il Fascismo. Approfondimenti, biografie, nuovi percorsi di ricerca

Barucci P., Bini P., Conigliello L. (a cura di), Il Corporativismo nell'Italia di Mussolini. Dal declino delle istituzioni liberali alla Costituzione repubblicana

Ciampi F., Come la consulenza direzionale crea conoscenza. Prospettive di convergenza tra scienza e consulenza 
Ciampi F., Knowing Through Consulting in Action. Meta-consulting Knowledge Creation Pathways

Ciappei C. (a cura di), La valorizzazione economica delle tipicità rurali tra localismo e globalizzazione

Ciappei C., Citti P., Bacci N., Campatelli G., La metodologia Sei Sigma nei servizi. Un'applicazione ai modelli di gestione finanziaria

Ciappei C., Sani A., Strategie di internazionalizzazione e grande distribuzione nel settore dell'abbigliamento. Focus sulla realtà fiorentina

Garofalo G. (a cura di), Capitalismo distrettuale, localismi d'impresa, globalizzazione

Laureti T., L'efficienza rispetto alla frontiera delle possibilità produttive. Modelli teorici ed analisi empiriche

Lazzeretti L. (a cura di), Art Cities, Cultural Districts and Museums. An Economic and Managerial Study of the Culture Sector in Florence

Lazzeretti L. (a cura di), I sistemi museali in Toscana. Primi risultati di una ricerca sul campo

Lazzeretti L., Cinti T., La valorizzazione economica del patrimonio artistico delle città d'arte. Il restauro artistico a Firenze

Lazzeretti L., Nascita ed evoluzione del distretto orafo di Arezzo, 1947-2001. Primo studio in una prospettiva ecology based

Meade S. Douglas (edited by), In Quest of the Craft. Economic Modeling for the 21st Century

Simoni C., Approccio strategico alla produzione. Oltre la produzione snella

Simoni C., Mastering the Dynamics of Apparel Innovation

\section{FILOSOFIA}

Baldi M., Desideri F. (a cura di), Paul Celan. La poesia come frontiera filosofica

Barale A., La malinconia dell'immagine. Rappresentazione e significato in Walter Benjamin e Aby Warburg

Berni S., Fadini U., Linee di fuga. Nietzsche, Foucault, Deleuze

Borsari A., Schopenhauer educatore? Storia e crisi di un'idea tra filosofia morale, estetica e antropologia

Brunkhorst H., Habermas

Cambi F., Pensiero e tempo. Ricerche sullo storicismo critico: figure, modelli, attualità

Cambi F., Mari G. (a cura di), Giulio Preti: intellettuale critico e filosofo attuale

Casalini B., Cini L., Giustizia, uguaglianza e differenza. Una guida alla lettura della filosofia politica contemporanea

Desideri F., Matteucci G. (a cura di), Dall'oggetto estetico all'oggetto artistico

Desideri F., Matteucci G. (a cura di), Estetiche della percezione

Di Stasio M., Alvin Plantinga: conoscenza religiosa e naturalizzazione epistemologica

Giovagnoli R., Autonomy: a Matter of Content

Honneth A., Capitalismo e riconoscimento

Michelini L., Il nazional-fascismo economico del giovane Franco Modigliani

Mindus P., Cittadini e no: Forme e funzioni dell'inclusione e dell'esclusione

Sandrini M.G., Lafilosofia diR. Carnaptraempirismoetrascendentalismo. (Inappendice: R. Carnap Sugli enunciati protocollari, Traduzione e commento di E. Palombi)

Solinas M., Psiche: Platone e Freud. Desiderio, sogno, mania, eros

Trentin B., La Città del lavoro. Sinistra e crisi del fordismo, a cura di Iginio Ariemma

Valle G., La vita individuale. L'estetica sociologica di Georg Simmel

FISICA

Arecchi F.T., Cognizione e realtà

LETTERATURA, FILOLOGIA E LINGUISTICA

Bastianini G., Lapini W., Tulli M., Harmonia. Scritti di filologia classica in onore di Angelo Casanova

Bilenchi R., The Conservatory of Santa Teresa 
Bresciani Califano M., Piccole zone di simmetria. Scrittori del Novecento

Caracchini C., Minardi E. (a cura di), Il pensiero della poesia. Da Leopardi ai contemporanei. Letture dal mondo di poeti italiani

Cauchi-Santoro R., Beyond the Suffering of Being: Desire in Giacomo Leopardi and Samuel Beckett

Colucci D., L'Eleganza è frigida $e$ L'Empire des signs. Un sogno fatto in Giappone

Dei L. (a cura di), Voci dal mondo per Primo Levi. In memoria, per la memoria

Ferrone S., Visioni critiche. Recensioni teatrali da «l'Unità-Toscana» (1975-1983), a cura di Teresa Megale e Francesca Simoncini

Ferrara M.E., Il realismo teatrale nella narrativa del Novecento: Vittorini, Pasolini, Calvino Filipa L.V., Altri orientalismi. L'India a Firenze 1860-1900

Francese J., Leonardo Sciascia e la funzione sociale degli intellettuali

Francese J., Vincenzo Consolo: gli anni de «l'Unità» (1992-2012), ovvero la poetica della colpa-espiazione

Franchini S., Diventare grandi con il «Pioniere» (1950-1962). Politica, progetti di vita e identità di genere nella piccola posta di un giornalino di sinistra

Francovich Onesti N., I nomi degli Ostrogoti

Frau O., Gragnani C., Sottoboschi letterari. Sei case studies fra Otto e Novecento. Mara Antelling, Emma Boghen Conigliani, Evelyn, Anna Franchi, Jolanda, Flavia Steno

Frosini G., Zamponi S. (a cura di), Intorno a Boccaccio / Boccaccio e dintorni

Galigani G., Salomè, mostruosa fanciulla

Gori B., La grammatica dei clitici portoghesi. Aspetti sincronici e diacronici

Gorman M., I nostri valori, rivisti. La biblioteconomia in trasformazione

Graziani M., Abbati O., Gori B. (a cura di), La spugna è la mia anima. Omaggio a Piero Ceccucci

Graziani M. (a cura di), Un incontro lusofono plurale di lingue, letterature, storie, culture

Guerrini M., De bibliothecariis. Persone, idee, linguaggi

Guerrini M., Mari G. (a cura di), Via verde e via d'oro. Le politiche open access dell'Università di Firenze

Keidan A., Alfieri L. (a cura di), Deissi, riferimento, metafora

Lopez Cruz H., America Latina aportes lexicos al italiano contemporaneo

Mario A., Italo Calvino. Quale autore laggiù attende la fine?

Masciandaro F., The Stranger as Friend: The Poetics of Friendship in Homer, Dante, and Boccaccio

Nosilia V., Prandoni M. (a cura di), Trame controluce. Il patriarca 'protestante' Cirillo Loukaris / Backlighting Plots. The 'Protestant' Patriarch Cyril Loukaris

Pagliaro A., Zuccala B. (edited by), Luigi Capuana: Experimental Fiction and Cultural Mediation in Post-Risorgimento Italy

Pestelli C., Carlo Antici e l'ideologia della Restaurazione in Italia

Rosengarten F., Through Partisan Eyes.. My Friendships, Literary Education, and Political Encounters in Italy (1956-2013). With Sidelights on My Experiences in the United States, France, and the Soviet Union

Ross S., Honess C. (edited by), Identity and Conflict in Tuscany

Totaro L., Ragioni d'amore. Le donne nel Decameron

Turbanti S., Bibliometria e scienze del libro: internazionalizzazione e vitalità degli studi italiani

Virga A., Subalternità siciliana nella scrittura di Luigi Capuana e Giovanni Verga

Zamponi S. (a cura di), Intorno a Boccaccio / Boccaccio e dintorni 2015

Zamponi S. (a cura di), Intorno a Boccaccio / Boccaccio e dintorni 2016

Zamponi S. (a cura di), Intorno a Boccaccio / Boccaccio e dintorni 2017

MATEMATICA

Paolo de Bartolomeis, Matematica. Passione e conoscenza. Scritti (1975-2016), a cura di Fiammetta Battaglia, Antonella Nannicini e Adriano Tomassini 


\section{MEDICINA}

Mannaioni P.F., Mannaioni G., Masini E. (a cura di), Club drugs. Cosa sono e cosa fanno Saint S., Krein S.L. (con Stock R.W.), La prevenzione delle infezioni correlate all'assistenza. Problemi reali, soluzioni pratiche

\section{PEDAGOGIA}

Mariani A. (a cura di), L'orientamento e la formazione degli insegnanti del futuro

\section{POLITICA}

Caruso S., Homo oeconomicus. Paradigma, critiche, revisioni

Cipriani A. (a cura di), Partecipazione creativa dei lavoratori nella 'fabbrica intelligente'. Atti del Seminario di Roma, 13 ottobre 2017

Cipriani A., Gramolati A., Mari G. (a cura di), Il lavoro 4.0. La Quarta Rivoluzione industriale e le trasformazioni delle attività lavorative

Corsi C. (a cura di), Felicità e benessere. Una ricognizione critica

Corsi C., Magnier A., L'Università allo specchio. Questioni e prospettive

De Boni C., Descrivere il futuro. Scienza e utopia in Francia nell'età del positivismo

De Boni C. (a cura di), Lo stato sociale nel pensiero politico contemporaneo. 1. L'Ottocento

De Boni C., Lo stato sociale nel pensiero politico contemporaneo. Il Novecento. Parte prima: da inizio secolo alla seconda guerra mondiale

De Boni C. (a cura di), Lo stato sociale nel pensiero politico contemporaneo. Il Novecento. Parte seconda: dal dopoguerra a oggi

Gramolati A., Mari G. (a cura di), Bruno Trentin. Lavoro, libertà, conoscenza

Gramolati A., Mari G. (a cura di), Il lavoro dopo il Novecento: da produttori ad attori sociali. La Città del lavoro di Bruno Trentin per un' "altra sinistra»

Lombardi M., Fabbrica 4.0: i processi innovativi nel Multiverso fisico-digitale

Ricciuti R., Renda F., Tra economia e politica: l'internazionalizzazione di Finmeccanica, Eni ed Enel

Spini D., Fontanella M. (a cura di), Sognare la politica da Roosevelt a Obama. Il futuro dell'America nella comunicazione politica dei democrats

Tonini A., Simoni M. (a cura di), Realtà e memoria di una disfatta. Il Medio Oriente dopo la guerra dei Sei Giorni

Zolo D., Tramonto globale. La fame, il patibolo, la guerra

\section{PSICOLOGIA}

Aprile L. (a cura di), Psicologia dello sviluppo cognitivo-linguistico: tra teoria e intervento Barni C., Galli G., La verifica di una psicoterapia cognitivo-costruttivista sui generis

Luccio R., Salvadori E., Bachmann C., La verifica della significatività dell'ipotesi nulla in psicologia

\section{SCIENZE NATURALI}

Bessi F.V., Clauser M., Le rose in fila. Rose selvatiche e coltivate: una storia che parte da lontano

Sánchez-Villagra M.R., Embrioni nel tempo profondo. Il registro paleontologico dell'evoluzione biologica

\section{SOCIOLOGIA}

Alacevich F., Promuovere il dialogo sociale. Le conseguenze dell'Europa sulla regolazione del lavoro

Alacevich F.; Bellini A., Tonarelli A., Una professione plurale. Il caso dellavvocatura fiorentina

Battiston S., Mascitelli B., Il voto italiano all'estero. Riflessioni, esperienze e risultati di un'indagine in Australia

Becucci S. (a cura di), Oltre gli stereotipi. La ricerca-azione di Renzo Rastrelli sull'immigrazione cinese in Italia 
Becucci S., Garosi E., Corpi globali. La prostituzione in Italia

Bettin Lattes G., Giovani Jeunes Jovenes. Rapporto di ricerca sulle nuove generazioni e la politica nell'Europa del sud

Bettin Lattes G. (a cura di), Per leggere la società

Bettin Lattes G., Turi P. (a cura di), La sociologia di Luciano Cavalli

Burroni L., Piselli F., Ramella F., Trigilia C., Città metropolitane e politiche urbane

Catarsi E. (a cura di), Autobiografie scolastiche e scelta universitaria

Leonardi L. (a cura di), Opening the European Box. Towards a New Sociology of Europe

Nuvolati G., Mobilità quotidiana e complessità urbana

Nuvolati G., L'interpretazione dei luoghi. Flânerie come esperienza di vita

Nuvolati G., Sviluppo urbano e politiche per la qualità della vita

Ramella F., Trigilia C. (a cura di), Reti sociali e innovazione. I sistemi locali dell'informatica

Rondinone A., Donne mancanti. Unanalisi geografica del disequilibrio di genere in India

\section{STORIA E SOCIOLOGIA DELLA SCIENZA}

Angotti F., Pelosi G., Soldani S. (a cura di), Alle radici della moderna ingegneria. Competenze e opportunità nella Firenze dell'Ottocento

Cabras P.L., Chiti S., Lippi D. (a cura di), Joseph Guillaume Desmaisons Dupallans. La Francia alla ricerca del modello e l'Italia dei manicomi nel 1840

Califano S., Schettino V., La nascita della meccanica quantistica

Cartocci A., La matematica degli Egizi. I papiri matematici del Medio Regno

Fontani M., Orna M.V., Costa M., Chimica e chimici a Firenze. Dall'ultimo dei Medici al Padre del Centro Europeo di Risonanze Magnetiche

Guatelli F. (a cura di), Scienza e opinione pubblica. Una relazione da ridefinire

Massai V., Angelo Gatti (1724-1798)

Meurig T.J., Michael Faraday. La storia romantica di un genio

Schettino V., Scienza e arte. Chimica, arti figurative e letteratura

STUDI DI BIOETICA

Baldini G. (a cura di), Persona e famiglia nell'era del biodiritto. Verso un diritto comune europeo per la bioetica

Baldini G., Soldano M. (a cura di), Nascere e morire: quando decido io? Italia ed Europa a confronto

Baldini G., Soldano M. (a cura di), Tecnologie riproduttive e tutela della persona. Verso un comune diritto europeo per la bioetica

Bucelli A. (a cura di), Produrre uomini. Procreazione assistita: un'indagine multidisciplinare

Costa G., Scelte procreative e responsabilità. Genetica, giustizia, obblighi verso le generazioni future

Galletti M., Zullo S. (a cura di), La vita prima della fine. Lo stato vegetativo tra etica, religione e diritto

\section{STUDI EUROPEI}

Guderzo M., Bosco A. (edited by), A Monetary Hope for Europe. The Euro and the Struggle for the Creation of a New Global Currency

Scalise G., Il mercato non basta. Attori, istituzioni e identità dell'Europa in tempo di crisi 

